\title{
Development of hydrogel tracer beads and comparative tracer tests to better understand contaminant fate and transport in karst systems
}

\author{
Amanda Laskoskie \\ West Virginia University
}

Follow this and additional works at: https://researchrepository.wvu.edu/etd

\footnotetext{
Recommended Citation

Laskoskie, Amanda, "Development of hydrogel tracer beads and comparative tracer tests to better understand contaminant fate and transport in karst systems" (2013). Graduate Theses, Dissertations, and Problem Reports. 307.

https://researchrepository.wvu.edu/etd/307

This Thesis is protected by copyright and/or related rights. It has been brought to you by the The Research Repository @ WVU with permission from the rights-holder(s). You are free to use this Thesis in any way that is permitted by the copyright and related rights legislation that applies to your use. For other uses you must obtain permission from the rights-holder(s) directly, unless additional rights are indicated by a Creative Commons license in the record and/ or on the work itself. This Thesis has been accepted for inclusion in WVU Graduate Theses, Dissertations, and Problem Reports collection by an authorized administrator of The Research Repository @ WVU. For more information, please contact researchrepository@mail.wvu.edu.
} 


\title{
Development of hydrogel tracer beads and comparative tracer tests to better understand contaminant fate and transport in karst systems
}

\section{Amanda Laskoskie}

Thesis submitted to the

Eberly College of Arts and Sciences at West Virginia University

in partial fulfillment of the requirements

for the degree of

Master of Science

in

Geology

\author{
Dorothy Vesper, Ph.D., Chair \\ Harry Edenborn, Ph.D. \\ Helen Lang, Ph.D. \\ Nicolas Zegre, Ph.D.
}

Department of Geology and Geography

Morgantown, West Virginia

2013

Keywords: karst; contaminants; non-aqueous phase liquid; NAPL; LNAPL; fate; transport; tracer; hydrogel tracer bead 


\section{Abstract \\ Development of hydrogel tracer beads and comparative tracer tests to better understand contaminant fate and transport in karst systems}

\section{Amanda Laskoskie}

Karst aquifers can be highly susceptible to contamination due to a close connection to the land surface, lack of filtration through a soil zone, and rapid transmission along solutionallyenhanced flowpaths. These factors also allow for aquifer contamination by direct injection of immiscible organic compounds in the form of non-aqueous phase liquids (NAPLs). The fate and transport of NAPLs in karst aquifers is poorly understood. Tracer tests allow for qualitative characterization of hydraulic flow in the surface and subsurface, but their results may not be applicable to the movement of NAPL for which density plays a critical role. Particulate tracers have been used to predict sediment transport but they fail to mimic the range of possible NAPL densities. Therefore, this research focused on the development and field testing of hydrogel tracer beads (HTBs), a non-toxic tracer made of calcium alginate (a derivative of marine algae), to better represent the behavior of NAPLs. The density of the HTBs can be readily modified to match different types of NAPLs. Sinking- and buoyant-HTBs were released during a preliminary field test at Hazel Run, in Bruceton Mills, WV. The buoyant-HTBs traveled the fastest and were recovered at the collection site, while the sinking-HTBs beads settled to the channel bed. Comparative tracer tests using fluorescein and buoyant-HTBs were completed at Buckeye Creek Cave near Lewisburg, WV and Rhine Creek in Terra Alta, WV. Despite the two systems being very different, the field tests in both systems demonstrated that the buoyant-HTBs had a greater velocity and had a lower mean transit time than did the fluorescein. These results are similar to what other comparable research has found - that particulate tracers travel faster than dissolved solutes. Based on the comparative tracer tests, light NAPLs (LNAPLs) may travel faster than dissolved tracers and travel times determined from solute tracers may not accurately reflect the appropriate time to collect water samples. 


\section{Acknowledgments}

Support of the work described was provided through Award Number P42ES017198 from the National Institute of Environmental Health Sciences to the PROTECT research project. The content is solely the responsibility of the authors and does not necessarily represent the official views or policies of the National Institute of Environmental Health Sciences, the National Institutes of Health, or the US Environmental Protection Agency.

The Department of Geology and Geography at West Virginia University provided immense and integral support for this project. The Division of Plant and Soil Sciences at WVU and the National Energy and Technology Lab in Pittsburgh also provided equipment that was essential to the work.

A debt of gratitude goes to Dr. Dorothy Vesper, infinitely wise and patient, who guided me through research and writing. I am grateful for all the time you spent on me and my research, answering questions and discussing new ideas. Your enthusiasm and support is greatly appreciated.

A huge thank you to all the individuals who helped this project come together: Dorothy Vesper, Dr. Hank Edenborn, Dr. Nic Zegre, Dr. Helen Lang, Dr. Akram Alshawabkeh, Dr. Ingrid Padilla, and Dr. Malcolm Field. To those who helped in the field: Dr. Kathy Benison, Annie Berlinghieri, Doug Boyer, Habib Bravo, Jessica DeWitt, Derek Hall, Dr. Ellen Herman, Andrea Sack, John Tudek, and Dr. James Zambito. To those that helped in the lab: Dr. Lewis McDonald, Joan Wright, and Dr. Sherry Hemmingson. And to those who helped in the lab and field: Hank Edenborn, Adam Hughes, Johnathan Moore, and Dorothy Vesper.

I would like to thank the West Virginia Association for Cave Studies for the use of the field station and the West Virginia Student Grotto for the lending of helmets and lights. I would also like to thank Ed and Mary Utterback for generously allowing me to work in their stream when Buckeye went dry. Ed was incredibly helpful with showing me the property and Mary had kind words about when research does not progress as planned. I could not have asked for nicer people to work with.

Lastly, to all of my family and friends that helped me throughout my graduate studies, I absolutely could not have done it without you. A special thank you to my mom, Barbara Laskoskie, who led me to be the person I am today. 


\section{Table of Contents}

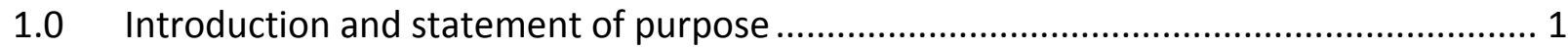

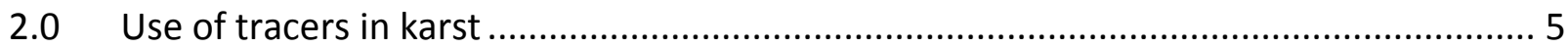

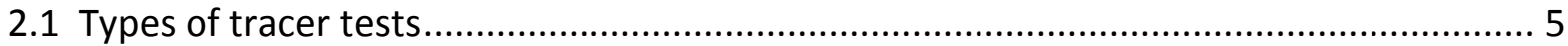

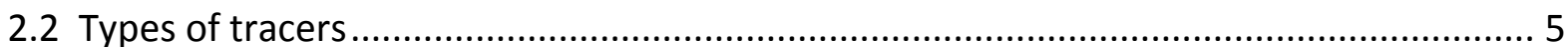

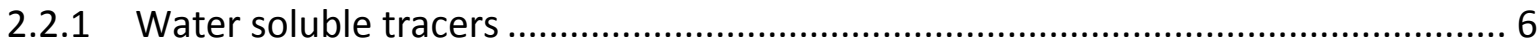

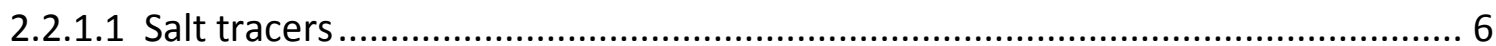

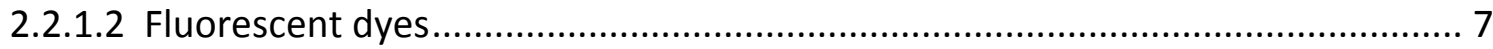

2.2.1.3 Other soluble tracers ................................................................................ 9

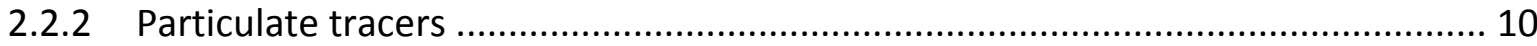

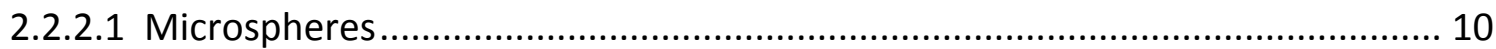

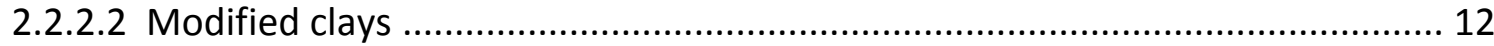

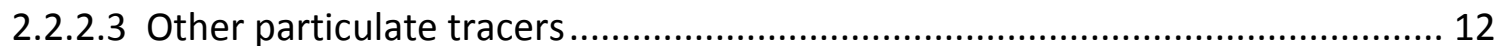

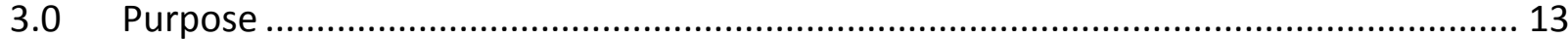

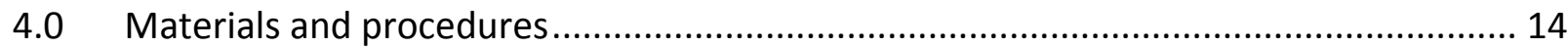

4.1 Hydrogel tracer bead preparation and development ........................................... 14

4.1.1 Construction of hydrogel tracer beads ......................................................... 14

4.1.2 Quantification and characterization of the HTBs ....................................... 18

4.1.3 Results of the HTBs optimization ................................................................... 19

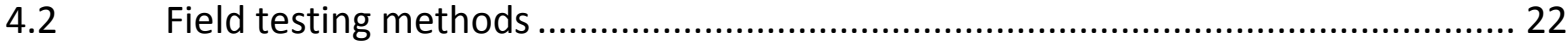

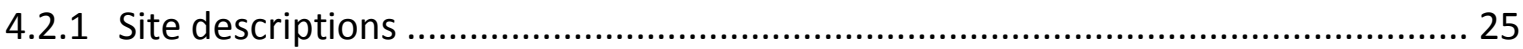

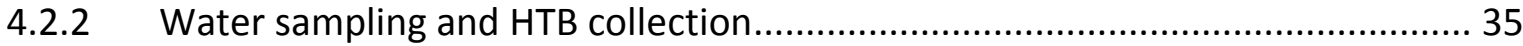

4.2.3 Stream discharge measurements .............................................................. 36

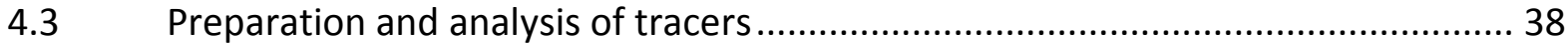

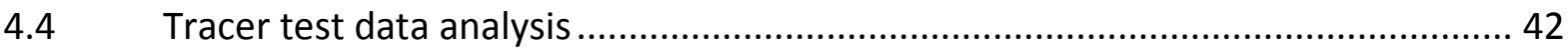

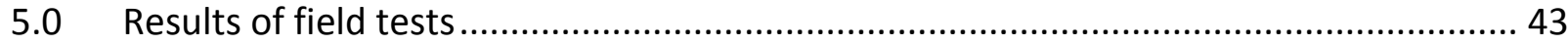

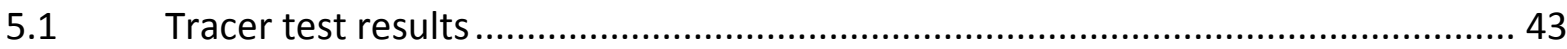

5.1.1 Results of preliminary field tests at Hazel Run ................................................ 43 


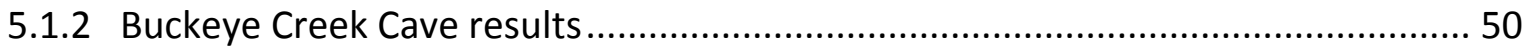

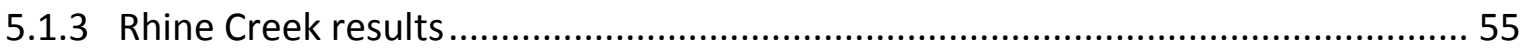

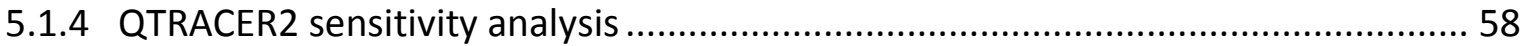

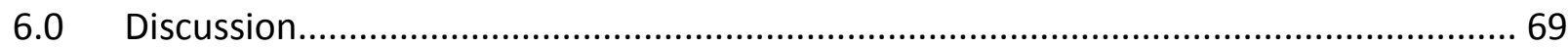

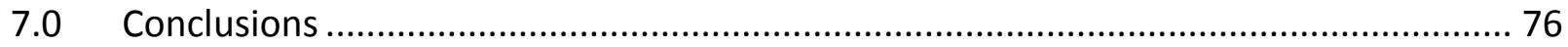

$8.0 \quad$ Future work

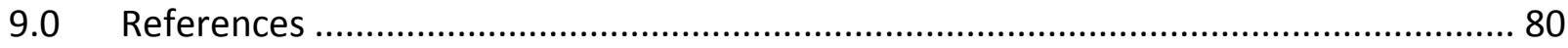




\section{List of Figures}

Figure 1: Diagram of the fate and transport of DNAPL (orange) and LNAPL (green) in the subsurface (modified from Vesper 2008) ........................................................................

Figure 2: Photos of formed HTBs at various alginate percents and drop heights.....................20

Figure 3: Hazel Run, site of the preliminary field test site near Bruceton Mills, WV (photo by

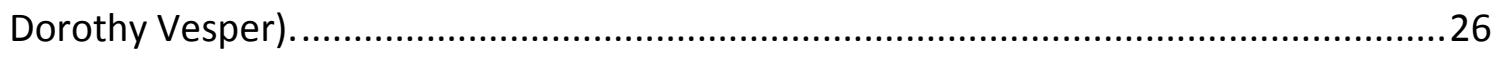

Figure 4: Map of field research sites for comparative tracer tests. .....................................27

Figure 5: Greenbrier group stratigraphic column (modified from Dasher and Balfour 1994)...29

Figure 6: Buckeye Creek Cave canyon section (photo by Ellen Herman). Width of the passage

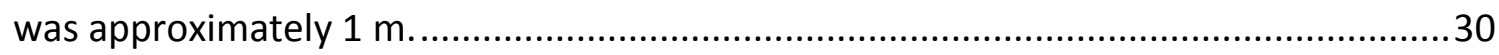

Figure 7: Buckeye Creek Cave release point (photo by Ellen Herman). Photo of release of fluorescein and HTBs at the beginning of the test section. Note the large scalloping on the walls of the cave, which are potential trapping features. Width of the passage was approximately $1 \mathrm{~m}$

Figure 8: Rhine Creek field site. Note the vegetation and bedload that breaks the surface of the water. Individuals are approximately $1.7 \mathrm{~m}$ tall.

Figure 9: Rhine Creek injection site. Photo shows a plume of fluorescein and beads traveling downstream shortly after release ( 1 minute). Flow direction was from the right to the left of the photo.

Figure 10: Rhine Creek collection site with beads being collected in a $25.4 \mathrm{~cm}$ aquarium net. This photo shows the net from the previous sampling interval being removed while the net for the current sampling interval was in place.

Figure 11: HTBs used for the preliminary tracer test at Hazel Run. Pictured are low-density green HTBs, medium-density yellow HTBs, and high-density pink HTBs (Photo by Hank Edenborn).

Figure 12: High-density, pink HTBs on the stream bed. Insert is an underwater photo of the HTBs in the larger photo.

Figure 13: Underwater photo of medium-density, yellow HTBs on the stream bead in an eddy. Insert shows a single bead trapped between two pebbles.

Figure 14: Low-density, floating HTBs being collected in pool skimmers at Hazel Run at the end of test stretch.

Figure 15: Breakthrough curve for Buckeye Creek Cave test A including data on fluorescein concentration and HTB counts. Line added to aid the eye.

Figure 16: Breakthrough curve for Buckeye Creek Cave test B including data on fluorescein concentration and HTB counts. Line added to aid the eye.

Figure 17: Breakthrough curve for Rhine Creek test $A$ including data on fluorescein concentration and HTB counts. Line added to aid the eye. 
Figure 18: Breakthrough curve for Rhine Creek test B including data on fluorescein concentration and HTB counts. Line added to aid the eye.

Figure 19: Schematic of alternate flow path at Rhine Creek. Arrows show estimated magnitude of water velocity, based on observed bead behavior.

Figure 20: Peak removal of Rhine Creek test A fluorescein data. Blue diamonds are the data points that were removed.

Figure 21: Peak removal of Rhine Creek test A HTBs data. Blue diamonds are the data points that were removed. Note: The data are plotted as single points and not columns for in order to see the fit better. .64

Figure 22: Peak removal of Rhine Creek test B fluorescein data. Blue diamonds are the data points that were removed. .65

Figure 23: Peak removal of Rhine Creek test B HTBs data. Blue diamonds are the data points that were removed. Note: The data are plotted as single points and not columns for in order to see the fit better. .66 


\section{List of Tables}

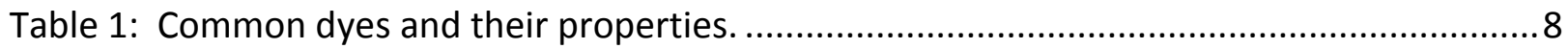

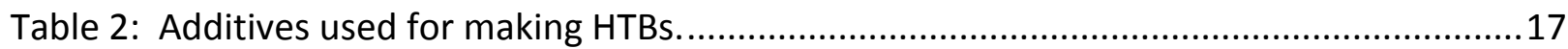

Table 3: Measured sphericity values for HTBs..............................................................21

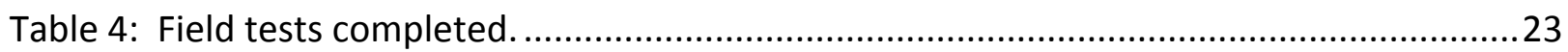

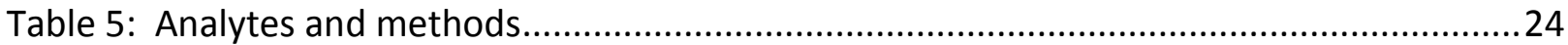

Table 6: Amount of fluorescein needed for tests at Buckeye Creek Cave using various

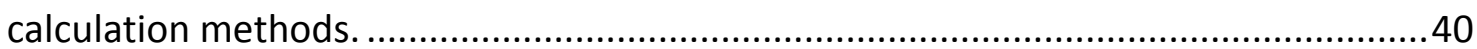

Table 7: Tracer amount released for the Buckeye Creek Cave and Rhine Creek tests..............41

Table 8: Results of the preliminary field testing of HTBs at Hazel Run, April 18, 2012............44

Table 9: Test parameters as calculated by QTRACER2. ........................................................51

Table 10: Absolute percent difference of tracers between tests A and B completed at Buckeye

Creek Cave.

Table 11: Absolute percent difference of tracers between tests A and B completed at Rhine Creek.

Table 12: QTRACER2 discharge and test section length sensitivity analysis for Rhine Creek test

A......

Table 13: QTRACER2 sensitivity analysis of dual peak removal of Rhine Creek data.

Table 14: Percent difference of the behavior of fluorescein versus HTBs at Buckeye Creek Cave

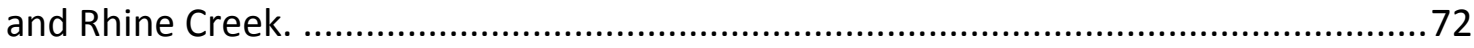

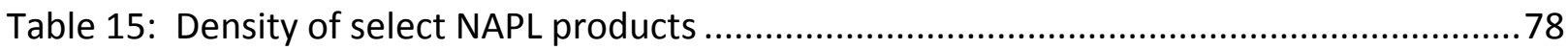




\section{List of Appendices}

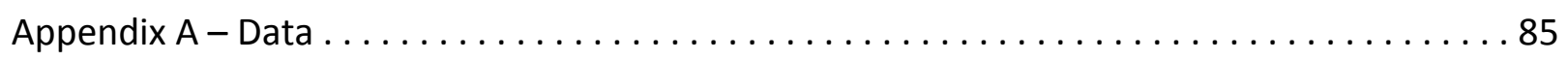

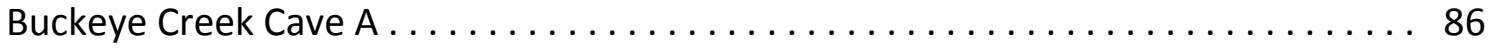

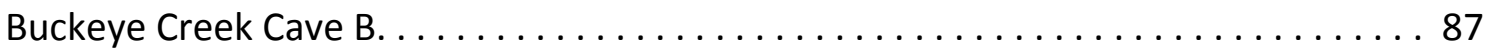

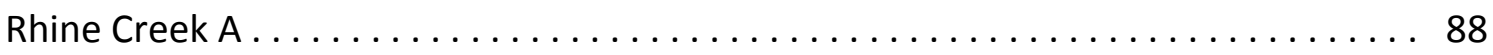

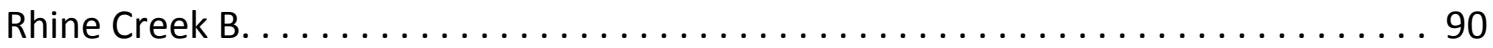

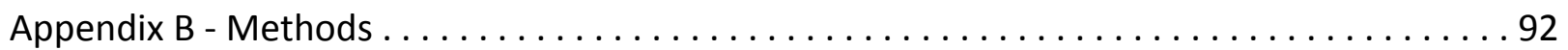

Vary Cary Eclipse Fluorescence Spectrophotometer. . . . . . . . . . . . 93

How to Make Hydrogel Tracer Beads . . . . . . . . . . . . . . . . . . . . . . . . .97 
Acronyms and abbreviations

DNAPL- Dense non-aqueous phase liquid

EHTD- Efficient hydrologic tracer-test design

HTBs- Hydrogel tracer beads

LNAPL- light non-aqueous phase liquid

NAPL- Non-aqueous phase liquid

Q-discharge

R. eutropha- Ralstonia eutropha $\mathrm{H} 16$

UV-Ultra violet 


\subsection{Introduction and statement of purpose}

Karst aquifers, developed in soluble rocks, underlie $20 \%$ of the United States (Ford and Williams 2007). Karst terrains are characterized by dissolution and precipitation features that result in a highly heterogeneous subsurface system. That heterogeneity, both spatially and temporally, makes the aquifers difficult to model.

Karst aquifers may be more susceptible to surface impacts than granular aquifers because contaminants can be rapidly injected into the aquifer via sinking streams, sinkholes, and solutionally-enlarged joints (Ewers et al. 1991). Dispersed recharge, which takes place more slowly through the vadose zone, may also contribute to contamination as karst rocks often have thin soils and therefore there is limited opportunity for filtration.

Soluble tracers can be added to the water and then tracked to determine the physical connections between input and output points as well as to quantify flow characteristics such as tracer velocity (Quinlan 1989). Although soluble-tracer tests may help define the transport of solutes, they do not necessarily define the transport of non-solute constituents in water such as colloids, particles, bed sediments or non-aqueous phase liquids (NAPLs). To better understand how the transport of dissolved and non-dissolved constitutes compare, researchers use different types of tracers along with soluble ones. For example, Sinreich et al. (2009) used microspheres to measure colloid transport; however, these do not necessarily behavior similarly to NAPL. The focus of this research is the development of a new tracer that is transported more similarly to NAPL in order to better understand its fate and transport in karst systems.

NAPLs exist when organic compounds are present at high enough concentrations. NAPLs form a separate phase system from the water, or be stored in the matrix pore spaces, and will only dissolve into the water at concentrations up to the compounds' solubility. NAPLs can be either light (LNAPLS) or dense (DNAPLs) (Testa and Winegardner 2000, Schwarzenbach et al. 2002, Connell 2005). The density determines whether the NAPL floats on or sinks through water. 
Common LNAPL-forming compounds are gasoline, diesel fuel and other petroleum hydrocarbons; common DNAPL-forming compounds are trichloroethylene, perchloroethene, and polychlorinated biphenyls.

Groundwater contamination by NAPLs is widespread (Barner and Uhlman 1995, Testa and Winegardner 2000). The release of NAPLs from underground storage tanks is common; leaks from pipelines, dry wells, and accidental spills also occur. Difficulties arise in locating NAPLs as they can exist in complex subsurface karst aquifers, where flow paths and trapping mechanisms are not easily identified.

LNAPL and DNAPL contaminants will migrate downward vertically in the vadose zone (Figure 1; Vesper 2008, Loop and White 2001, Ewers et al. 1991). LNAPLs pool on top of the water table, whereas DNAPLs sink through the water column until they reach an impermeable layer where they will become trapped. In karst, the LNAPLs can become trapped behind features that interrupt the surface of the water and be released only at times of low flow (Ewers et al. 1991). DNAPLs can form pools and remain immobile if not enough energy is present to transport the DNAPL downgradient (Loop and White 2001). Low concentrations of the NAPL contaminants will be present in the water according to the solubility of the compound.

Several case studies have illustrated the difficulty in tracking NAPL contamination in karst. A tanker truck carrying diesel fuel spilled on Interstate 65 near Park City, KY (Stephenson et al. 2003). The karst of this region is known to have caves and large solution features. Four types of geophysical studies were completed to characterize the site: electromagnetic conductivity, spontaneous potential, electrical resistivity imaging, and a microgravity survey. Boreholes were drilled and wells installed based on the data from the geophysical studies. Parker Cave, which is situated below the tanker truck spilled, has a known connection to Mill Hole spring via fractures, conduits, and cave streams. Based on dye traces, the travel time between the two sites is 2-42 hours. No diesel product was detected at Mill Hole or in the boreholes in the year after the spill; however, the time from the spill to when water sampling began was not reported. The conclusions of this work were that the diesel product remained localized to the soils around the spill area. 


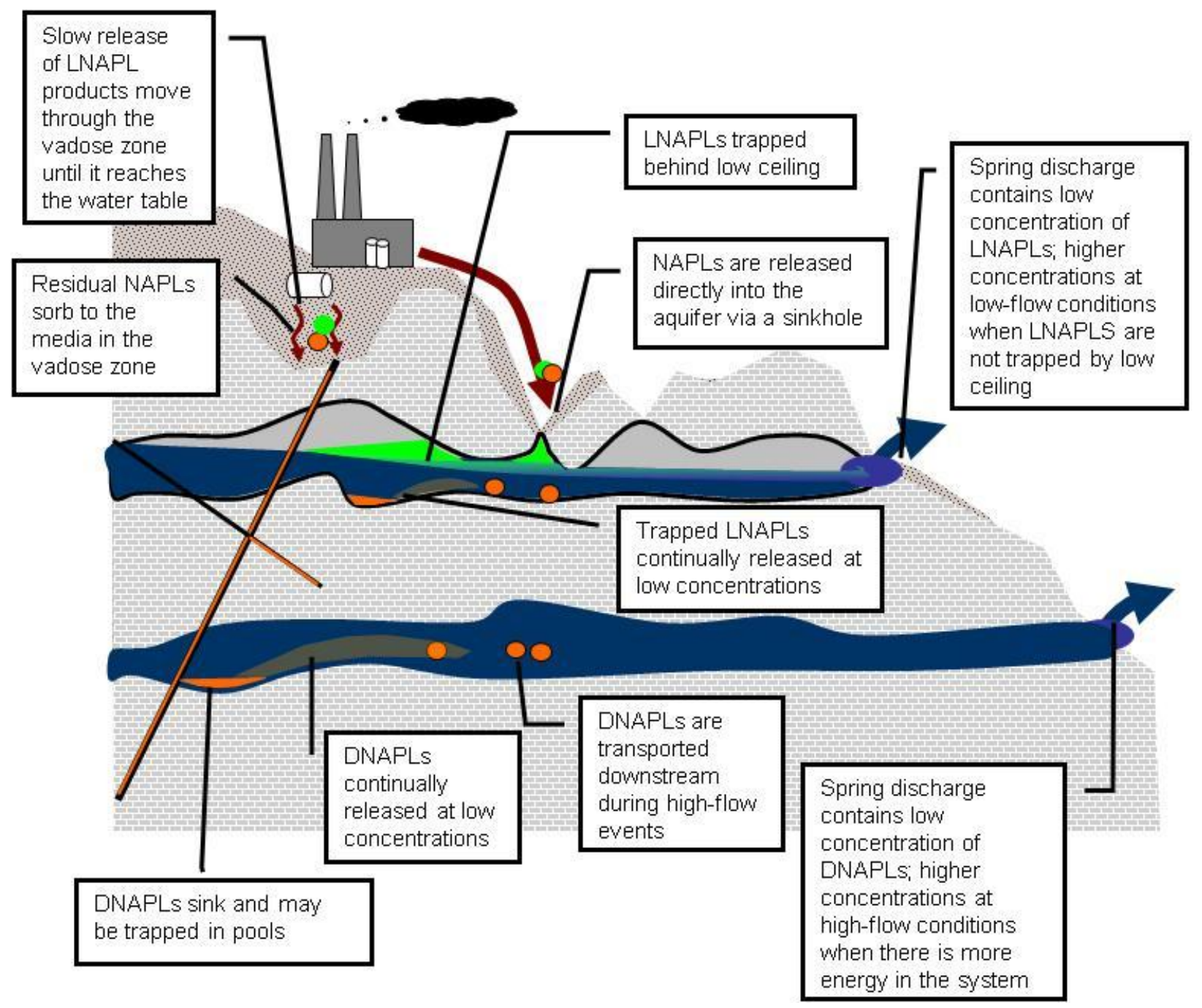

Figure 1: Diagram of the fate and transport of DNAPL (orange) and LNAPL (green) in the subsurface (modified from Vesper 2008). 
In Richmond, $\mathrm{KY}$, an underground storage tank at a gas station leaked product into a limestone aquifer (Ewers et al. 1991). A fluorescein dye trace showed connections from the gas station to nearby Tennis Court and Little Caesar Springs. Monitoring of the springs included high- and low-flow periods. Gasoline product was recovered at Tennis Court Spring, but not at Little Caesar Spring despite the known connection. The interpretation by the authors was that LNAPL was free to travel to Tennis Court Spring but the flowpath connected to the other spring was fully submerged and able to trap LNAPL.

Campbell Army Airfield is located in Christian County, KY (Ewers et al. 1991). Sampling of monitoring wells at the airfield show there was as much as $4.9 \mathrm{~m}$ of free-phase jet fuel in the underlying karst. Dye tracing had determined the main discharge of the airfield to be Quarles Spring. However, monitoring at the spring has not recovered LNAPL jet fuel in the water. The conclusion of this study was the jet fuel was trapped and thus immobile.

Lastly, a wood preserving company, Brown Wood, was in business in Live Oak, FL for 30 years (Price 1989). They used creosote and pentachlorophenol to treat their wood product and disposed of their waste in a nearby 3-acre lagoon. The creosote mixture sank through the water in the lagoon forming a DNAPL-sludge on top of a natural clay layer. During the site investigation, two collapse features opened that allowed the of creosote sludge to leak into the underlying aquifer. It was later discovered that some DNAPL product had migrated down sand columns near the collapse feature. These sand columns were excavated where DNAPL products were found. However, it is possible that heavier DNAPLs sank through the sand faster than others and still exist as at greater depths than what was explored.

These case studies are examples of when NAPLs in karst aquifers did not travel in a predictable way. NAPL-forming compounds are used world-wide in a variety of ways including uses as fuels, solvents, and lubricants. Contamination of karst aquifers by NAPL contaminants is a pressing issue when considering how to best protect drinking water sources. In order to understand NAPL transport in karst, work should focus on developing a tracer that mimics NAPL behavior. 


\subsection{Use of tracers in karst}

Tracers are materials that are released into the water in order to understand hydraulic conditions and to quantify hydraulic properties (Aley and Fletcher 1978). Tracers can be solutes or particulates and can be used either quantitatively or qualitatively. Tracers can be used to understand flow-paths of the water, connectivity of conduits, residence time of water in the system, and velocity of the water moving through the system.

\subsection{Types of tracer tests}

Tracer tests can be qualitative, quantitative, or semi-quantitative (Field 2002). Quantitative tests yield numerical information, qualitative tests are based on observations and do not yield quantitative data, and semi-quantitative tests yield some quantitative data but lack the precision and accuracy to result in fully quantitative results. Qualitative tests are used to understand flow paths, are more cost-effective, and generally require less detailed planning. If the hydrology of the system is not well understood, a qualitative test is conducted before a quantitative test to understand flow paths in order to know where and how often sampling should occur (Quinlan 1989). Quantitative tests are more rigorous to complete but yield results about the physical properties of the system such as channel and transport zone volume, surface area, and head loss as well as more general parameters such as water and tracer velocity. QTRACER2, developed by the United States Environmental Protection Agency, analyzes the tracer breakthrough curve (Field 2002). QTRACER2 calculations are based on determining the area under the breakthrough curve of the tracer of interest to yield numerical information on properties of the system.

\subsection{Types of tracers}

Tracers are categorized by their physical nature (soluble versus particulate) or by their transport behavior (conservative versus non-conservative) (Käss 1998). Conservative tracers do not 
interact chemically or physically with the system they are in and travel with the water. In contrast, non-conservative tracers can become trapped, move in slower flow paths, or react chemically with the system and thus experience retarded or enhanced transport relative to the water in the system.

\subsubsection{Water soluble tracers}

Soluble tracers dissolve into the water and can be detected through analysis of the water-tracer mixture. Examples include salts, dyes, surfactants, aromas, radioactive isotopes, and stable isotopes

\subsubsection{Salt tracers}

A salt is defined as an inorganic compound which dissolves into cations and anions in water (Käss 1998). There is limited retardation of salts; what exists is caused by ion exchange. This is especially pertinent when high amounts of solids and organic material are present in the system. In the event that high retardation is suspected (when there is a large lag in detection of tracers released simultaneously at a sampling point, low recovery rates), analysis for other ions can be conducted. In general, anions are less likely to be subject to exchange processes than are cations (Goldscheider et al. 2008). Despite the possibility of higher retardation rates, cations are favored over anions as tracers because ease of analysis as well as a wider choice of cations to select from (Käss 1998). Examples of salt tracers are potassium bromide or sodium chloride.

Salts are inexpensive and readily available; however, water samples should be analyzed before completing a salt test to determine which salt should be used (Quinlan 1989). High background concentration of an element would mean a larger mass of salt would be needed to override the background salt in the water. This can be both costly and dangerous, based on the salt used and the flora and fauna inhabiting the test location, so consideration must be taken (Quinlan 1989). 


\subsubsection{Fluorescent dyes}

A wide variety of soluble fluorescent dyes are available for use in tracer studies (Table 1). They can be released in low enough concentrations that the color of the water is not changed enough for the human eye to detect but can still be detected by a fluorometer (Aley 2002). Dyes are used in qualitative testing to determine flow paths, as well as in quantitative testing.

Each dye has an optimal excitation and emission wavelength for florescence (Table 1; Goldscheider et al. 2008). When a water sample containing dye is excited by an energy source, it emits light at a lower energy than the excitation due to absorbance of that light by the sample. There are a variety of ways to analyze for fluorescence. One method is to excite the sample by a single excitation wavelength and scan over a range of emission wavelengths. Alternately, synchronously scanning the excitation and emission wavelengths can be done. This method removes the signal from the natural fluorescence of. Standards are prepared in the same water the fluorescent dye was released into for testing. This practice removes any matrix interference that can enhance or diminish the fluorescence. Standards should range from 1$100 \mu \mathrm{g} / \mathrm{L}$ (pers. comm. Malcolm Field). Samples with concentrations above the highest standard tested should be diluted and reanalyzed for accuracy.

Problems can exist with fluorescent dyes. Pyranine changes fluorescence intensity when dissolved in solutions that are greater than $\mathrm{pH} 10$ or less than $\mathrm{pH} 4.5$; however, those $\mathrm{pH}$ values are uncommon in natural waters (Table 1; Benischke et al. 2007). Fluorescein photodecays and is not suitable for surface water tracing when it would be exposed to the sun for long periods of time (Field 2002). Rhodamine B has a very high tendency to sorb to the media matrix. Eosin contains bromine which will interfere with bromide analysis if it is being used simultaneously as a salt tracer. The intensity of rhodamine WT is temperature dependent. Rhodamine WT decays to become carboxylic fluorescein, which will interfere if fluorescein is being released simultaneously. This will also result in low recovery because the dye decayed to a different compound that is not being analyzed for (Field 2002). 
Table 1: Common dyes and their properties.

\begin{tabular}{l|rrrrr}
\hline & $\begin{array}{r}\text { Maximum } \\
\text { excitation } \\
(\mathrm{nm})\end{array}$ & $\begin{array}{r}\text { Maximum } \\
\text { emission } \\
(\mathrm{nm})\end{array}$ & $\begin{array}{r}\text { Fluorescence } \\
\text { intensity }(\%)\end{array}$ & $\begin{array}{r}\text { Sorption to } \\
\text { limit }(\mu \mathrm{g} / \mathrm{L})\end{array}$ & $\begin{array}{r}\text { aquifer media } \\
\text { Dye }\end{array}$ \\
\hline Sodium Fluorescein & 492 & 513 & 100 & 0.002 & very low \\
Eosin & 515 & 535 & 18 & 0.010 & low \\
Rhodamine B & 555 & 582 & 60 & 0.006 & strong \\
Rhodamine WT & 558 & 583 & 25 & 0.005 & moderate \\
Sulpho Rhodamin B & 560 & 584 & 30 & 0.007 & moderate \\
Pyranine $\quad \mathrm{pH} \geq 10$ & 460 & 512 & 18 & & \\
& 407 & 459 & 6 & & \\
\hline
\end{tabular}

Data from Field, 2002 
Sorption of dyes on natural materials may make them non-conservative. Kasnavia et al. (1999) studied the sorption of fluorescein, rhodamine B, rhodamine WT, and sulforhodamine B on alumina and silica. Their findings showed that the surface charge and structure of the dye played a role in the sorption tendency. Fluorescein, which has negatively-charged functional groups, sorbed mostly to the positively-charged alumina surface. Rhodamine B and rhodamine WT, which have both positive and negative functional groups, sorbed to the positively-charged alumina and negatively-charged silica surfaces. Kasnavia et al. (1999) concluded that when choosing a fluorescent dye for a study, the chemical properties of that dye and the media matrix in which the test will be conducted should be considered in order to complete a successful test.

Ghanem et al. (2003) ran a series of column and batch tests in which five fluorescent dyes were assessed as partitioning tracers. A partitioning tracer is one that is retarded when it partitions into a non-aqueous phaseTwo columns were used: one containing soil and dye and one containing soil, dye and sorbed tetrachloroethene (PCE). The transport of rhodamine WT, sulforhodamine $B$, and eosine was retarded due to partitioning into the $P C E$, while the other dyes traveled similarly in both columns. The purpose of the Ghanem et al. (2003) study was to determine if suites of tracers could be used to confirm the presence of NAPL in the subsurface. Their results suggest that dyes traditionally considered to be conservative tracers may not be so.

\subsubsection{Other soluble tracers}

Surfactants used as tracers pose a variety of issues: they can be toxic in high concentrations, they break down over time, and a quantitative analysis is determined by the height of the foam that is produced (Käss 1998). Since they break down, the height of the foam may not be accurate; therefore error is introduced into the test. Stable isotopes are becoming increasingly popular, but sample analysis can increase experiment costs. 


\subsubsection{Particulate tracers}

Particulate tracers can be used to predict transport of particle-bound contaminants (Käss 1998). These tracers do not break down, dissolve, or dissociate in water. Examples include microspheres, modified clays, and other drift particles.

\subsubsection{Microspheres}

Microspheres are small (1-1000 $\mu \mathrm{m}$ diameter), synthetically-made spheres which can be readily altered. Commercially-made spheres come in a variety of sizes, colors, surface coatings, fluorescence, and materials. Microspheres have been considered ideal for understanding the fate and transport of bacteria due to similarities in size (approximately $1 \mu \mathrm{m}$ ), however, more recent work suggests otherwise. Sinreich et al. (2009) completed comparative tracer tests using fluorescent dye, microspheres and nonpathogenic bacteria. They found that while the microspheres and bacteria were similar in size and had similar breakthrough curves, the microspheres had significantly reduced recovery because the microspheres sorb onto the matrix of the aquifer whereas the bacteria do not.

For tracing tests in natural water system, neutrally-charged microspheres must be used, or the microspheres sorb onto the surface of the matrix (Käss 1998). This was shown in a tracer test where neutrally charged polystyrene microspheres and charged carboxylated microspheres were released into a natural system. The neutrally charged polystyrene microspheres were recovered while charged carboxylated microspheres were not (Käss 1998).

Tauro et al. (2012) proposed the use of microspheres for particle-tracking velocimetry to measure discharge of streams when traditional methods cannot be used. The method uses a digital camera and UV light to photograph the buoyant fluorescent microspheres in situ. The UV light excites the fluorescent microspheres to produce light emission, which is captured by the digital camera. The images are manipulated to enhance the light signal and are then analyzed to calculate the tracer travel time. This work was tested in a mountain stream where the section was too small to accurately measure discharge with flow meters. This method of 
measurement was comparable to discharge measured using rhodamine. The benefit of using the Tauro et al. (2012) method is the ability to measure discharge in areas that are difficult to access with traditional methods. Examples of these areas are highly-sloped mountain streams or locations where the water body is too wide or deep to measure.

Toran and Palumbo (1992) ran a series of sand column tests that included a variety of hallow tubes inserted to represent fractures. Variations included differing number of tubes, length of tubes, and diameter of tubes. Microspheres, bacteria, and colloidal organic material (collectively referred to as particulates) were injected into the column along with a fluorescent dye. Results showed that the particulates moved through the system faster than the dye. Recovery rates of the particulates were higher in the presence of the tubes, and they traveled faster when longer tubes were used. The particulates preferentially travelled in the faster flow path, which in this case was the tubes, rather than travel in the tortuous flow-paths in the pore space of the sand. The preferential travel along the fastest route resulted in the quicker first detection of the particulate tracers at the end of the sand column, independent of the presence of the hollow tubes.

Göppert and Goldscheider (2008) completed a set of comparative tracer tests in karst conduit systems under variable flow conditions. The first test was conducted under low-flow conditions and included a fluorescent dye, 1- $\mu \mathrm{m}$ microspheres, and 5- $\mu \mathrm{m}$ spheres. The microspheres traveled faster than the soluble fluorescent dye under the low-flow conditions. There was low recovery of the 5- $\mu \mathrm{m}$ spheres during low-flow, so the high-flow tests used only the fluorescent dye and 1- $\mu \mathrm{m}$ microspheres. During high-flow conditions, the microspheres and soluble fluorescent dyes travelled at similar rates.

Sinreich et al. (2009) completed a comparative tracer test using iodide, microspheres, and Ralstonia eutropha $\mathrm{H} 16$ ( $R$. eutropha), a non-pathogenic bacterium. R. eutropha and the microspheres were similarly sized. They found that the microspheres and $R$. eutropha moved through the system at similar velocities, but the $R$. eutropha concentrations peaked later than the microspheres. The maximum concentration of the microspheres was 15-30 times less than the R. eutropha. The microsphere recovery was only $2 \%$ of what was recovered of the $R$. 
eutropha. The authors concluded that the microspheres sorbed on the surface of the rock matrix while the R. eutropha did not. This work showed that particle size is not the only controlling factor in transport.

\subsubsection{Modified clays}

Mähler et al. (1998a, 1998b) labeled clay tracers with lanthanides and DNA. Lanthanide elements were sorbed onto Wyoming montmorillonite and tested in the lab and field, in both surface and ground waters. The lanthanide labeled clays traveled similarly to rhodamine but their concentration peaked before the rhodamine. The lanthanide-labeled clay was not detected in low-flow conditions likely due to gravitational settling. The DNA-labeled clays were made with Wyoming montmorillonite and quartz clay. Both clays were stable in the lab using deionized water, but the quartz clay was not stable in spring waters with high amounts of calcium bicarbonate.

\subsubsection{Other particulate tracers}

A variety of other particulate tracers exists. Lycopodium spores (from a clubmoss) have been used but sample collection is difficult, so they are not used for quantitative tests. Bacteria and phages have been used since 1894, however, they are becoming problematic (Käss 1998, Göppert and Goldscheider 2008). Samples must be analyzed within 24 hours, thus restricting the duration of the tracer test. Human and animal safety is also a common issue when using bacteria and phages. Serratia marcescens was a popular choice for a bacterial tracer but is now classified as a pathogen and is considered unsuitable (Göppert and Goldscheider 2008). 


\subsection{Purpose}

Although many types of tracers exist, few have flow properties similar to LNAPLs. Therefore, the overall goal of this research was to create a new tracer that better mimics LNAPL behavior. The four objectives of this work were to:

1. Develop and optimize the hydrogel tracer beads (HTBs), a tracer made from alginate gel,

2. conduct preliminary field tests using HTBs with various densities,

3. conduct comparative tracer tests in karst streams using low-density HTBs and solute tracers, and,

4. assess and compare the behavior of the HTBs with solute tracers. 


\subsection{Materials and procedures}

\subsection{Hydrogel tracer bead preparation and development}

Hydrogel tracer beads (HTBs) are organic, non-toxic beads made from alginate. Alginate is produced from the cell walls of brown algae (Dragnet et al. 2006). Harvested from the North Atlantic and North Pacific shores, primary sources of alginate are rockweeds and kelp. Sodium alginate, $\mathrm{C}_{6} \mathrm{H}_{8} \mathrm{O}_{6} \mathrm{Na}$, is colorless to light yellow and is sold as a powder, granules, or filaments. Alginate forms a viscous colloid when dissolved in water (Dragnet et al. 2006). Alginate is used in the following industries: food, pharmaceutical, medical, dentistry, textile, paper, cosmetics, and paint (Ren 2008). This research focuses on the development and modification of alginate gel beads to mimic the contaminant fate and transport of NAPLs.

\subsubsection{Construction of hydrogel tracer beads}

Alginate solutions form a gel by chemically linking with divalent cations (Ren 2008). One method of alginate bead production is the extrusion technique. Alginate is dissolved into deionized water and delivered through a needle into a divalent cation solution, in this case, calcium chloride. When the drop of alginate solution hits the surface of the water, the divalent cation cross-links the alginate chain on the surface of the drop, producing a bead with a thin skin on the surface (Ren 2008). Calcium in the solution diffuses through the bead's skin and cross-links the alginate chains that are inside the bead, thus increasing the firmness of the bead during a curing process.

Alginate solutions made with higher percent alginate will take longer to form a bead that has been fully cross-linked throughout as there is more alginate present (Dragnet et al. 2006). Increasing the concentration of divalent cations in solution will decrease the time it takes for the alginate chains to fully cross-link because there are more cations available in solution to diffuse into the bead. 
HTBs form from 2-4\% weight per weight (w/w) alginate solution. Solutions of greater than $4 \%$ $\mathrm{w} / \mathrm{w}$ are highly-viscous and thus difficult to push through the needle to deliver the alginate gel to the calcium solution. Alginate solutions that are less than $2 \% \mathrm{w} / \mathrm{w}$ are not viscous enough to form a proper bead.

In this study, three grams of low viscosity sodium alginate powder (Sigma Aldrich, St. Louis, MO) were added to 97 grams of deionized water and stirred overnight or until the alginate was thoroughly dissolved. A solution of 0.5-1.0 M calcium chloride dihydrate (Sigma Aldrich, St. Louis, MO) was used for HTB formation and curing. The alginate solution was delivered to the calcium solution via needle ( 25 or 20 gauge) and syringe from a drop height of approximately $30 \mathrm{~cm}$ above the surface of the solution. The solution was stirred at a constant rate of about 80 rpm. After the formation, the beads were transferred to a fresh 0.5-1.0 M calcium solution for continued curing and storage. Both the alginate and the curing solutions were at room temperature. A detailed procedure for creating HTBs is included in Appendix B.

HTBs can be refrigerated in the curing solution for long periods of time ( $>1$ year) as long as they were made in a sterile setting (Ren 2006). Some bacteria eat alginate, so it is important that the work station is sterile to avoid introducing bacteria to the HTBs, if the HTBs are meant for long-term storage. During the course of the research, some HTBs became moldy 6 months after being stored in a calcium solution at room temperature; others were stored in calcium solution refrigerated for greater than 18 months without growing mold. Some alginate solutions became moldy when left on the stir plate for 48 hours. HTBs stored at room temperature showed accelerated breakdown by the formation of mold on the beads. As the HTBs are non-toxic, complete collection and degradation is not a concern because they are not dangerous to the health of biota, although the growth of mold is evidence that the HTBs do biodegrade.

The hydrogel tracer beads were readily modified in size by changing the gauge of the needle from which the alginate solution is delivered to the curing solution. Highly viscous solutions 
were difficult to push through smaller diameter needles and low viscosity solutions form streams as the alginate solution was pushed through the larger diameter needles.

Fluorescent pigments can be incorporated into the alginate solution to colore the HTBs. This research used insoluble fluorescent pigments (Risk Reactor, Santa Ana, CA) in various colors. The colors were easily distinguishable from one another in both natural and UV light. One issue encountered with the fluorescent pigments was maintaining a homogenous solution being delivered from the needle. Some of the pigment did not mix with the alginate but floated on the surface of the solution instead. This caused the HTBs to have variable densities if some HTBs had higher amounts of pigment than others. To avoid this problem, only low concentrations of dyes were added ( $1 \% \mathrm{w} / \mathrm{w})$.

Density was modified by the addition of heavy mineral powders such as barite $\left(\mathrm{BaSO}_{4}\right)$ or buoyant 3M ${ }^{\oplus}$ Glass Bubbles S22 (3M, Saint Paul, MN). Three different density HTBs were used in this research (Table 2); low-density buoyant HTBs were made with a $3 \%$ alginate solution with $1 \% \mathrm{w} / \mathrm{w}$ fluorescent pigment and $1 \% \mathrm{w} / \mathrm{w}$ glass bubbles. Palm Leaf Green fluorescent pigment was used for making the low-density HTBs for the preliminary field tests at Hazel Run. Clownfish Orange, Yellow Tang, and Coral Red fluorescent pigments were used to make the low-density HTBs used at Buckeye Creek Cave. The medium-density HTBs used at Hazel Run were made with a $3 \%$ alginate solution and $1 \% \mathrm{w} / \mathrm{w}$ Yellow Tang fluorescent pigment. The high-density HTBs used at Hazel Run were made with 3\% alginate, 1\% w/w Magenta Sea Foam fluorescent pigment, and $20 \%$ powdered barite $\left(\mathrm{BaSO}_{4}\right)$, which has a density of $3.68 \mathrm{~g} / \mathrm{cm}^{3}$.

All additions were added after the alginate solution had been thoroughly solubilized. A known mass of alginate solution was transferred to a pre-weighed centrifuge tube and mass was recorded. The additives were then weighed and added to the centrifuge tube. Some additives require a longer mixing time than others. The glass bubbles and some UV pigments mix readily and only needed to be mixed on a Vortex mixer at for one minute to ensure thorough mixing. 
Table 2: Additives used for making HTBs.

\begin{tabular}{l|ccc|c}
\hline & \multicolumn{3}{|c|}{ Hazel Run } & $\begin{array}{c}\text { Buckeye Creek Cave } \\
\text { Rhine Creek }\end{array}$ \\
\hline \multicolumn{1}{c|}{ Relative density } & Low & Medium & High & Low \\
\hline Alginate & 3 & 3 & 3 & 3 \\
\% w/w fluorescent pigment & 1 & 1 & 1 & 1 \\
\%w/w glass bubbles & 1 & 0 & 0 & 1 \\
\% w/w powdered barite & 0 & 0 & 20 & 1 \\
$\begin{array}{l}\text { Molarity (moles/L) calcium } \\
\text { solution }\end{array}$ & 0.4 & 0.4 & 0.4 & 20 \\
Needle gauge & 25 & 25 & 25 & $\begin{array}{c}\text { Coral Red } \\
\text { Fluorescent pigment color }\end{array}$ \\
\hline Palm Leaf Green & Yellow Tang & Magenta Sea Fan & Yellow Tang \\
\hline
\end{tabular}

$\mathrm{w} / \mathrm{w}$ is the weight per weight of material added to alginate solution 
The Yellow Tang UV pigment was not as easily mixed and required manual stirring to disperse the pigment throughout the alginate solution.

Relatively small volumes $(10 \mathrm{~mL})$ of homogeneous alginate/particulate solutions were used to make beads to prevent the settling of the insoluble particles. While this method takes longer, the HTBs were homogenous and then there were fewer waste HTBs, making the overall process shorter and more cost effective.

Hydrogel tracer beads were inexpensive to make. While there was a significant amount of startup costs in purchasing materials, over 10,000 HTBs were produced from $250 \mathrm{~mL}$ of $3 \%$ alginate. That relates to approximately 7.5 grams of alginate, 60 grams of calcium chloride

dihydrate, 2.5 grams of pigment, 2.5 grams of $3 \mathrm{M}^{\odot}$ Glass Bubbles, three $50 \mathrm{~mL}$ syringes, and 3 needles. The cost of making 10,000 HTBs was approximately $\$ 8.00$ and this was enough HTBs for the comparative tracer tests conducted for this research.

\subsubsection{Quantification and characterization of the HTBs}

Quantification was achieved by manual counting, which is facilitated by coloring the HTBs. Measuring the mass of the HTBs as a means of quantification is less accurate because the bead is about $95 \%$ water and removal of the surficial water without removal of the water inside the bead is not feasible.

HTB optimization experiments were conducted to determine the conditions that produced the most spherical HTBs of consistent size. Parameters that were tested were percent alginate solution and drop height. Pure alginate solution with no additives was used to create the HTBs. Alginate concentrations tested include 2, 3 and 4\%. Drop heights, the height from the tip of the needle to the surface of the curing solution were 10, 30, 50 and $100 \mathrm{~cm}$. HTBs were produced and allowed to cure for at least one minute before removal from the calcium solution. They 
were then stored in a $0.5 \mathrm{M}$ calcium curing solution until later analysis. Stirring of the calcium solution remained at a constant $80 \mathrm{rpm}$ for all trials.

Analysis of the HTBs was based on sphericity, a comparative measure of the long and short axes of the HTB. A minimum of ten HTBs were measured for each test condition. The HTBs were placed on a weigh boat and dabbed with KimWipes ${ }^{\mathrm{TM}}$ to remove excess moisture. This was done to decrease the amount of shadow and thus uncertainty produced when viewing through the microscope. The microscope used was a Leica Wild M3Z (Germany) with an Intralux 6000-1 Fiberoptic Illuminator (Switzerland). The magnification was set at +6.5 times. Photos of the HTBs (Figure 2) were taken and bead size was measured using Infinity Analyze, release 5.0 software from Lumenera Corp. (Ottawa, Ontario, Canada). The size measurements were of the long and short axes and sphericity was determined by dividing the long axis by the short axis. Perfectly spherical HTBs yielded a sphericity number of 1.

Determining the density of the HTBs is of interest in order to be able to determine what NAPL compounds they are most similar to. Various methods for determining the density of HTBs were considered. For this research, HTBs density was classified only relative to water because of difficulties in calculating exact densities.

\subsubsection{Results of the HTBs optimization}

The most spherical beads formed from $3 \%$ alginate at a $30 \mathrm{~cm}$ drop height (Table 3). The 3\% HTBs had a sphericity of less than 1.1 at all drop heights. The 4\% HTBs only had sphericity less than 1.1 when dropped from $10 \mathrm{~cm}$. The $2 \%$ alginate did not form beads at drop heights of 30 $\mathrm{cm}$ or greater.

In creating HTBs for the comparative tracer tests at Buckeye Creek Cave and Rhine Creek, 3\% alginate solution was used, at a drop height of $30 \mathrm{~cm}$. 


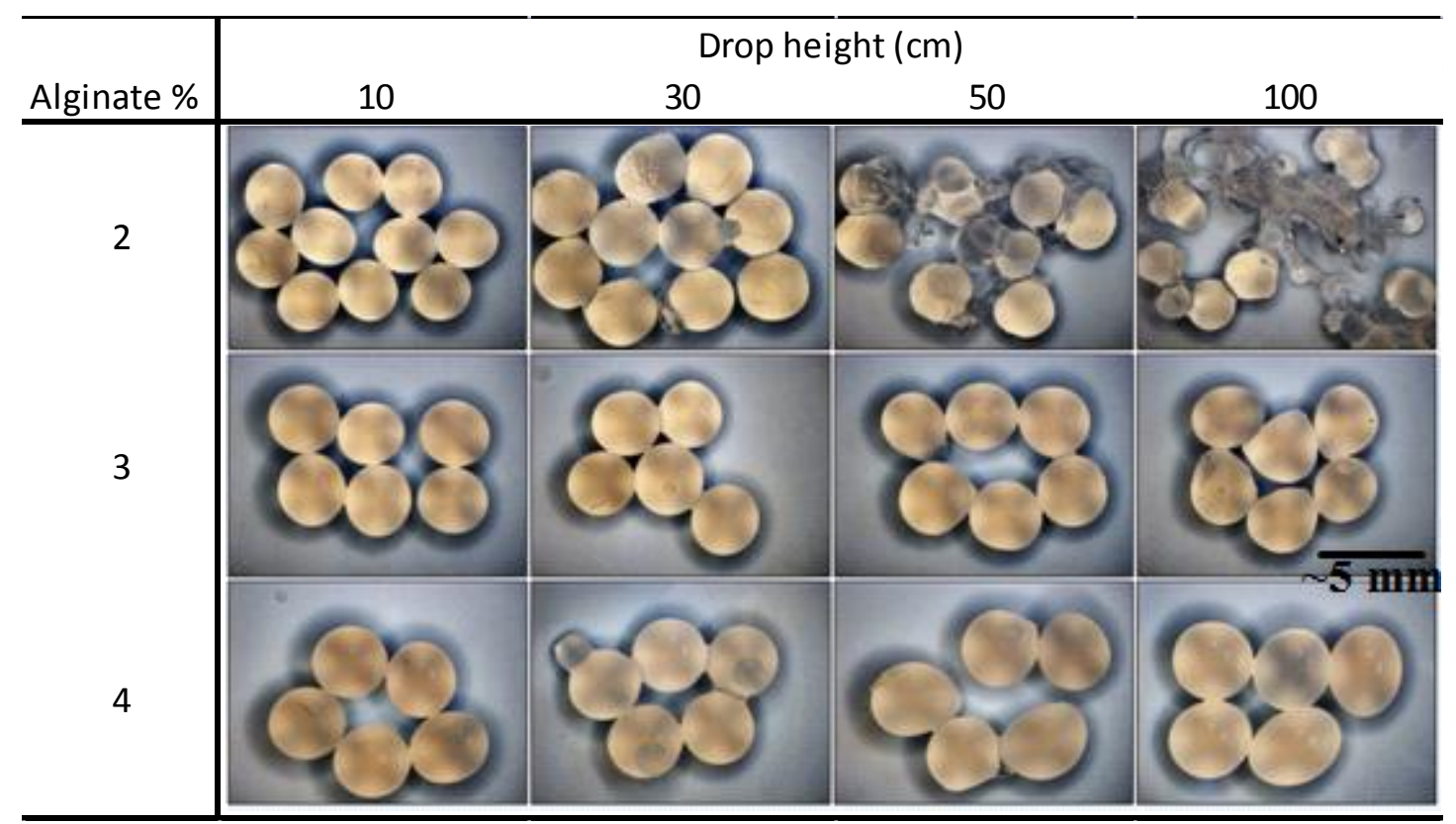

Figure 2: Photos of formed HTBs at various alginate percents and drop heights. 
Table 3: Measured sphericity values for HTBs.

\begin{tabular}{r|rrrr}
\hline & \multicolumn{4}{|c}{ Drop height } \\
Alginate & \multicolumn{5}{|c}{ percent } & $10 \mathrm{~cm}$ & $30 \mathrm{~cm}$ & $50 \mathrm{~cm}$ & $100 \mathrm{~cm}$ \\
\hline $2 \%$ & 1.075 & -- & --- & -- \\
$3 \%$ & 1.078 & 1.049 & 1.071 & 1.081 \\
$4 \%$ & 1.062 & --- & 1.193 & 1.172 \\
\hline
\end{tabular}

--- means beads did not form under the tested condtions

Spherosity values a re a comparitive measure of the length of the short and long axis of beads. Values closer to one indicate a more spherical bead while values greater than one are more ovular. 


\subsection{Field testing methods}

Field testing of HTBs took place at three locations: Hazel Run, Buckeye Creek Cave, and Rhine Creek (Table 4). The first tracer test was a preliminary test to evaluate how different density HTBs traveled relative to one another. High-, medium-, and low-density HTBs were used for preliminary testing. After successful testing at Hazel Run, two sets of comparative tracer tests were completed. The first set of tests was at Buckeye Creek Cave and the second was at Rhine Creek. Three tests were completed at each location. The first test at each location was a trial test, and no data were recorded. The trial test was to make sure that the collection method worked and to predict the duration of the tests. A slug of potassium bromide was injected into the water to create a spike in conductivity. The conductivity was monitored on a YSI 556 Mulitprobe System ${ }^{\odot}$ (YSI Inc., Yellow Springs, $\mathrm{OH}$ ). The test was considered complete when the conductivity recovered to background readings.

After the initial trial test, two quantitative comparative tracer tests were completed at both Buckeye Creek Cave and Rhine Creek. Fluorescein and low-density HTBs were released simultaneously. Different colored HTBs were injected for each test to eliminate contamination from previous tests. The fluorescein solution was pre-mixed in a $500 \mathrm{~mL}$ amber glass bottle. The fluorescein was emptied into at 5-gallon bucket. The amber glass bottle was rinsed with creek water and added to the bucket. The HTBs were then added to the 5 gallon bucket. The tracers were released into the stream and the bucket was quickly rinsed and any residual tracers released twice more. It was estimated that it took no longer than 10 seconds to deliver all tracers to the stream.

Downstream water samples were collected as discrete grab samples every 20 seconds. HTBs were collected continuously with nets using a 20-second collection interval. Bead collection was less complete at Buckeye Creek Cave due to the challenges of collecting numerous samples in a short time in a cave setting. Collection at Rhine Creek was greatly improved by having individual nets for each collection interval. A new net was in the water before the previous 
Table 4: Field tests completed.

\begin{tabular}{|c|c|c|c|c|c|c|}
\hline Location & Date & $\begin{array}{l}\text { \# of tests } \\
\text { completed }\end{array}$ & $\begin{array}{l}\text { Total duration } \\
\text { of testing }\end{array}$ & What was accomplished & $\begin{array}{r}\text { Mass of } \\
\text { fluorescein }(\mathrm{g})\end{array}$ & $\begin{array}{r}\text { Number of } \\
\text { HTBs }\end{array}$ \\
\hline Hazel Run & April 18, 2012 & 1 & $\sim 30$ minutes & $\begin{array}{l}\text { Preliminary testing of three different } \\
\text { density HTBs, exploration of collection } \\
\text { methods }\end{array}$ & - & - \\
\hline $\begin{array}{l}\text { Buckeye Creek } \\
\text { Cave }\end{array}$ & May 18, 2012 & 2 & $\sim 3$ hours & $\begin{array}{l}\text { Comparative tracer tests over a } 64 \text { m } \\
\text { stream section including low-density } \\
\text { HTBs and fluorescein }\end{array}$ & $1.96,1.92$ & 3000 per test \\
\hline Rhine Creek & October 5, 2012 & 2 & $\sim 2$ hours & $\begin{array}{l}\text { Comparative tracer tests over a } 64 \text { m } \\
\text { stream section inlcuding low-density } \\
\text { HTBs and fluorescein }\end{array}$ & $0.97,0.98$ & 1500 per test \\
\hline
\end{tabular}


Table 5: Analytes and methods

\begin{tabular}{|c|c|c|}
\hline & Fluorescence & Anions \\
\hline Bottle size & $40 \mathrm{~mL}$ & $20-30 \mathrm{~mL}$ \\
\hline Bottle type & Glass & Plastic \\
\hline Preservative & Cold & Cold \\
\hline Filtered or raw & Raw & Filtered \\
\hline Analysis & Spectrofluorometer & Ion Chromotography \\
\hline
\end{tabular}

List of analytes and methods. The anion measured was $\mathrm{Br}^{-}$. 
sampling interval had ended. When the 20 seconds was over, the net that had been collecting HTBs was pulled from the water and the new net was in place so very few HTBs were missed at the collection site.

Length of the test section was measured using a measuring tape and standing in the center of the stream. The resulting value was the actual distance the tracers traveled, and therefore no correction for sinuosity needed to be made when modeling the data. For groundwater tracing, QTRACER2 allows the user to input a value for sinuosity of the channel in order to calculate and precise value for test section length.

Discharge was measured in triplicate at Buckeye Creek Cave and Rhine Creek after the tracer tests was completed. Discharge at Buckeye Creek Cave was measured using a Swoffer 3000 meter and rod (Swoffer, Seattle, WA). Discharge at Rhine Creek was measured using afloat method (Lazorchak et al. 1998). Tests at Buckeye Creek Cave and Rhine Creek were short $(<30$ minutes) and discharge was assumed to be over constant throughout the tests.

\subsubsection{Site descriptions}

A preliminary field test was conducted in a tributary to Hazel Run, near Bruceton Mills, West Virginia (Figure 3). The stream has a slight meander and the bedload is a mixture of cobble, pebble, sand, and silt. The section tested was $15 \mathrm{~m}$ long, and the stream width ranged from 0.3-1.5 m. There were many trapping features present: exposed sand bars, meanders in the channel, eddies, vegetation, tree roots, and bedload sediment.

The first comparative tracer test site was Buckeye Creek Cave near Lewisburg, West Virginia (Figure 4). Buckeye Creek Cave is situated in the Greenbrier Valley karst region of southern West Virginia. Buckeye Basin is bounded on the east by the Maccrady and Pocahontas undifferentiated deposits and on the west by the Mauch Chunk Group (Dasher and Balfour 1994). The southern end is bounded by the Saint Clair Fault. The Greenbrier Valley karst is 


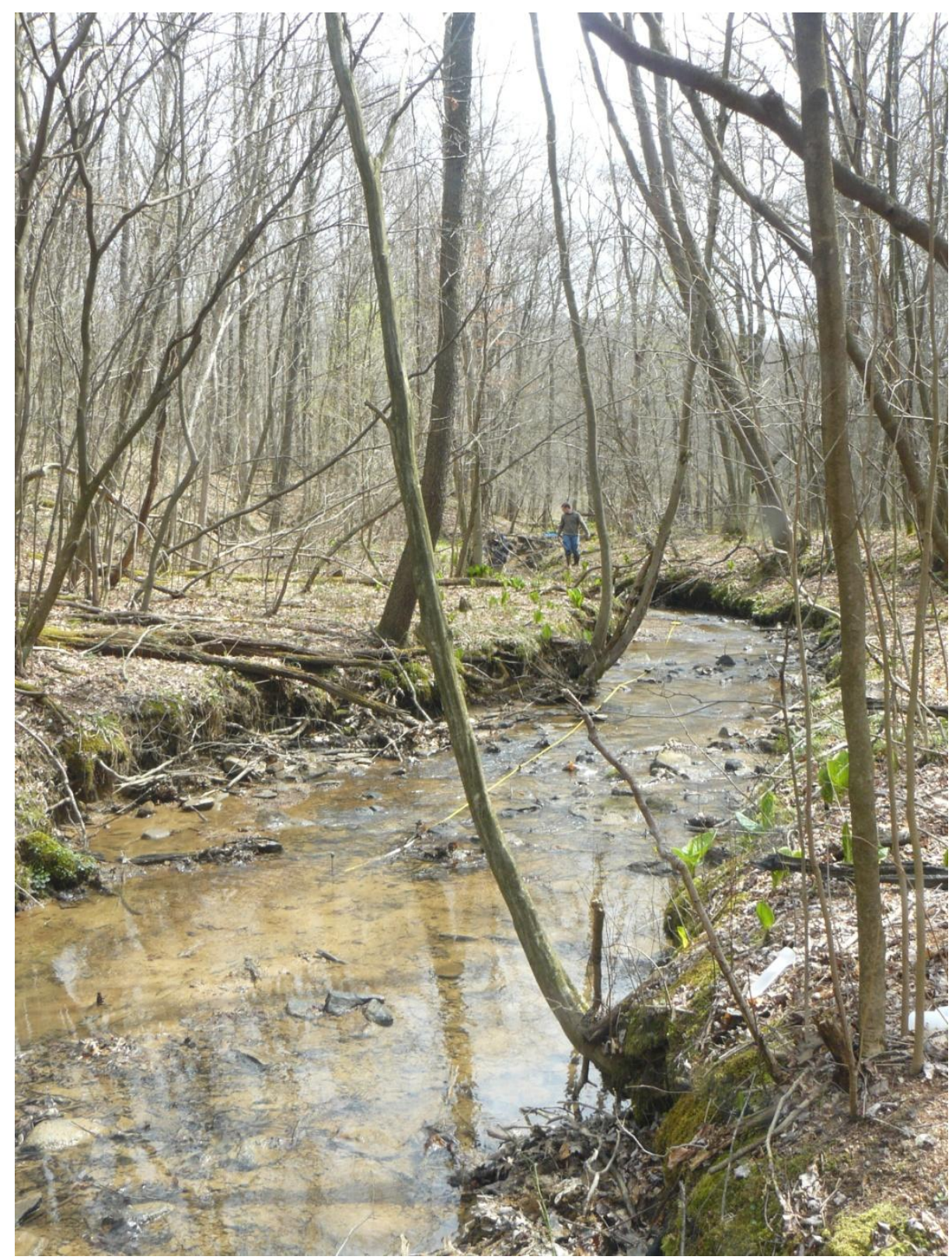

Figure 3: Hazel Run, site of the preliminary field test site near Bruceton Mills, WV (photo by Dorothy Vesper). 


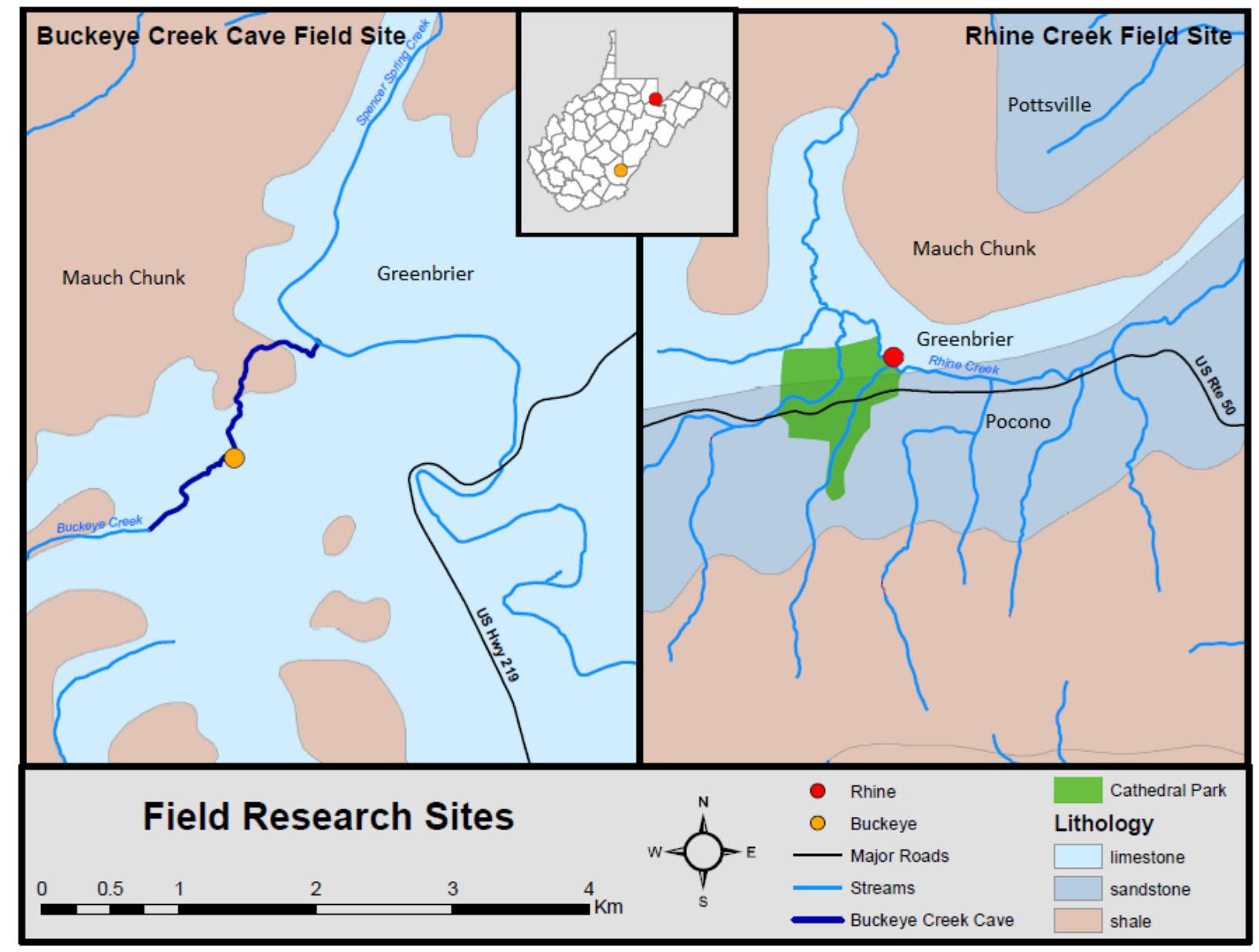

Figure 4: Map of field research sites for comparative tracer tests. 
formed in the Greenbrier Group (Figure 5), a Mississippian age deposit consisting of limestone, dolomite, and calcareous shale (Dasher and Balfour 1994). In Greenbrier Valley, the rock is shallowly dipping 3 degrees to the west. Buckeye Creek Cave developed in the Union limestone, which is described as a being a $15 \mathrm{~m}$ thick, white to grey, fossiliferous limestone that is oolitic in some areas. The Union limestone forms many large caves.

The test section of Buckeye Creek Cave was a $64 \mathrm{~m}$ canyon (Figures 6-7). The stream was less than $1 \mathrm{~m}$ wide, and the water level during the test was about $0.6 \mathrm{~m}$ at the deepest. The flow was constricted on the sides and bottom by bedrock. There was minimal sediment bedload, with the majority of what was present being pebble to sand sized. Trapping mechanisms were limited in the Buckeye system but included eddies and scallops in the passage wall. The discharge at the time of testing at Buckeye Creek Cave was $140 \mathrm{~L} / \mathrm{s}$.

The second set of comparative tracer tests was completed in Rhine Creek in Terra Alta, West Virginia (Figure 4). The test section was on the property of Ed and Mary Utterback, owners of Brookside Farms. The surface stream developed in parts of the Mauch Chunk, Greenbrier, and Pocono Group but the test section is in the Union Limestone member of the Greenbrier group (Figure 5), similar to Buckeye Creek Cave. The stream section used for the tracer work was in limestone; however, $\mathrm{pH}$ values were less than 6 .

Over the test section, Rhine Creek was about $3 \mathrm{~m}$ wide with depths less than $0.2 \mathrm{~m}$ (Figures 810). There was significant cobble to silt size bedload present. Trapping mechanisms in the Rhine Creek system were abundant and included vegetation, a small island feature, bedload that broke the water surface, and eddies. The discharge at the time of testing at Rhine Creek was $85 \mathrm{~L} / \mathrm{s}$. 


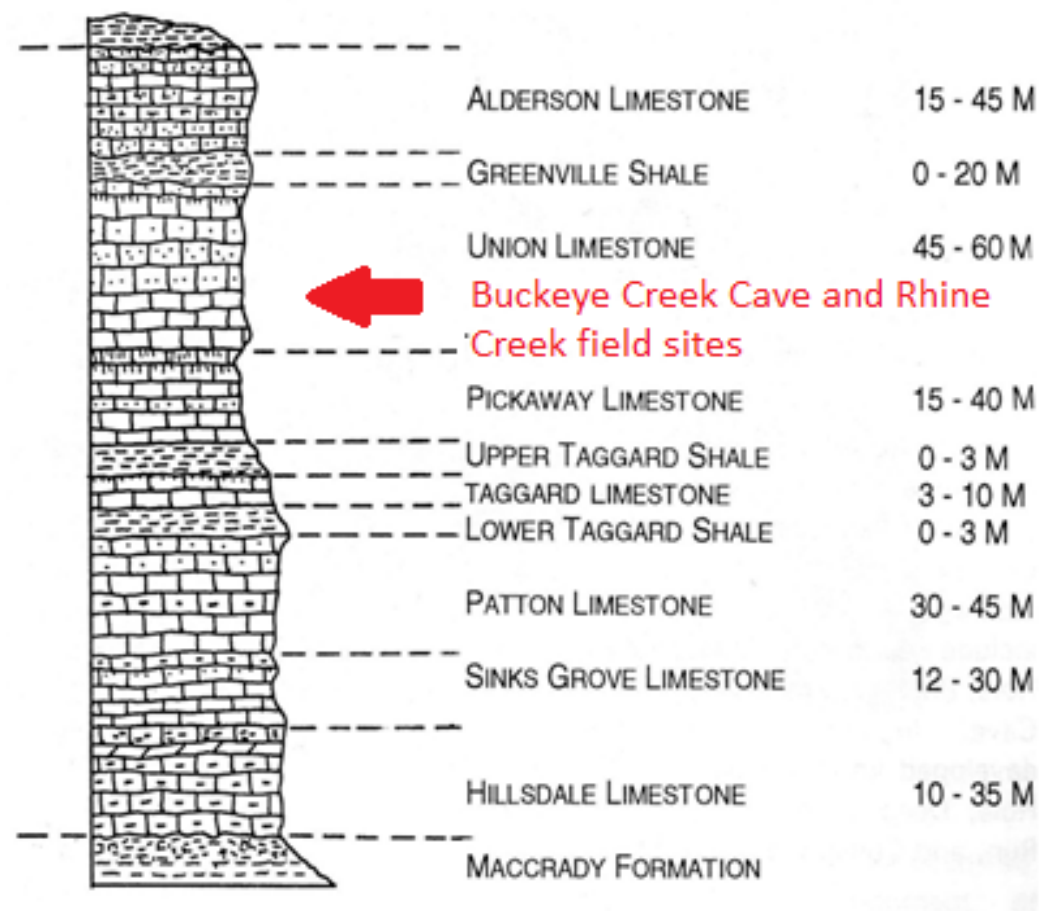

Figure 5: Greenbrier group stratigraphic column (modified from Dasher and Balfour 1994). 


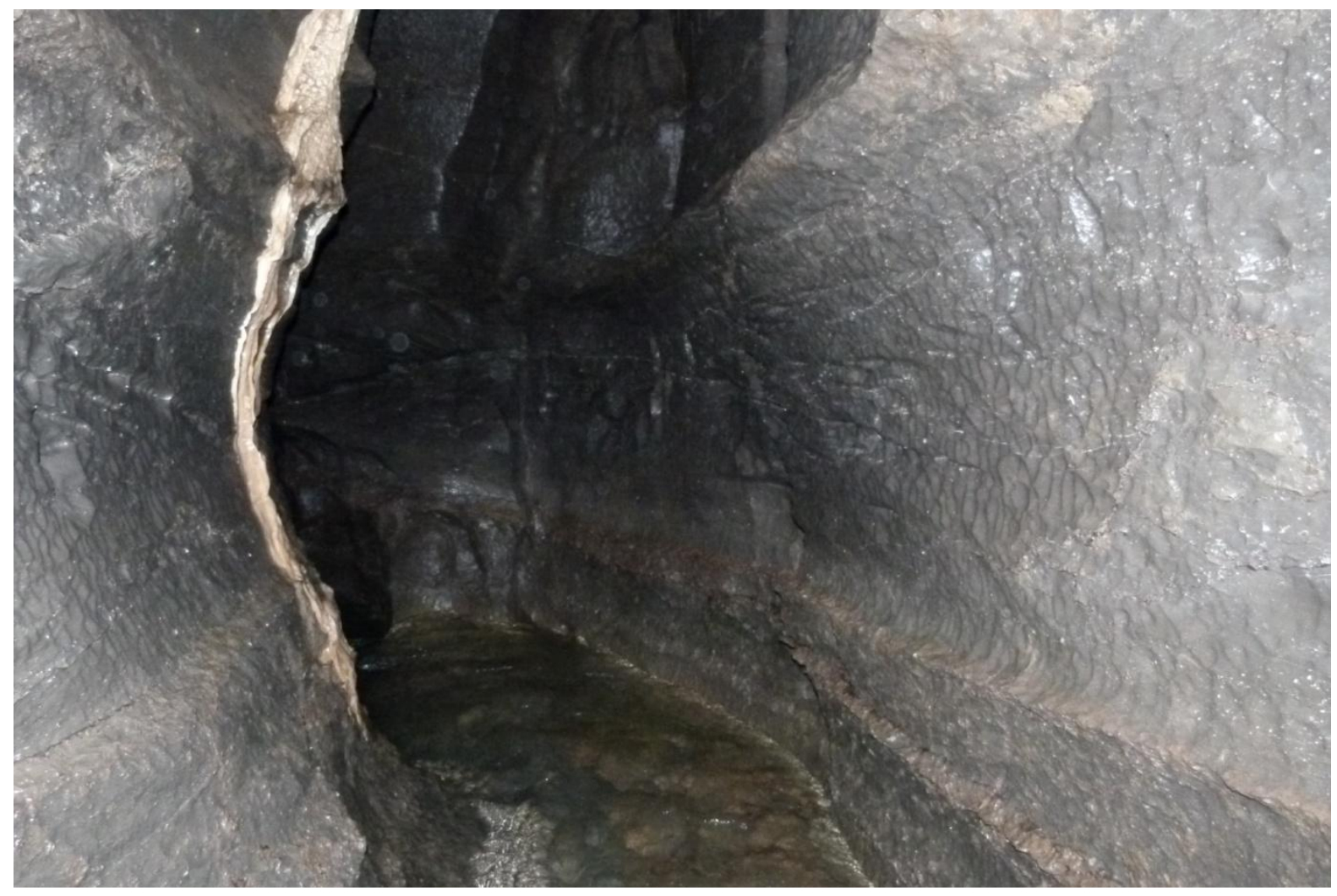

Figure 6: Buckeye Creek Cave canyon section (photo by Ellen Herman). Width of the passage was approximately $1 \mathrm{~m}$. 


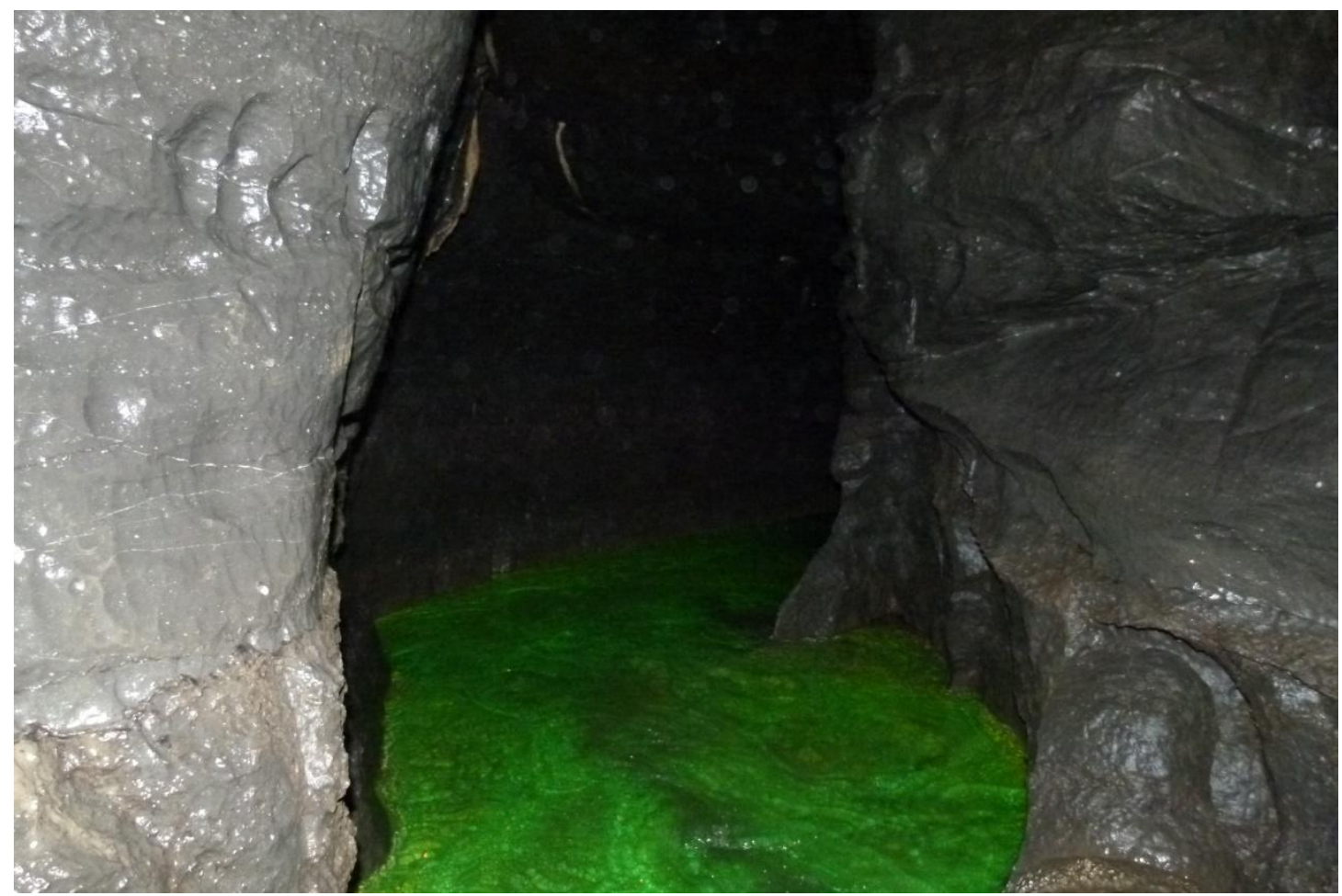

Figure 7: Buckeye Creek Cave release point (photo by Ellen Herman). Photo of release of fluorescein and HTBs at the beginning of the test section. Note the large scalloping on the walls of the cave, which are potential trapping features. Width of the passage was approximately $1 \mathrm{~m}$. 


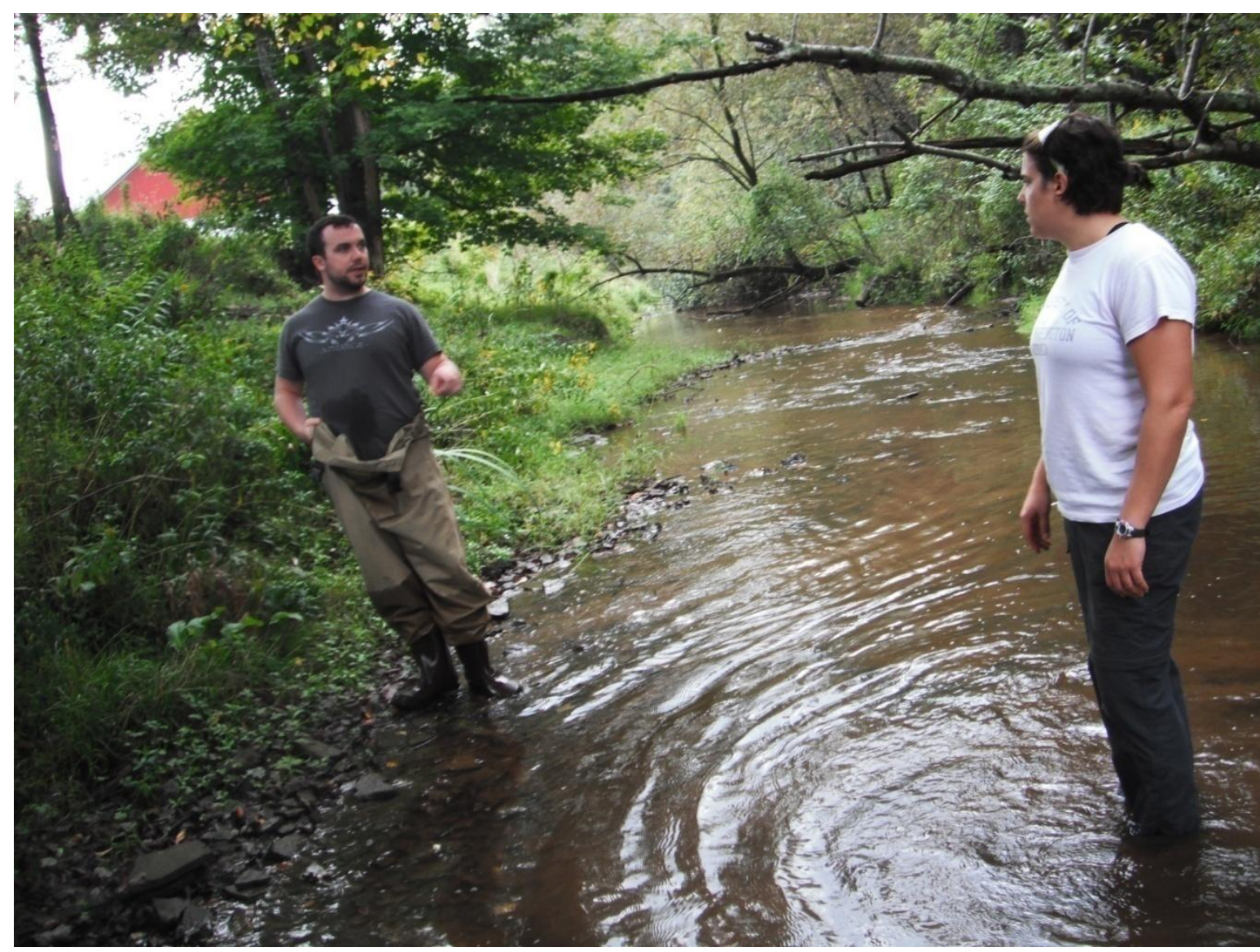

Figure 8: Rhine Creek field site. Note the vegetation and bedload that breaks the surface of the water. Individuals are approximately $1.7 \mathrm{~m}$ tall. 


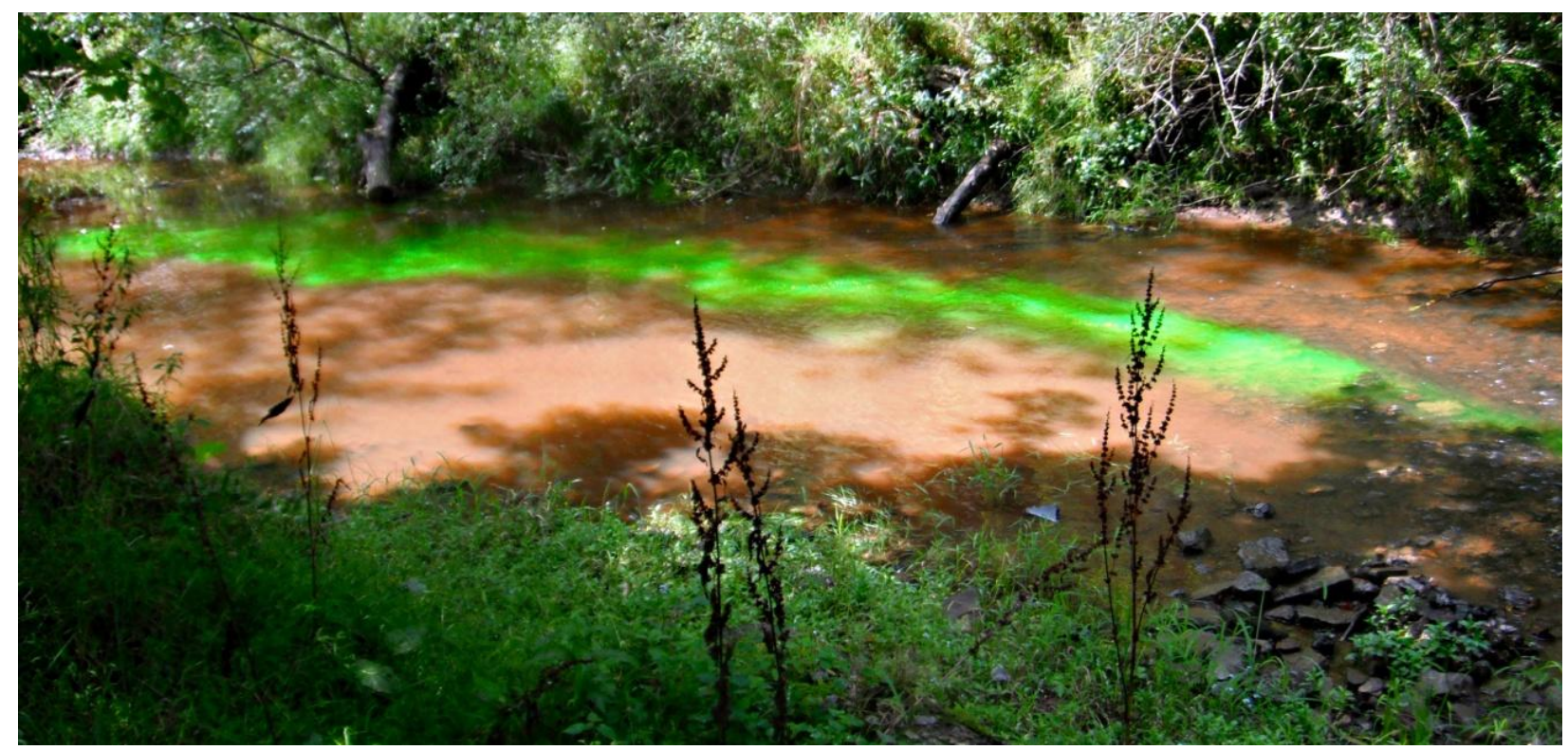

Figure 9: Rhine Creek injection site. Photo shows a plume of fluorescein and beads traveling downstream shortly after release ( 1 minute). Flow direction was from the right to the left of the photo. 


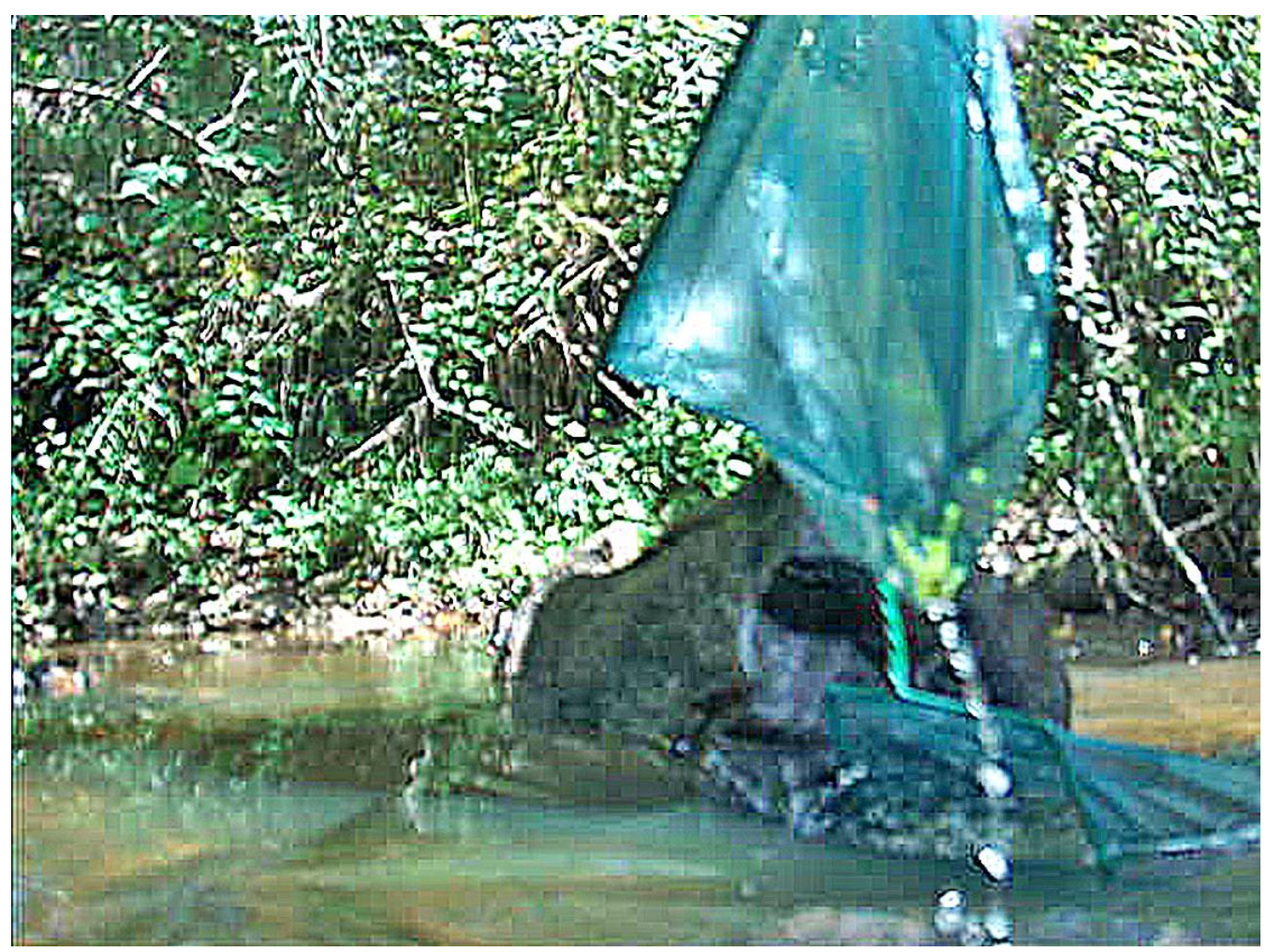

Figure 10: Rhine Creek collection site with beads being collected in a $25.4 \mathrm{~cm}$ aquarium net. This photo shows the net from the previous sampling interval being removed while the net for the current sampling interval was in place. 


\subsubsection{Water sampling and HTB collection}

Baseline parameters for the field tests were measured on a YSI 556 Mulitprobe System ${ }^{\odot}$ (YSI Inc., Yellow Springs, $\mathrm{OH}$ ). The meter was calibrated before beginning the tests. Calibrations for $\mathrm{pH}$ were completed using a standard two-point method using 4.00 and 7.00 standards (Thermo Fisher Scientific Inc., Waltham, MA). The conductivity was calibrated using a $1409-\mu S / \mathrm{cm}$ standard created in the laboratory using $\mathrm{KCl}$.

Buckeye Creek Cave water samples were collected in 250-mL plastic bottles and kept on ice until separated into bottles for anion, cation, and fluorescence within 24 hours of collection (Table 5). HTBs were collected in pool skimmers and folded in aluminum foil sheets. The sheets were stored in bags for later counting.

Water samples from Rhine Creek were collected in 40-mL amber glass vials and preserved on ice until they were refrigerated in the lab (Table 5). HTBs were collected in individual 25.4-cm nets and transferred to individual bags for counting (Figure 10).

Quality control samples included deionized water blanks and duplicates. The deionized water was used to make sure the equipment was not causing contamination, as well as to check that the sample bottles were not contaminated. Duplicates were tested to check equipment precision. Deionized water was used to flush the pool skimmers used at Buckeye Creek Cave to determine if there was a significant amount of fluorescein adhering to the netting. Stream water blanks were also collected to make sure there was no background fluorescence. The relative standard deviation (RSD) of anions measured in duplicate samples ranged from 0-9.7\% with an average of $1.5 \%$. The RSD of fluorescein measured on the Turner Designs 3100 Laboratory Fluorometer ranged from $0.9-8.7 \%$ with an average of 3.9\%. Fluorescein was undetectable in control samples. They HTBs were counted twice before being packaged for the tests. Each collected sample of HTBs was also counted twice. 


\subsubsection{Stream discharge measurements}

Two methods of measuring discharge were used for this research. Discharge was measured at Buckeye Creek Cave with a Swoffer 3000 meter and rod (Swoffer, Seattle, WA) using the midsection assumption (Buchanan and Somers 1969). Between the testing at Buckeye Creek Cave and Rhine Creek, the Swoffer 3000 meter broke, so an alternate float method (Lazorchak et al. 1998) was used for discharge measurements at Rhine Creek.

Standard methods of measuring discharge based on the midsection assumption were used at Buckeye Creek Cave (Buchanan and Somers 1969). The midsection assumption is that the velocity of a rectangular area is equivalent to the cross-sectional area of the rectangle multiplied by the velocity measured at 0.6 times the water depth. Using this approach, velocity was measured at 0.6 times the depth every $15 \mathrm{~cm}$ across the profile of the stream. The standard method calls for at least 20 stations along the cross-section; however, the stream was too narrow. Straight, channelized sections with no obstructions were chosen for discharge measurement. Measurements were completed in triplicate to create an average. Discharge was calculated as the summation of the discharge of each rectangular interval as per the following equation:

$$
Q=\sum(a * v)
$$

where $Q$ is the discharge, $a$ is the area of the rectangular section and $v$ is the velocity at that station. The following equation is used to determine the discharge over a rectangular stream section:

$$
q_{x}=v_{x}\left[\frac{b_{(x+1)}+b_{(x-1)}}{2}\right] d_{x}
$$


where $q_{x}$ is the discharge of the section $x, v_{x}$ is the measured velocity of section $x, b_{(x-1)}$ is the distance from the station where the velocity is measured to the previous station, $b_{(x+1)}$ is the distance from the station where the velocity is measured to the next station, and $d_{x}$ was the depth of the water at the station. The discharge of each rectangular section was then added to determine the total discharge of the stream's cross-section.

At Rhine Creek, discharge was measured using a float method (Lazorchak et al. 1998). A 6-m long section was chosen, and the cross-sectional area of the stream was measured at the end of the section. The cross-sectional area was determined using height of the water column and distance from each height measurement, similarly to the Buchanan and Somers method. Measurements were made every $15 \mathrm{~cm}$. A 30-mL plastic sample bottle was filled to neutral buoyancy, or when approximately half of the bottle was under the surface of the water, and half was above the surface of the water. This allowed for the bottle to not drag along the bottom of the stream but also not be influenced by wind on the surface of the stream. The bottle was dropped into the stream at the beginning of the 6-m section and the time of travel to reach the end of the section was recorded. The test was repeated if the bottle did not travel smoothly downstream (e.g. it got caught on debris in the stream, scraped the channel bed) or if it became fully submerged. These measurements were also done in triplicate to determine method precision; the average discharge is reported. The cross-sectional area was calculated using the following equation:

$$
A_{c x}=\left(\frac{b_{(x+1)}+b_{(x-1)}}{2}\right) d_{x}
$$

where $A_{c x}$ is the cross-sectional area in the units of measurement, $b_{(x-1)}$ is the distance from the station where the velocity is measured to the previous station, $b_{(x+1)}$ is the distance from the station where the velocity is measured to the next station, and $d_{x}$ is the depth of the water at the station. Discharge is calculated as: 


$$
Q=A * \frac{l}{t}
$$

where $Q$ is the discharge, $I$ is the distance the neutrally- buoyant bottle $30-\mathrm{mL}$ bottle travelled, and $t$ is the time it took for the neutrally- buoyant bottle $30-\mathrm{mL}$ bottle to travel distance $I$.

\subsection{Preparation and analysis of tracers}

Fluorescein was used as the solute tracer at Buckeye Creek Cave and Rhine Creek because it is a conservative dye over short distances and is readily analyzed on a spectrofluorometer. Three different methods were used to calculate the mass of fluorescein to be released. The first method was by Käss (1998), as follows:

$$
M=L * k * B
$$

where $M$ is the mass in grams, $L$ is the length of the test section in kilometers, $k$ is a coefficient for the tracer, and $B$ is a factor for the prevailing test conditions (varies from karst to granular aquifer). The calculation for fluorescein in Buckeye Creek Cave was:

$$
M=0.1 * 1 * 0.9=0.09 \mathrm{~g}
$$

The next method of calculation is by Worthington and Smart (2003), which states:

$$
M=19 *(L C Q)^{0.095}
$$

where $M$ is the mass in grams, $L$ is the length of the test section in meters, $C$ is the goal concentration in $\mathrm{g} / \mathrm{m}^{3}$, and $Q$ is the discharge in $\mathrm{m}^{3} / \mathrm{sec}$. The mass of fluorescein recommended 
for Buckeye, according to the method of Worthington and Smart (2003) and using the same values as the Käss calculation, is as follows:

$$
M=19 *(100 * 0.1 * 0.066)^{0.095}=0.026 \mathrm{gr}
$$

Lastly, the Tracer-Test Planning Using the Efficient Hydrologic Tracer-Test Design (EHTD) Program 2005 was used (Field 2003). The EHTD program is a computer program where field parameters such as discharge, length of stream section, and cross-sectional area are input. The program uses the advection-dispersion equation and an ideal tracer concentration to calculate the amount of tracer needed for a successful test as well as the sampling frequency. This method recommended a fluorescein tracer mass of $0.0025 \mathrm{~g}$.

The three predicted quantities of the tracer mass needed were decidedly different (Table 6). Results of the EHTD program calculated a mass that was an order-of-magnitude less than Käss (1998) and Worthington and Smart (2003). Calculations from Käss (1998) resulted in a value almost four times that of Worthington and Smart (2003). Based on this result, it was decided to inject the greatest calculated mass of $0.09 \mathrm{~g}$ multiplied by a factor of 20 to ensure a positive test result. Approximately $2 \mathrm{~g}$ of fluorescein was dissolved into one liter of Buckeye Creek Cave water for the tests completed at Buckeye Creek Cave (Table 7). This amount was chosen due to the uncertainty of the discharge and the expectation of a high amount of dilution in the system. Additionally, the cave setting was expected to mask colored water if the mass released was large enough to significantly color the water. Rhine Creek tests used $1 \mathrm{~g}$ of fluorescein dissolved into $1 \mathrm{~L}$ of Rhine Creek water.

The fluorescein to be released was dissolved into the pre-collected water from each test site in the laboratory. The fluorescein solution was put in amber glass vials to decrease the photodecay of the dye.

Fluorescein concentrations were measured using a scanning Varian Cary Eclipse Fluorescence Spectrophotometer (Agilent Technologies, Santa Clara, CA) with a synchronous scan over 450- 
Table 6: Amount of fluorescein needed for tests at Buckeye Creek Cave using various calculation methods.

Fluorescein amount

Method (grams)

Käss 1998 0.09

Worthington and Smart 2003 0.026

Efficient Hydrologic Tracer-Test Design 2003 
Table 7: Tracer amount released for the

Buckeye Creek Cave and Rhine Creek tests.

\begin{tabular}{l|rr}
\hline Test & $\begin{array}{r}\text { Fluorescein } \\
\text { mass (g) }\end{array}$ & $\begin{array}{r}\text { Number of } \\
\text { beads injected }\end{array}$ \\
\hline Buckeye A & 1.96 & 3000 \\
Buckeye B & 1.92 & 3000 \\
Rhine A & 0.97 & 1500 \\
Rhine B & 0.98 & 1500 \\
\hline
\end{tabular}

Amount of tracer used in each test. 
$550 \mathrm{~nm}$ with a delta-wavelength of $5 \mathrm{~nm}$, or a single excitation Turner Designs 3100 Laboratory Fluorometer (Turner Designs Hydrocarbon Instruments, Inc., Fresno, CA) with a mercury vapor lamp. Filters used in the lab fluorometer had a set excitation of $486 \mathrm{~nm}$ and emission of 510$700 \mathrm{~nm}$. Calibration standards were diluted in creek water that was collected prior to testing to account for matrix interference. HTBs were quantified by manual counting.

\subsection{Tracer test data analysis}

Fluorescein and HTBs data were entered into QTRACER2 (Field 2002). The program uses a series of computations based on user input files which include tracer concentrations and information on the system the test was conducted in, such as stream length, discharge and sinuosity. The program is valid for a variety of settings including karst, surface-water, granular aquifers, fractured rock and subsurface channels. Breakthrough curves were produced and analyzed by QTRACER2 to calculate tracer percent recovery, time of first detection, time of peak detection, peak concentration, mean velocity of the tracer, and mean tracer transit time.

In order to use QTRACER2 for HTBs data analysis, the number of HTBs collected was assumed equal to a concentration. The percent recovery of the HTBs was determined by dividing the sum of bead collected by the number of HTBs released times 100 . The data for fluorescein were entered as reported for concentration. 


\subsection{Results of field tests}

\subsection{Tracer test results}

\subsubsection{Results of preliminary field tests at Hazel Run}

The goal of the preliminary field test was to observe the behavior of different density HTBs in a stream setting to make sure they behaved as anticipated (Table 8 ). These tests included three different density HTBs: low-density floating, medium-density sinking, and high-density sinking (Figure 11). The stream test section was approximately $15 \mathrm{~m}$ in length.

The various density HTBs were released into the stream. The preliminary tracer test demonstrated that the HTBs were effective in mimicking different types of known NAPL behavior (Table 8). DNAPL are denser than water and sink through the water column until they reach a barrier (Loop and White 2001). They can then incorporate into sediment piles and remain stationary until there is enough energy provided to move them downstream. This was very similar to the behavior of the medium- and high-density HTBs. LNAPLs will float on the surface of the water until they reach a barrier (Ewers et al. 1991). The low-density HTBs traveled on the surface of the stream and became trapped when there were obstructions on the surface of the water.

The high-density HTBs sank immediately and stayed in clusters (Figure 12). While a few moved slightly downstream $(\sim 5 \mathrm{~cm})$, none were recovered at the collection point and more than $95 \%$ of the highly dense HTBs were recovered at the injection point. A temporary increase in water velocity was caused by manually pushing the water downstream. The high-density HTBs became suspended in the water column and transported slightly downstream until they sank again due to gravitational sedimentation. 
Table 8: Results of the preliminary field testing of HTBs at Hazel Run, April 18, 2012.

\begin{tabular}{llcl}
\hline HTBs density & First arrival of HTBs $\%$ recovery & Comments \\
\hline Low & 1 minute & 77 & $\begin{array}{l}\text { Floated on water surface and moved quickly through } \\
\text { the system; very few caught in eddies and on sand bars }\end{array}$ \\
Medium & 8 minutes, 15 seconds & 2 & $\begin{array}{l}\text { Bounced along the bottom of the stream and floated on } \\
\text { the surface; many trapped in eddies and on top of sand } \\
\text { bars }\end{array}$ \\
High & N/A & 0 & $\begin{array}{l}\text { Sunk almost immediately and did not move from } \\
\text { injection point }\end{array}$ \\
\hline
\end{tabular}




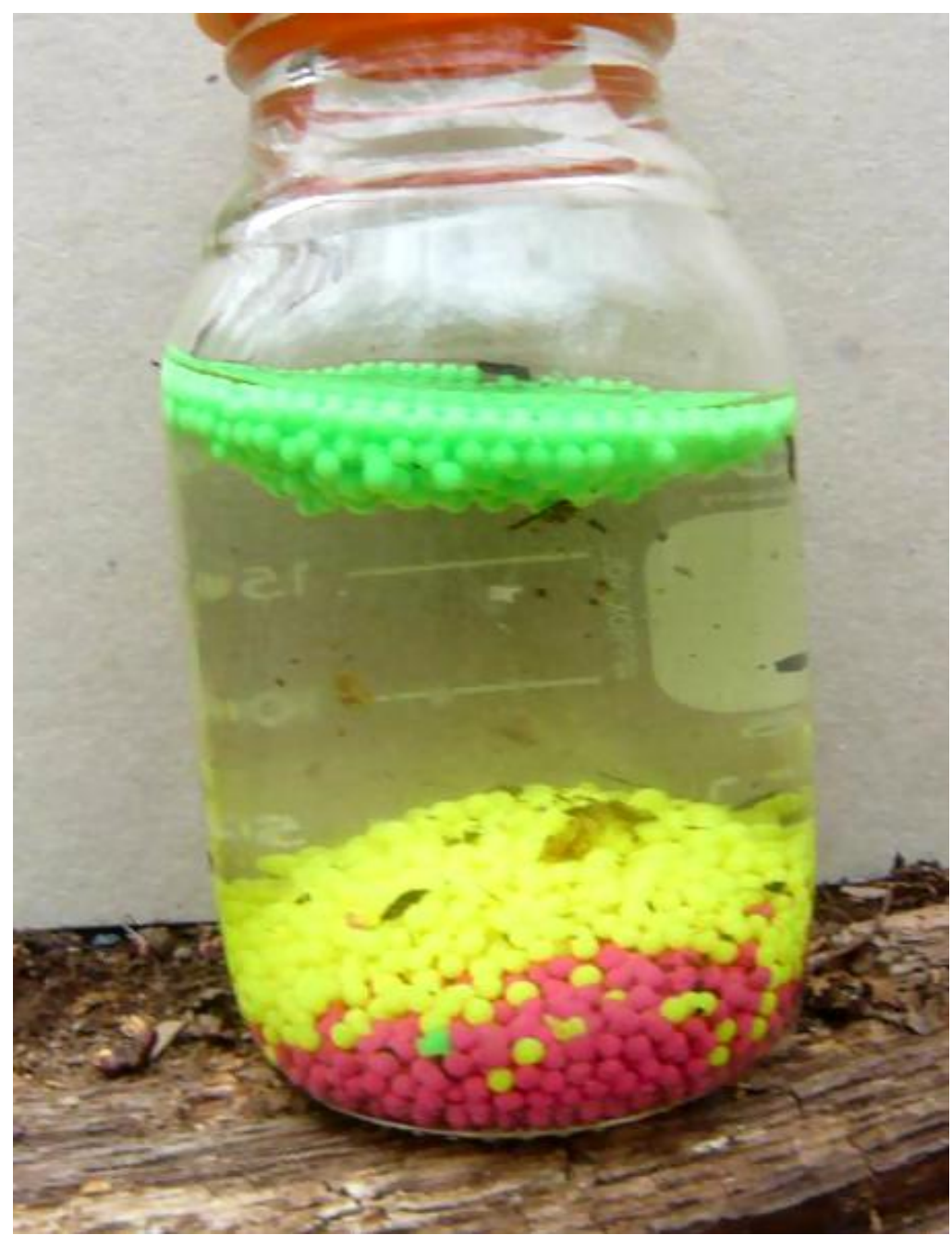

Figure 11: HTBs used for the preliminary tracer test at Hazel Run. Pictured are low-density green HTBs, medium-density yellow HTBs, and high-density pink HTBs (Photo by Hank Edenborn). 


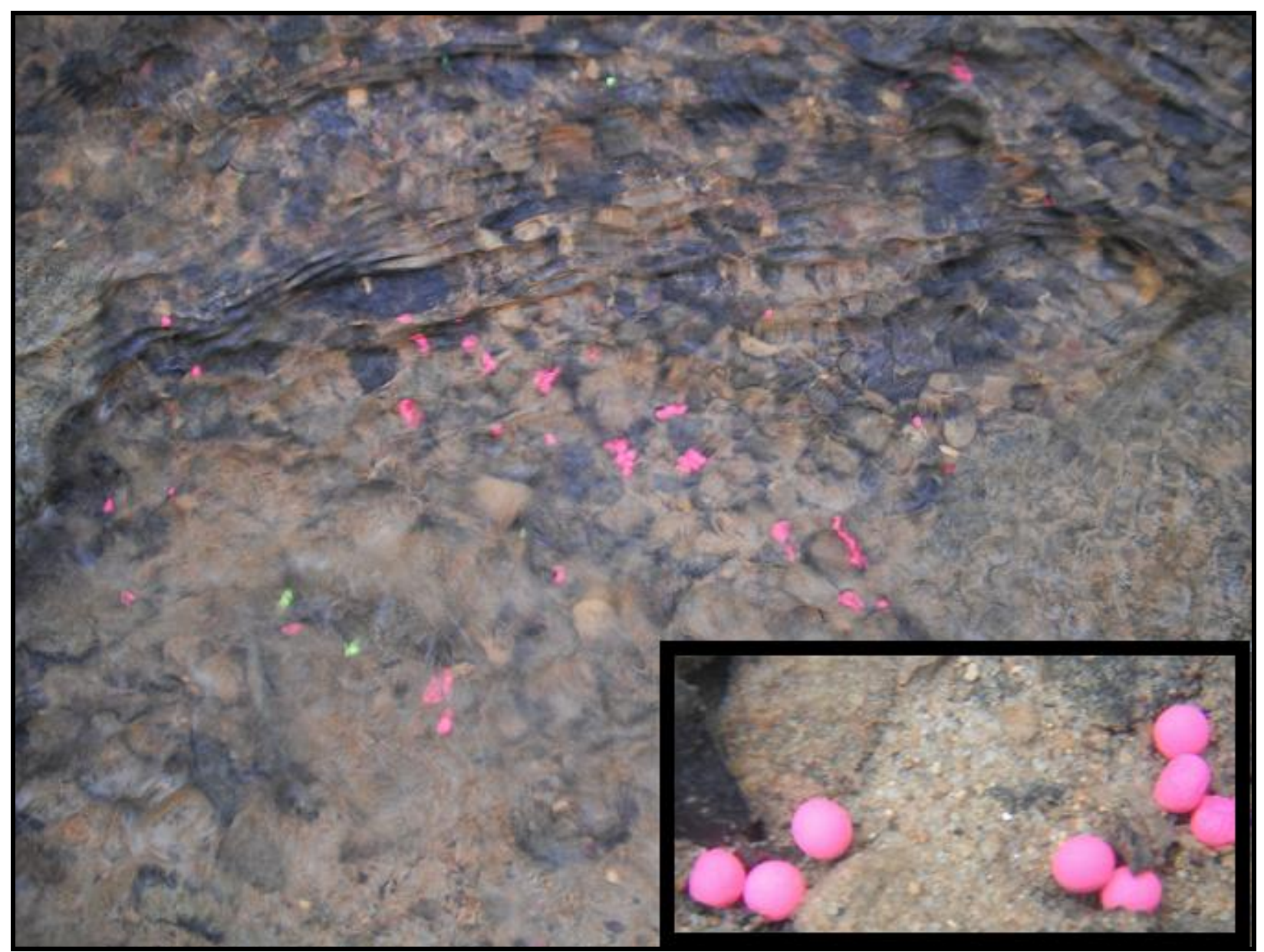

Figure 12: High-density, pink HTBs on the stream bed. Insert is an underwater photo of the HTBs in the larger photo. 
The medium-density HTBs sank similarly to the high-density HTBs but were slowly transported away from the injection site. These HTBs were found trapped in low velocity areas as well as on sediment and leaf debris (Figure 13). Most of the medium-density HTBs sank through the water column and rested on the channel bed. Some of the trapped medium-density HTBs were caught in eddies. The first medium density bead was collected at the end of the stretch at 8 minutes and 15 seconds into the test. Of the 100 medium-density HTBs released, only two HTBs were recovered at the downstream location during the duration of the test.

A closer look at the sediments where the HTBs became trapped shows that the high-density HTBs became trapped in areas of coarser sediment than the medium-density HTBs. This indicates the HTBs sank through the water column at areas of different energies. DNAPLs will only be transported when an energy threshold is breached that will move the contaminant along (Loop and White 2001), which is similar to what was observed with the dense HTBs.

The low-density, buoyant HTBs moved quickly through the system with a small number of beads getting trapped in features that were above the water surface. One example was a pile of leaves that had piled up on the stream bed and broke the surface of the water. Another trapping feature was on top of a sandbar above the water surface. Some HTBs were pushed onto the sandbar by the water as they rounded a bend towards the sandbar. Some low-density HTBs also flowed into an eddy where they got pinned between a rock and stick. Some beads got trapped behind a large log, but water velocity was strong enough to push the HTBs under or along the branch until they broke free of the obstruction and continued downstream. The first low-density HTB was recovered at the collection site one minute after release of the HTBs. The number of low-density HTBs released was 1000. Of those, 777 were collected downstream during the duration of the test (Figure 14).

The preliminary field tests at Hazel Run showed that the HTBs behaved as anticipated. The dense HTBs sank and had extremely low recovery at the collection site and were not included in further testing. The low-density HTBs remained floating for the entirety of the test and were readily recovered. Based on this, the low-density HTBs were ready for comparative testing. 


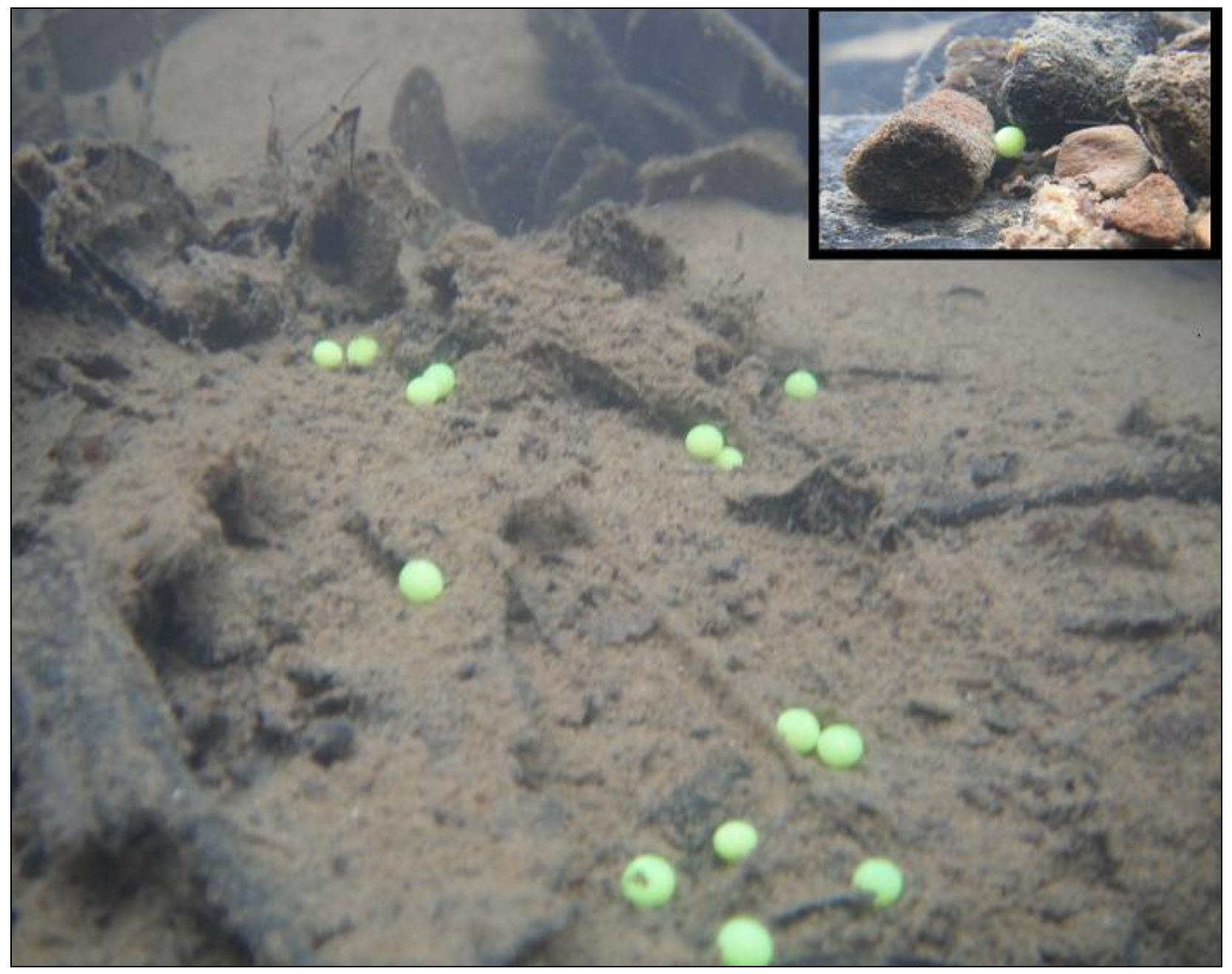

Figure 13: Underwater photo of medium-density, yellow HTBs on the stream bead in an eddy. Insert shows a single bead trapped between two pebbles. 


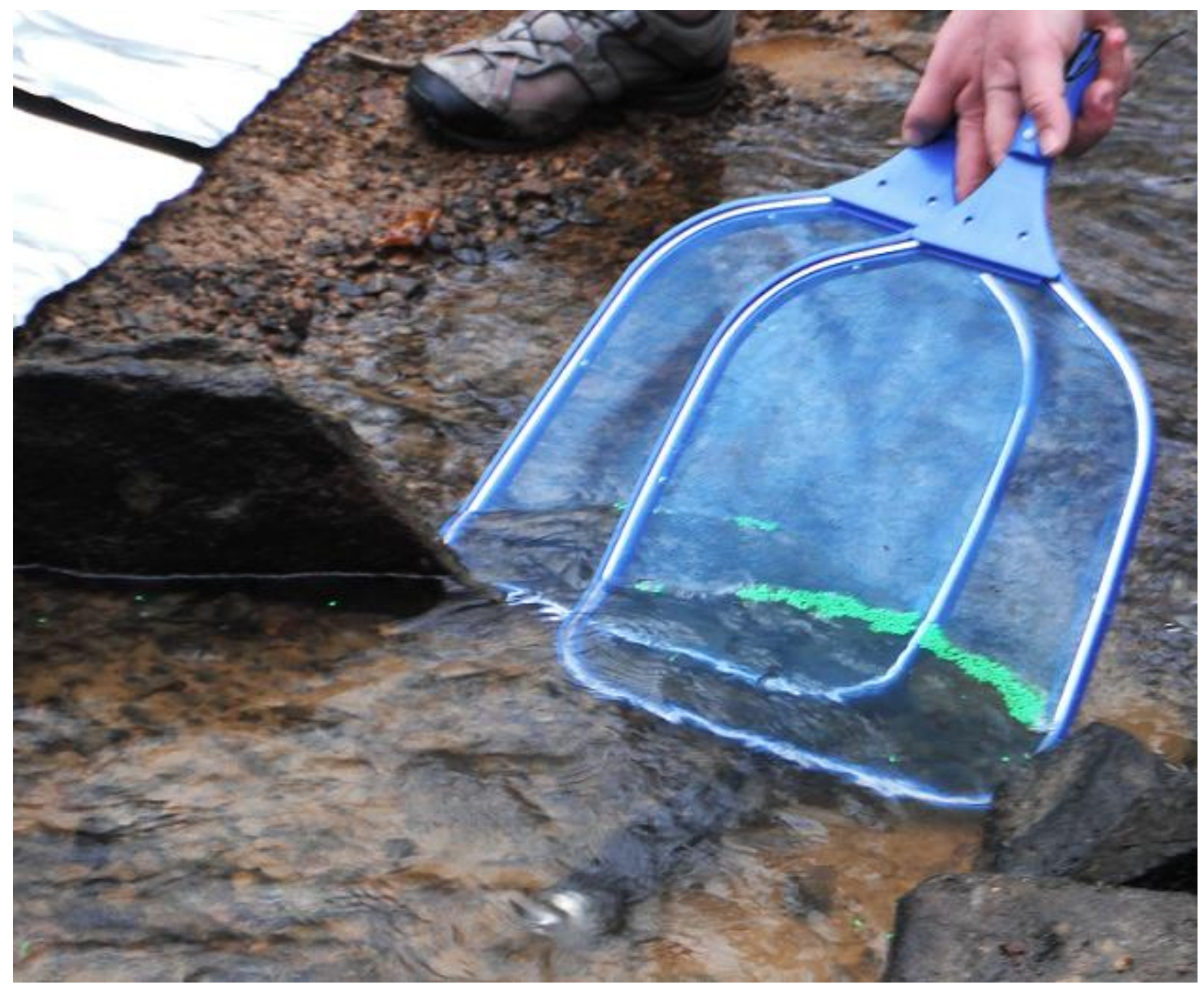

Figure 14: Low-density, floating HTBs being collected in pool skimmers at Hazel Run at the end of test stretch. 


\subsubsection{Buckeye Creek Cave results}

Results from Buckeye Creek Cave tests show that the low-density HTBs travelled faster than the fluorescein (Table 9, Figures 15-16). The tests were over a 64-m section, the discharge was 140 $\mathrm{L} / \mathrm{s}$, and the duration was 420 seconds in total. The times of first detection of the fluorescein and HTBs were 180 and 160 seconds, respectively. The fluorescein recovery in the Buckeye Creek tests was $90 \%$.

The recovery of HTBs at Buckeye Creek Cave was $58 \%$ and $73 \%$. Of the 6,000 HTBs released, only 1 was found in the traced section after the tests. The recovery rates do not reflect this fact likely due to poor collection efficiency at the sampling location. The greater recovery of HTBS for test B at Buckeye Creek Cave was most likely due to improved sampling procedure.

The mean velocity of the HTBs was greater than that of the fluorescein, being $1167 \mathrm{~m} / \mathrm{h}$ and $994 \mathrm{~m} / \mathrm{h}$, respectively. Peak velocity was also greater for the HTBs than the fluorescein, being $1440 \mathrm{~m} / \mathrm{h}$ and $1280 \mathrm{~m} / \mathrm{h}$, respectively. The HTBs took less time to travel the $64 \mathrm{~m}$ through the system. On average, the HTBs took 3.4 minutes to travel from the injection site to the collection site, while the fluorescein took 3.9 minutes.

Percent difference was used for compare the transport of the tracers in the two tests (Table 10):

$$
\text { absolute } \% \text { difference }=\left|\frac{\text { Test } A-\text { Test } B}{\text { Test } A} \times 100\right|
$$

With the exception of the percent recovery, the calculated QTRACER2 parameters agreed within $10 \%$ for the two tests at Buckeye Creek Cave (Table 10). For the mean velocity and mean tracer transit time, the agreement was within $3 \%$. 
Table 9: Test parameters as calculated by QTRACER2.

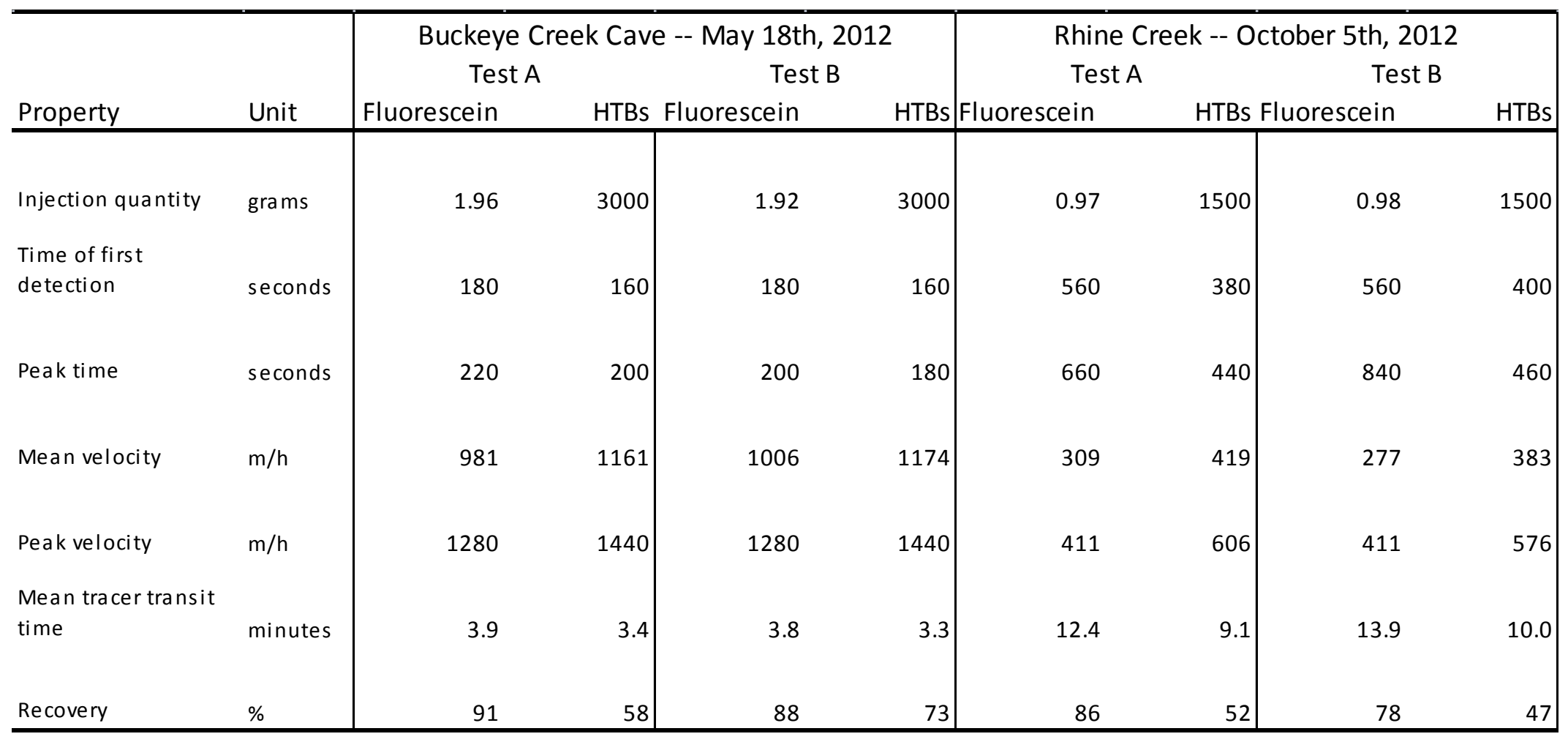




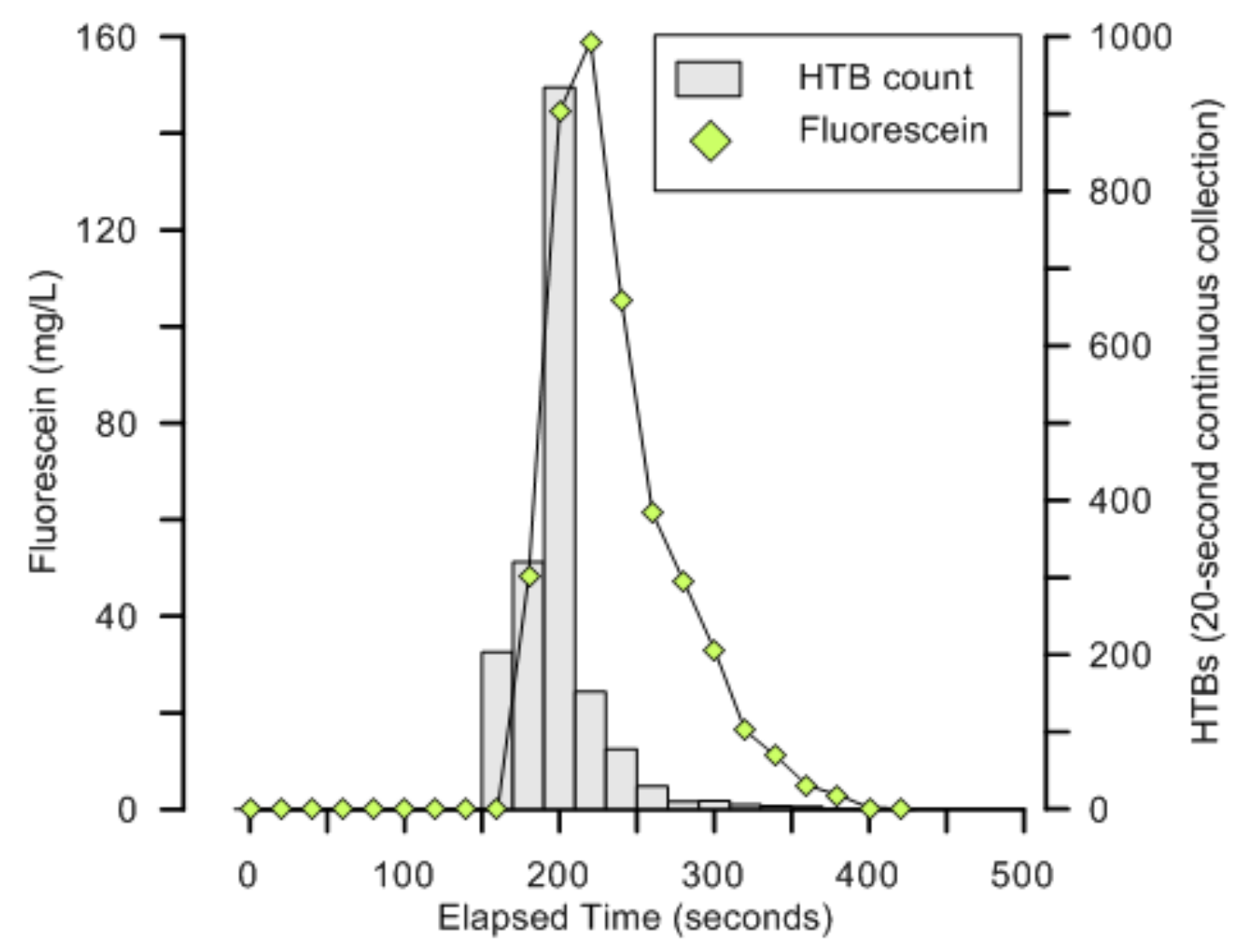

Figure 15: Breakthrough curve for Buckeye Creek Cave test A including data on fluorescein concentration and HTB counts. Line added to aid the eye. 


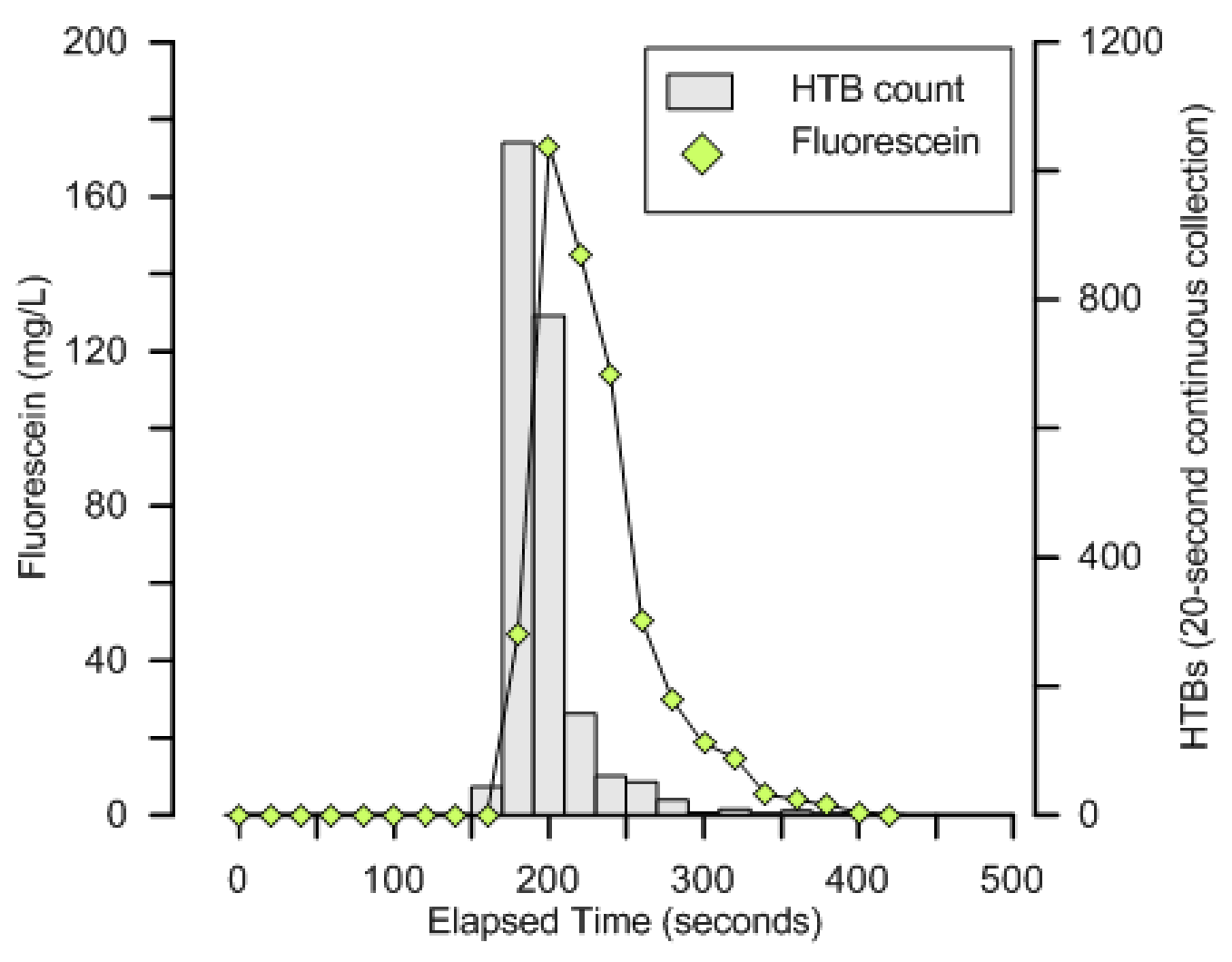

Figure 16: Breakthrough curve for Buckeye Creek Cave test B including data on fluorescein concentration and HTB counts. Line added to aid the eye. 
Table 10: Absolute percent difference of tracers between tests $A$ and $B$ completed at Buckeye Creek Cave.

\begin{tabular}{|c|c|c|}
\hline \multirow[b]{2}{*}{ Property } & \multicolumn{2}{|c|}{$\begin{array}{l}\text { absolute } \% \text { difference of } \\
\text { test } B \text { from test } A\end{array}$} \\
\hline & Fluorescein & HTBS \\
\hline $\begin{array}{l}\text { Time of first } \\
\text { detection }\end{array}$ & 0 & 0 \\
\hline Peak time & 9.1 & 10 \\
\hline $\begin{array}{l}\text { Mean } \\
\text { velocity }\end{array}$ & 2.5 & 1.1 \\
\hline $\begin{array}{l}\text { Mean tracer } \\
\text { transit time }\end{array}$ & 2.6 & 2.9 \\
\hline Recovery & 3.3 & 25.9 \\
\hline
\end{tabular}




\subsubsection{Rhine Creek results}

The Rhine Creek tests show that the low-density HTBs travelled faster than the soluble tracers (Table 9, Figures 17-18). The values reported in the text are an average of the results of tests $A$ and B completed at each location. The tests were over a 64-m section with a discharge of 85 L/s.

Rhine Creek breakthrough curves had more than one peak for both fluorescein and the HTBs. For test A, fluorescein peaks around 640-680 seconds and later at 840-860 seconds. The HTBs peak at 460 seconds and later at 660 seconds. For test $B$, the fluorescein and HTBs breakthrough curves are not smooth and show high variation in the declining limb of the breakthrough curve. Reasons for this are discussed as part of the QTRACER2 sensitivity analysis.

At Rhine Creek, the first detection of fluorescein and HTBs was at 560 and 390 seconds, respectively. The tests at Rhine Creek were completed within 1300 and 1320 seconds for test $A$ and test $B$, respectively.

Fluorescein recovery at Rhine Creek was $82 \%$. Reasons why fluorescein recovery for Rhine Creek was not nearer $100 \%$ are the same as for Buckeye Creek Cave, with the addition of the dye photo decaying in the sunlight. It is also possible that not all of the fluorescein was introduced to the system at the release point, and some adhered to the amber glass bottle or the bucket.

The recovery of HTBs at Rhine Creek was 50\%. For the Rhine Creek tests, HTBs were found trapped in vegetation, on top of sand bars, in eddies, and along the edges of the channel in low velocity areas. Most often HTBs were found on the side of the channel where they had migrated during the course of the test and became trapped along the bank in vegetation. There were spots where grasses grew from the bottom of the streambed and breached the surface. Another reason for low recovery of HTBS at Rhine Creek was the presence of an island section that caused the stream flow to diverge. The island section had downed branches and 


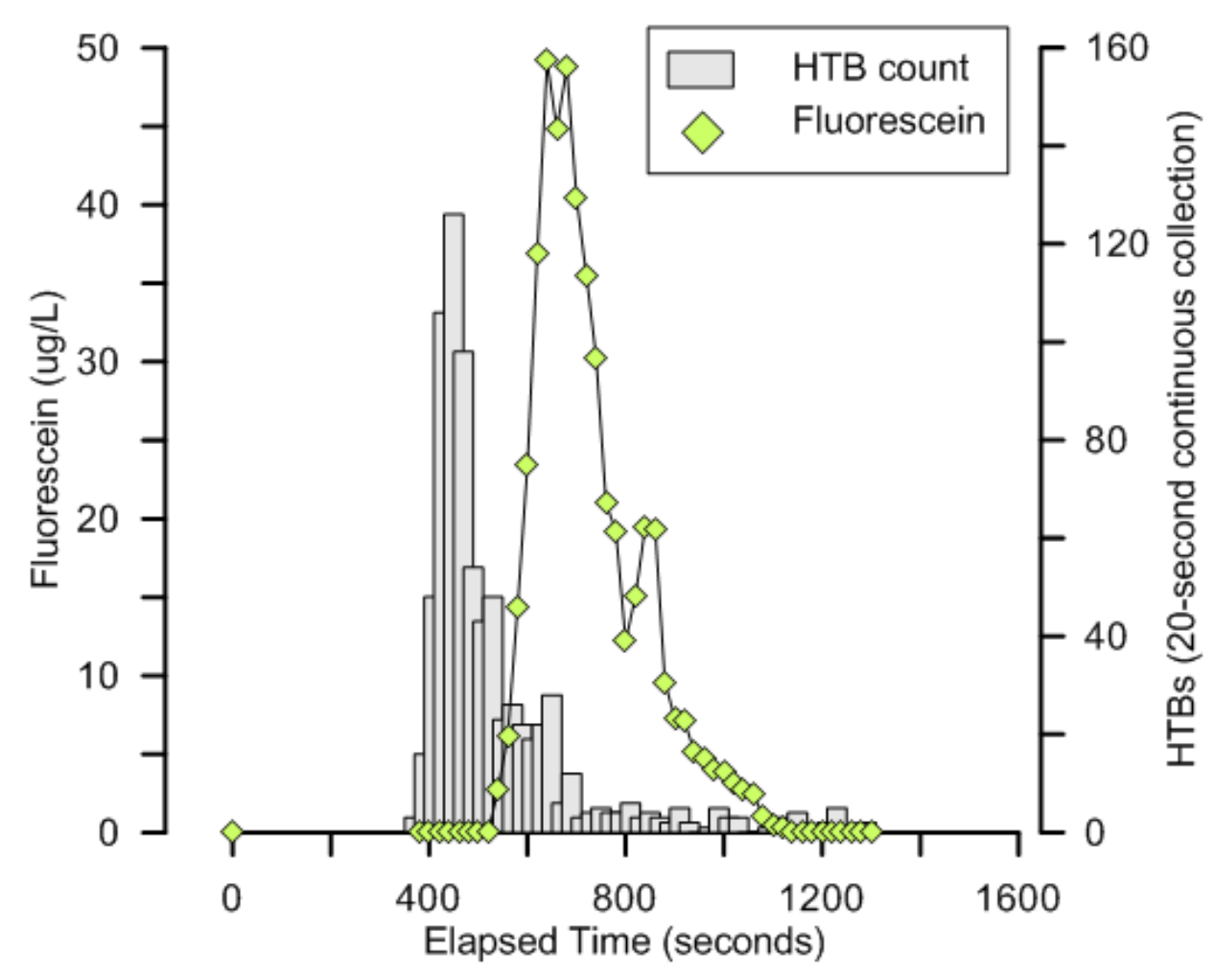

Figure 17: Breakthrough curve for Rhine Creek test $A$ including data on fluorescein concentration and HTB counts. Line added to aid the eye. 


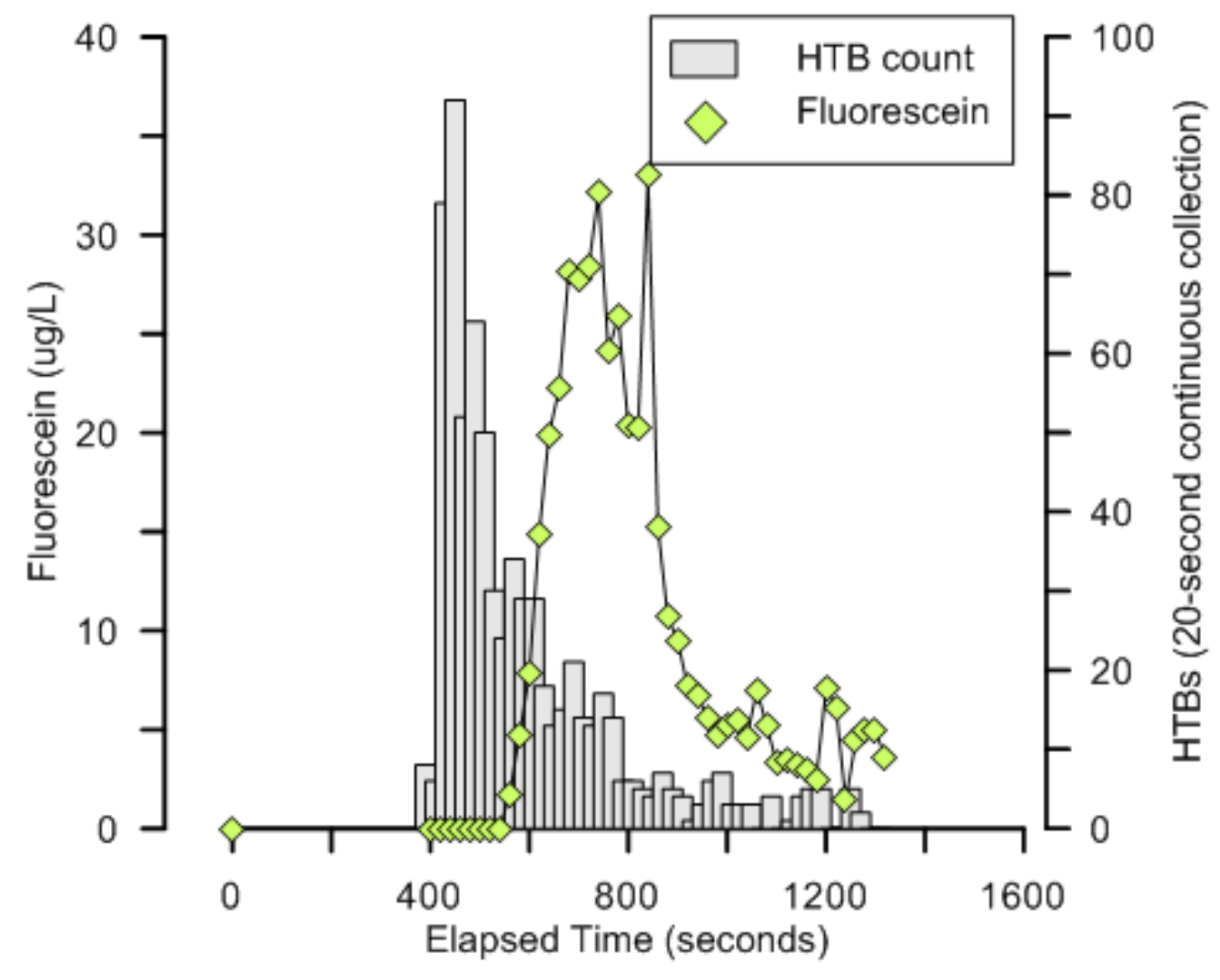

Figure 18: Breakthrough curve for Rhine Creek test B including data on fluorescein concentration and HTB counts. Line added to aid the eye. 
grass where a few HTBs got trapped. A few HTBs moved through the rock weir that channelized the stream to funnel the HTBs at the collection site (Figure 10). Considering the stream morphology and presence and variety of trapping mechanisms, the recovery of the HTBs at Rhine Creek tests was good.

The mean velocity of the HTBs was greater than that of the fluorescein, being $401 \mathrm{~m} / \mathrm{h}$ and 293 $\mathrm{m} / \mathrm{h}$, respectively. Peak velocity was also greater for the HTBs than the fluorescein, being 591 $\mathrm{m} / \mathrm{h}$ and $411 \mathrm{~m} / \mathrm{h}$, respectively. The HTBs took less time to travel the $64 \mathrm{~m}$ through the system. On average, the HTBs took 9.5 minutes to travel from the injection site to the collection site while the fluorescein took 13.2 minutes.

Percent difference was used for compare the transport of the tracers in the two tests at Rhine Creek (Table 11). The absolute \% difference shows that the HTBs behaved more consistently between the two tests than fluorescein. The percent difference in peak time of fluorescein between tests $A$ and $B$ is very high due to double peaks in the data. Otherwise, percent differences are around $10 \%$ for tests $A$ and $B$.

\subsubsection{QTRACER2 sensitivity analysis}

There is inherent error associated with these input parameters used for QTRACER2. Sensitivity analysis of the model was completed by varying a single input parameter and holding the others constant at the measured value. Mean tracer velocity was used as the output parameter of interest, as it is most indicative of the transport behavior of the tracers.

The concentrations of fluorescein and the HTBs were not altered for the sensitivity analysis. The error in the fluorescein concentrations was low, as previously discussed, and the HTBs were counted twice before release and after collection.

Sinuosity changes the length of the test section, but does not influence the QTRACER results because the stream-length measurement included bends in the flow path. Sinuosity is important when direct access to the stream is not possible, such as in testing in underground 
Table 11: Absolute percent difference of tracers between tests $A$ and $B$ completed at Rhine Creek.

\begin{tabular}{|c|c|c|}
\hline \multirow[b]{2}{*}{ Property } & \multicolumn{2}{|c|}{$\begin{array}{c}\text { absolute } \% \text { difference } \\
\text { of test B from test A }\end{array}$} \\
\hline & Fluorescein & HTBS \\
\hline $\begin{array}{l}\text { Time of first } \\
\text { detection }\end{array}$ & 0 & 5.3 \\
\hline Peak time & 27.3 & 4.5 \\
\hline $\begin{array}{l}\text { Mean } \\
\text { velocity }\end{array}$ & 10.4 & 8.5 \\
\hline $\begin{array}{l}\text { Mean tracer } \\
\text { transit time }\end{array}$ & 12.1 & 8.1 \\
\hline Recovery & 9.3 & 9.6 \\
\hline
\end{tabular}


conduits, but this study allowed for directly measuring the true travel distance so no correction for sinuosity was needed.

Independently altering the mass of tracer injected and discharge by $+/-10 \%$ of the measured values did not change the mean velocity of the tracer. Changes in the test distance caused a proportional change in the mean tracer velocity (Table 12). For example, if the length of test section was doubled, the mean tracer velocity doubled. Given that the dyes and HTBs were tested together, changing the test length only produces a proportional error in mean tracer velocities.

There are two peaks in the Rhine Creek breakthrough curves; the second peak occurs on the shoulder of the main peak. There are two possible explanations for the second peak. The first is due to the rinsing of the mixing bucket when releasing the tracers into the stream. Because the release of tracers was not a true slug injection, the multiple peaks could be caused by the introduction of more tracer after the initial slug was released. Another possibility is due to multiple flow paths at Rhine Creek. One area of the creek had an island where water was diverted (Figure 19). Before the main tracer injection, about 15 HTBs were released into the center of the stream 5 meters upstream of the island. The HTBs on the back side of the island traveled faster than the HTBs in the main channel.

The same tracer-release method was used at Buckeye Creek Cave and Rhine Creek, including the rinsing of the bucket. While the systems are different, there was no second flow path for the tracers to take at Buckeye Creek Cave, and there is no double peak at Buckeye Creek Cave. It is likely that the dual peaks at Rhine Creek were caused by divided flow around the island.

To determine the influence of the duel peaks on the QTRACER2 calculations, the second peak was manually removed from the Rhine Creek data and then the simplified data were input into QTRACER2 (Figures 20-23). Peaks were chosen by clear deviation from the general shape of the breakthrough curve. For tests $A$ and $B$, removal of the second peak changed the mean tracer velocity by $0.6 \%$ and $4 \%$ for the fluorescein and $1.2 \%$ and $1.0 \%$ for HTBs, respectively (Table 13). Therefore, the impact of second peak on the mean tracer velocity was low for the tested scenarios. 
Table 12: QTRACER2 discharge and test section length sensitivity analysis for Rhine Creek test $A$.

\begin{tabular}{|c|c|c|c|}
\hline \multicolumn{4}{|c|}{ Rhine Creek Test A } \\
\hline \multirow[b]{2}{*}{ Parameter } & \multirow{2}{*}{$\begin{array}{c}\% \text { change from } \\
\text { measured }\end{array}$} & \multicolumn{2}{|c|}{ Mean tracer velocity $(\mathrm{m} / \mathrm{h})$} \\
\hline & & Fluorescein & Low-density HTBs \\
\hline \multirow{3}{*}{$\begin{array}{c}\text { Test section } \\
\text { length }\end{array}$} & -10 & 309 & 411 \\
\hline & 0 & 618 & 822 \\
\hline & +10 & 927 & 1233 \\
\hline
\end{tabular}




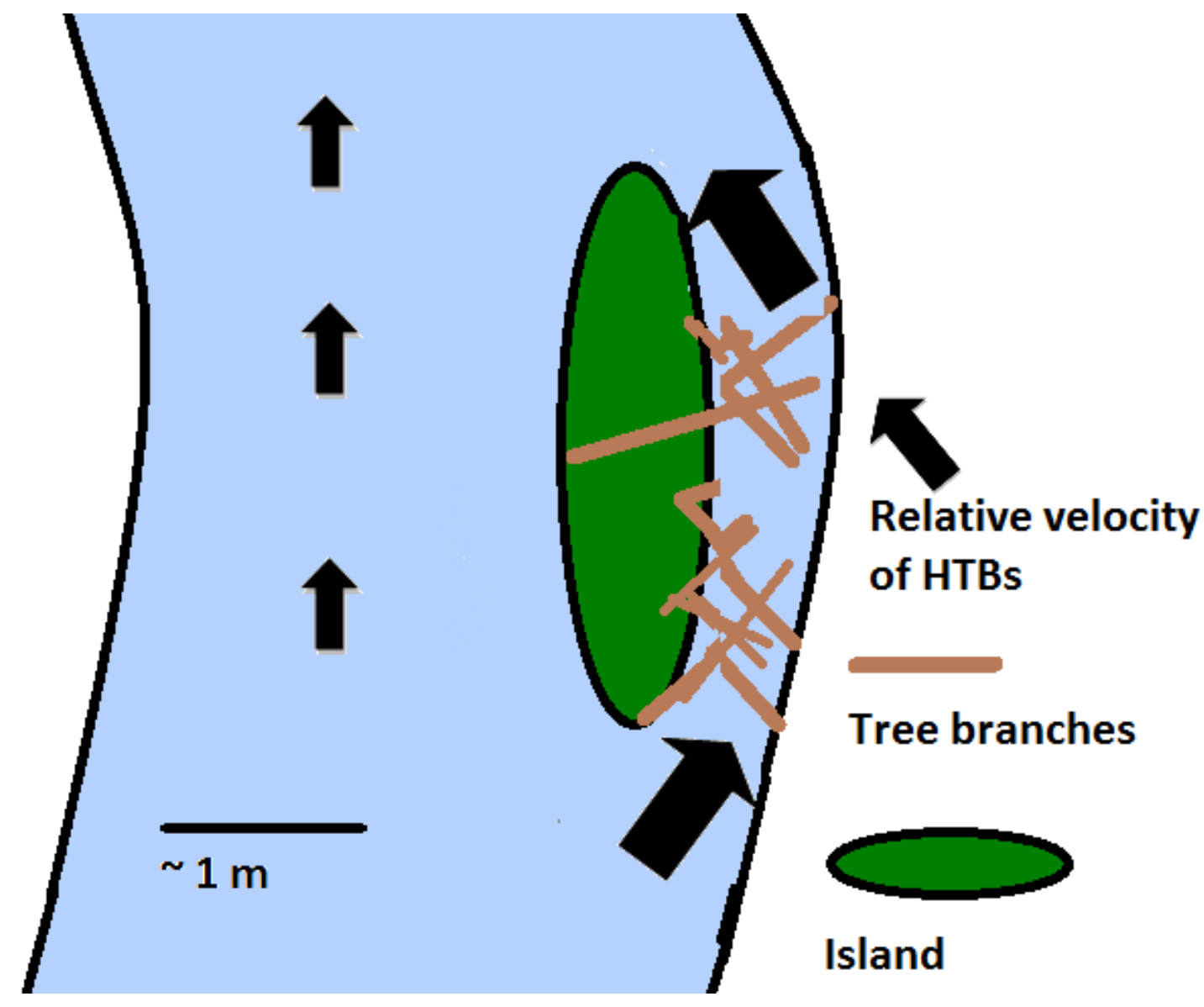

Figure 19: Schematic of alternate flow path at Rhine Creek. Arrows show estimated magnitude of water velocity, based on observed bead behavior. 


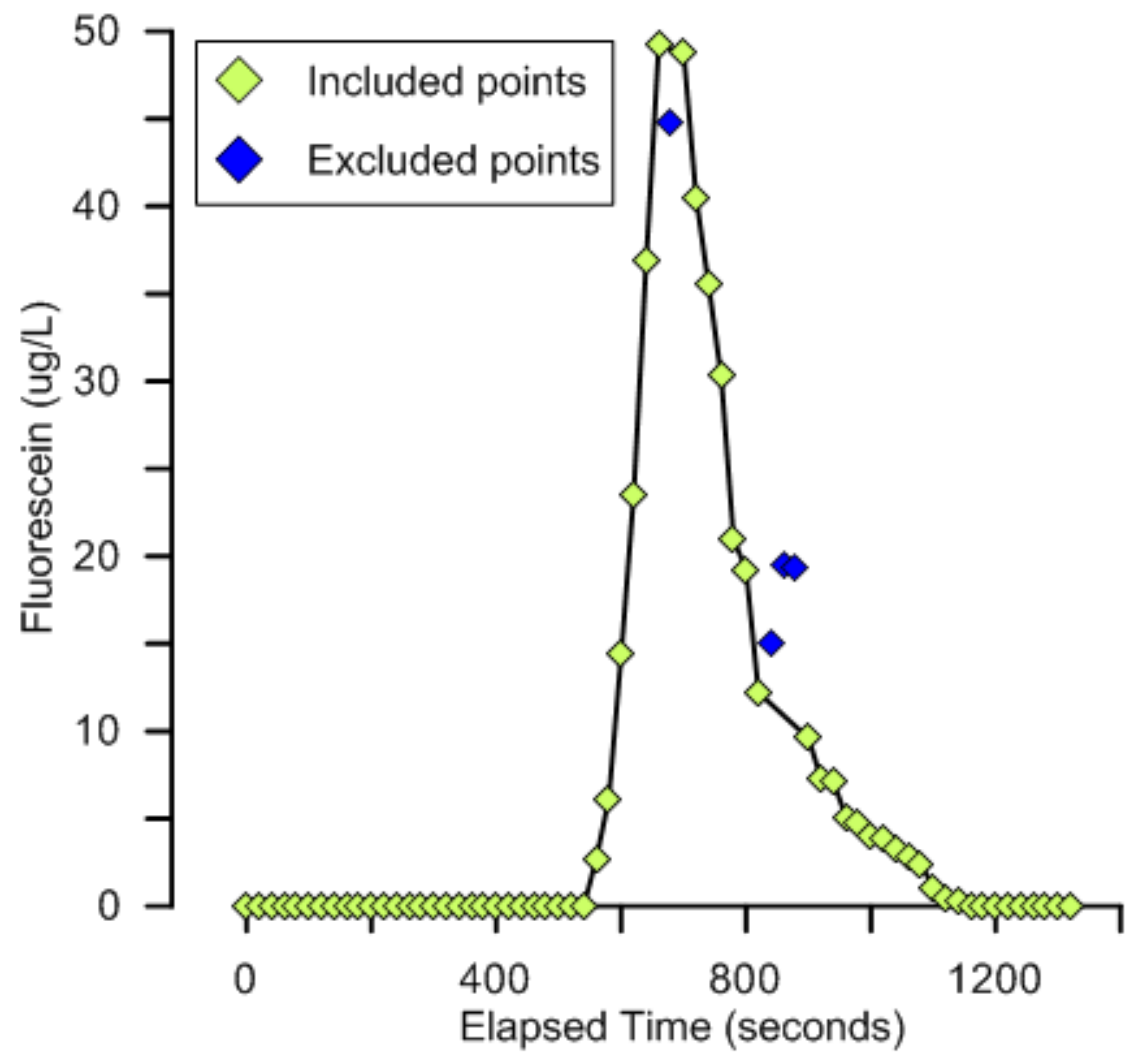

Figure 20: Peak removal of Rhine Creek test A fluorescein data. Blue diamonds are the data points that were removed. 


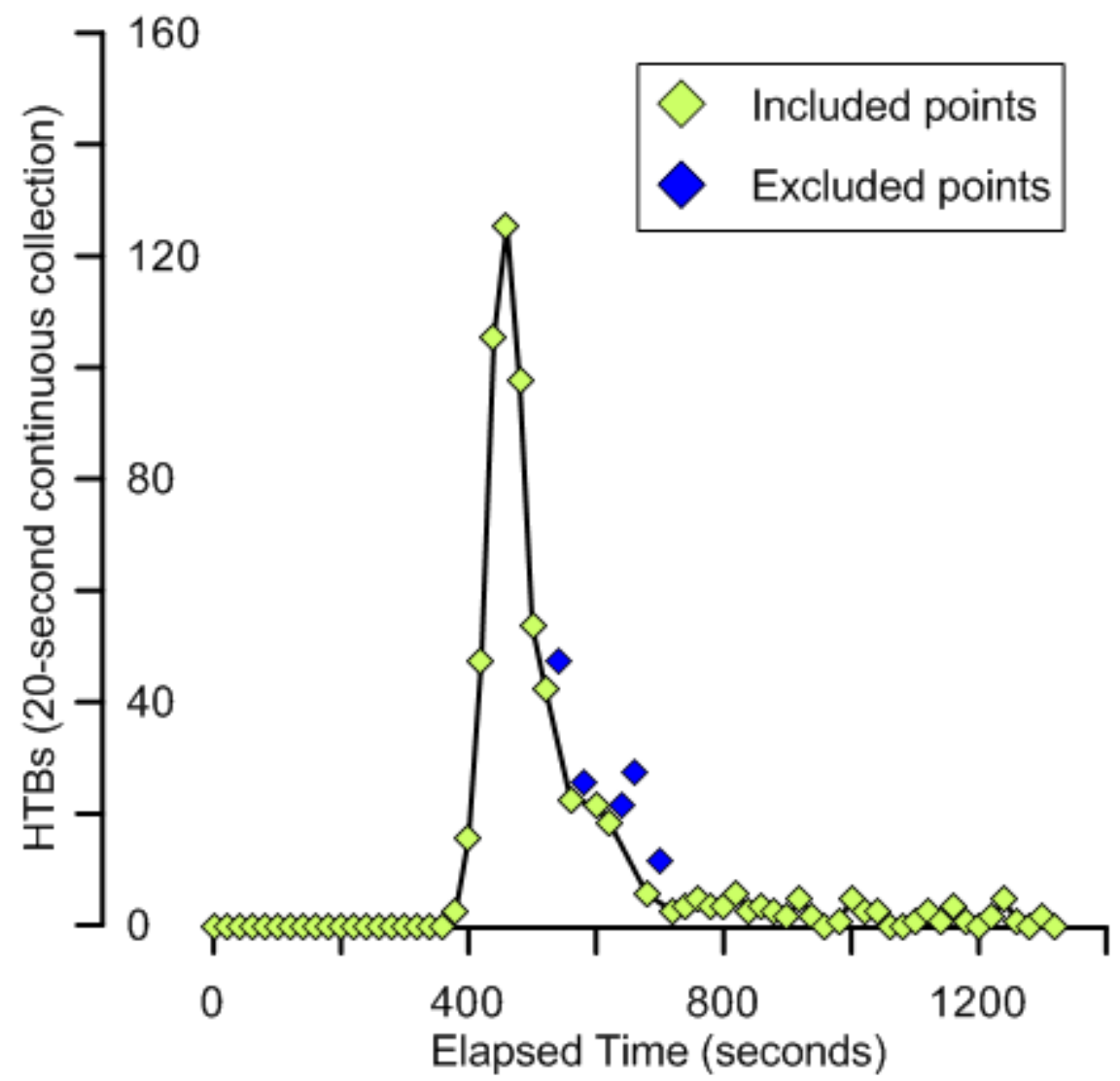

Figure 21: Peak removal of Rhine Creek test A HTBs data. Blue diamonds are the data points that were removed. Note: The data are plotted as single points and not columns for in order to see the fit better. 


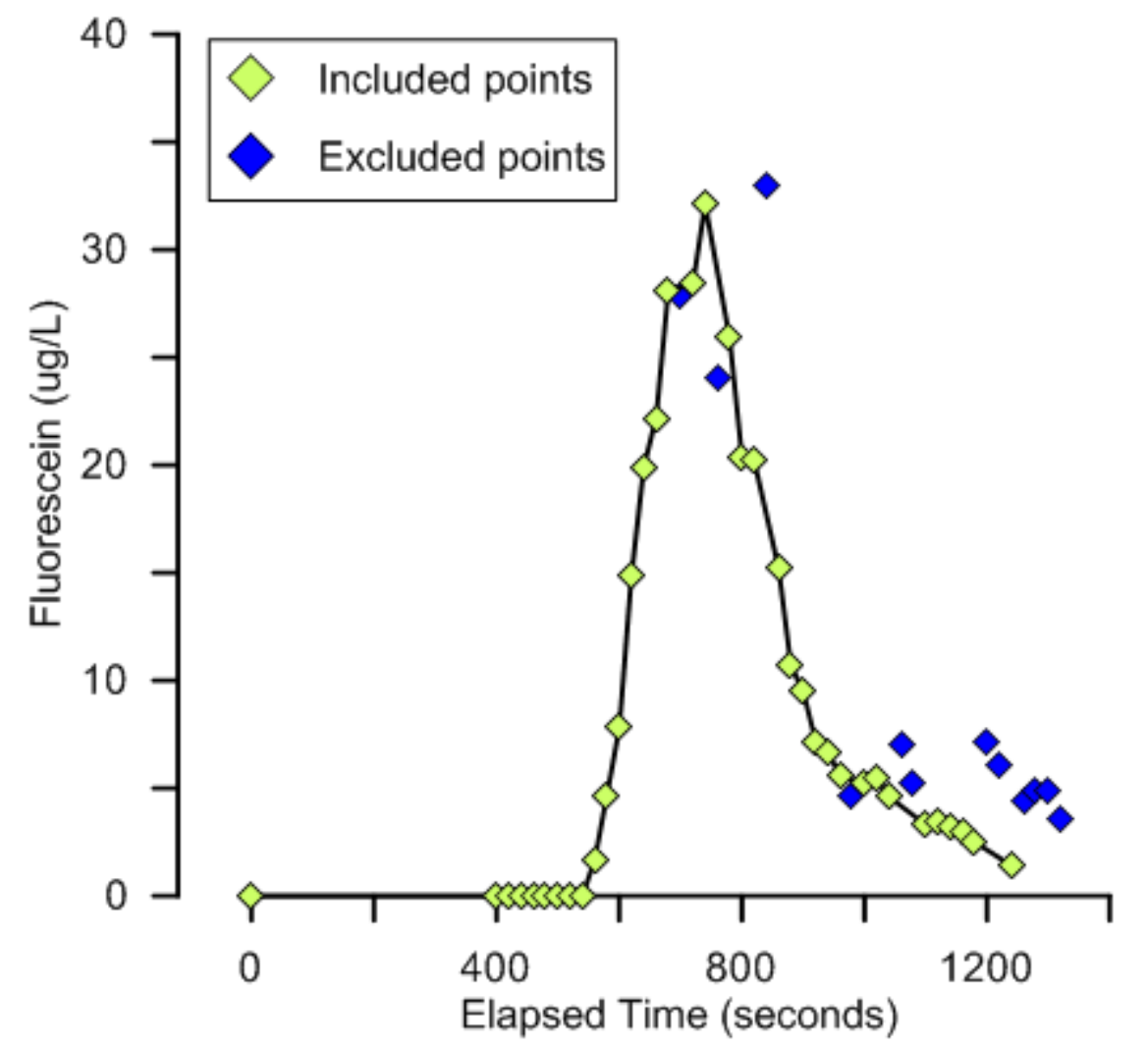

Figure 22: Peak removal of Rhine Creek test B fluorescein data. Blue diamonds are the data points that were removed. 


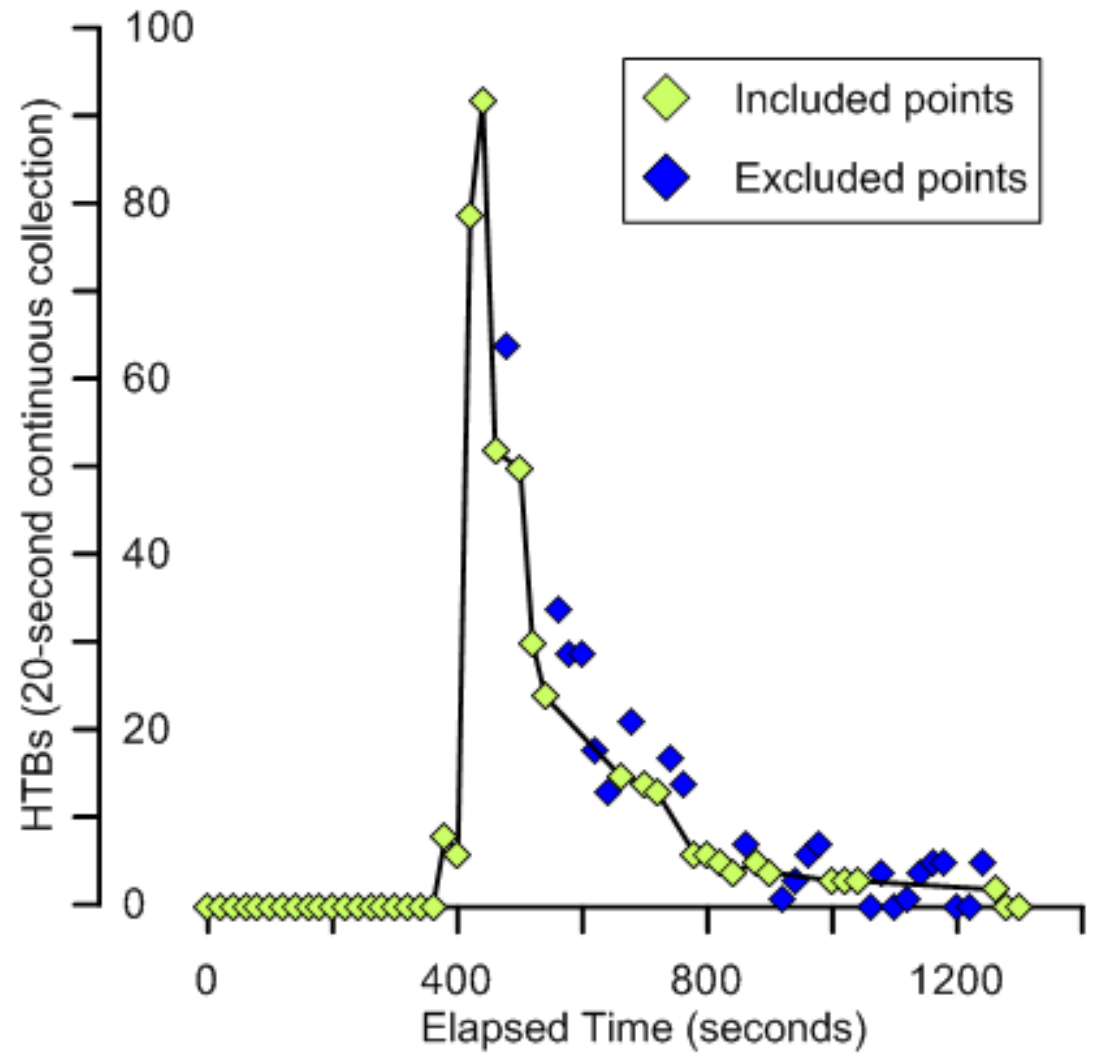

Figure 23: Peak removal of Rhine Creek test B HTBs data. Blue diamonds are the data points that were removed. Note: The data are plotted as single points and not columns for in order to see the fit better. 
Table 13: QTRACER2 sensitivity analysis of dual peak removal of Rhine Creek data.

Mean tracer velocity $(\mathrm{m} / \mathrm{h})$

Fluorescein Low-density HTBs

\begin{tabular}{llcc}
\hline & Actual data & 309 & 419 \\
Test A & $\begin{array}{l}\text { Peaks removed } \\
\text { \% difference } \\
\text { from actual }\end{array}$ & 311 & 424 \\
& Actual data & 0.6 & 1.2 \\
Test B & $\begin{array}{l}\text { Peaks removed } \\
\text { \% difference } \\
\text { from actual }\end{array}$ & 287 & 383 \\
\hline
\end{tabular}

Peak removed velocities match illustrations on figures 20-23. 
The parameter that impacts the mean tracer velocity the most is the length of test section. Given that the same distance was used for each field test, any error in the distance will only cause a consistent error in the relative transit times of the tracers. Removing the multiple peaks at Rhine Creek resulted in less than $5 \%$ difference in the calculated mean tracer transit time. Therefore, error generated from input parameters and the presence of multiple peaks on the BTC did not impact the interpretation of the modeled data. 


\subsection{Discussion}

It is important to consider how closely the HTBs mimic NAPLs. NAPLs will form in a continuous layer on the surface of the water or on the surface of an impermeable layer (Testa and Winegardner 2000). The HTBs cannot form a single continuous layer but they were observed traveling in groups during the field tests and tend to stay as an associated group when placed in a beaker in the laboratory. Given the intermolecular forces between organic compounds in general (Schwarzenbach et al. 2002), it is possible that an attraction exists between the beads. Individual compounds within the NAPL will solubilize at concentrations up to the solubility of the compound (Vesper et al. 2000), but the HTBs cannot do this. The purpose of this research was to develop the HTB to mimic contaminants in the NAPL form, not in the dissolved phase. Solute tracers may be suitable for understanding how organic compounds that are dissolved in the water behave.

The case studies of the diesel fuel tanker truck spill by Park City, KY (Stephenson et al. 2003), the leaking of an underground gasoline storage tank in Richmond, KY (Ewers et al. 1991), and the $4.9 \mathrm{~m}$ of jet fuel sampled in monitoring wells at Campbell Army Airfield in Kentucky (Ewers et al. 1991) are examples of how LNAPL can be trapped or its transport slowed in a karst aquifer. In those case studies, positive dye tracing resulted in locating discharge points for the contaminated areas, but no LNAPLs were observed at these points. LNAPLs can become trapped behind features that disrupt the water surface and migrate upwards through a fully submerged aquifer via joints and fractures (Ewers et al. 1991). The low-density HTBs became trapped on exposed sand bars and behind leaf piles that broke the surface of the water at Hazel Run and Rhine Creek. Some low-density HTBs traveled along an obstruction and then continued to transport downstream. Low-density HTBs are limited in migration through joints and fractures because of size of the HTB, the inability of the HTB to change shape, and the size of the joint or fracture. The trapping of the low-density HTBs could be similar to what was experienced by LNAPLs at the case study sites in Kentucky. 
DNAPLs sink through the water column until they reach a barrier that prevents them from sinking further (Loop and White 2001). DNAPLs can sink into sediment piles (Fitts 2002). At low saturation in the sediment piles, the DNAPL can be present as spherical blobs. At high saturation, the blobs will begin to join and form gaglia, which are irregularly shaped DNAPLs interconnected through multiple pores (Fitts 2002). High-density HTBs tested at Hazel Run sank to the bottom of the stream bed where they remained relatively immobile over the test period. The high-density HTBs will settle into sediments but cannot change shape or size to fit into the pore space between sediments. Some HTBs became caught between sediments, but not entrained within them.

While the HTB cannot form a continuous layer of tracer and cannot change size and shape to fit into openings in a rock, the various density HTBs were successful in mimicking certain behaviors of NAPL contaminants. The fate and transport of NAPLs is a function of their density; density determines where NAPLs are located in the water column and what trapping mechanisms affect their fate and transport (Testa and Winegardner 2000). The density of the HTBs can be modified to transport in parts of a stream that a certain NAPL would. Therefore, HTBs are a suitable tracer for mimicking NAPL fate and transport.

Quantitative comparative tracer tests were completed using low-density HTBs in two very different systems: Buckeye Creek Cave and Rhine Creek. The tests were conducted over the same length of stream and both systems have a free-water surface. Differences between Rhine Creek and Buckeye Creek Cave at the time of testing include, but are not limited to, a cave stream versus surface stream, amount of discharge, the amount of trapping mechanisms, the types of trapping mechanisms, size of bedload sediments, amount of bedload sediments, width of the channel, depth of the channel, and the presence of known alternate flow paths. These two sites are not directly comparable to one another. Despite all of the differences, the same result was found at both locations; the low-density HTBs traveled faster than the solute tracers.

Percent difference of the transport behavior of the fluorescein versus the HTBs was calculated to understand how different the two tracers traveled from one another. This was calculated 
using the average parameter values of tests A and B at both Buckeye Creek Cave and Rhine Creek using the following equation:

$\%$ difference of fluorescein versus low-density HTBs $=\frac{\overline{\text { fluoresceln }}-\overline{H T B S}}{\overline{\text { fluoresceln }}} \times 100$

At Rhine Creek, the HTBs mean velocity was $37 \%$ greater than the fluorescein (Table 14). At Buckeye Creek Cave, the HTBs mean velocity was 17\% greater than the fluorescein (Table 14). The tracers behaved more similarly to one another at Buckeye Creek Cave than they did at Rhine Creek. This shows that the HTBs can successfully be used in different systems.

Similar results were found in comparative tests using particulate tracers and solutes: particulate tracers travel faster than solute tracers. This has been reported with microspheres (in both conduit and granular aquifer settings), clays, and bacteria. Göppert and Goldscheider (2008) conducted comparative tracer tests using uranine (a variation of fluorescein that has two sodium molecules attached) and 1- $\mu$ m microspheres. They conducted tests in Hölloch cave over a $9.6 \mathrm{~km}$ long test section. The stream in Hölloch cave has an air-water interface similar to Buckeye Creek Cave. However, Hölloch also has siphons that obstruct flow on the surface of the water. Neither the authors nor the company that makes the microspheres report density values for the microspheres used for the research. Göppert and Goldscheider (2008) completed two sets of comparative tracer tests at the Hölloch cave site; one at low-flow conditions, with the water discharge at the collection spring of $172 \mathrm{~L} / \mathrm{s}$, and one at high-flow, with the water discharge at the collection spring ranging from 580-2691 L/s. Göppert and Goldscheider (2008) found that the microspheres traveled more similarly to the uranine at high-flow than at low flow, and the microspheres traveled faster than the uranine in both tests.

Toran and Palumbo (1991) tested colloid transport through an artificially-fractured and unfractured sand column in a laboratory. They tested 1- $\mu \mathrm{m}$ microspheres, bacteria, and colloidal organic material (collectively referred to as particulates) and a salt tracer to test the 
Table 14: Percent difference of the behavior of fluorescein versus HTBs at Buckeye Creek Cave and Rhine Creek.

\begin{tabular}{|c|c|c|c|}
\hline \multirow[b]{2}{*}{ Property } & \multicolumn{2}{|c|}{$\%$ difference fluorescein vs HTB } & \multirow[b]{2}{*}{ Conclusion } \\
\hline & Buckeye Creek Cave & Rhine Creek & \\
\hline $\begin{array}{l}\text { Time of first } \\
\text { detection }\end{array}$ & 11 & 30 & $\begin{array}{l}\text { HTBs arrived at collection } \\
\text { site first }\end{array}$ \\
\hline Peak & & & \\
\hline $\begin{array}{l}\text { concentration } \\
\text { time }\end{array}$ & 10 & 40 & $\begin{array}{l}\text { HTBs had an earlier peak } \\
\text { detection }\end{array}$ \\
\hline Mean velocity & -17 & -37 & $\begin{array}{l}\text { HTBs traveled faster than the } \\
\text { solutes }\end{array}$ \\
\hline Peak velocity & -12 & -44 & \\
\hline $\begin{array}{l}\text { Mean tracer } \\
\text { transit time }\end{array}$ & 13 & 25 & $\begin{array}{l}\text { HTBs took less time to travel } \\
\text { from the injection site to the } \\
\text { collection site }\end{array}$ \\
\hline Recovery & 27 & 40 & $\begin{array}{l}\text { HTBs recovery was less than } \\
\text { fluorescein recovery }\end{array}$ \\
\hline
\end{tabular}

Negative values indicate the solute was less than the HTBs, and positive number indicate the solute was greater than the HTBs 
impact of fractures in the system on transport. This was completed in a sand column that had a $5-\mathrm{cm}$ diameter and $65-\mathrm{cm}$ length. Pore space between the sand grains was large enough for the particulates to travel through. Fractures in the form of small tubes were inserted into the sand column. The results showed enhanced transport and greater recovery of the particulates when the fractures were present. When the fractures were not present, recovery was lower for each particulate because sorption of the particulate to the sand. While recovery of the particulate tracers was much lower than the solute tracer, in both artificially-fractured and unfractured systems, the particulate materials traveled faster than the solute tracer.

Mähler et al. (1998b) conducted comparative tracer tests using lanthanide-labeled clays and solute tracers. Two comparative tracer tests took place at Sirena Spring, the end of a $219 \mathrm{~m}$ subsurface karst conduit in central Texas. These tests were done under high- and low-flow conditions, with the discharge at the collection spring being $27 \mathrm{~L} / \mathrm{s}$ and $14 \mathrm{~L} / \mathrm{s}$, respectively. The tests used lanthanide-labeled clays and rhodamine WT as a solute tracer. A third test took place in Wallace Creek, a small surface stream in an urban area of Texas, using lanthanidelabeled clays and sodium chloride. Sampling took place $15 \mathrm{~m}$ and $65 \mathrm{~m}$ downstream of the injection site. Discharge measurements were not provided for the Wallace Creek location. The clays were not recovered at the collection site under low-flow conditions at Sirena Spring. The lack of recovery at Sirena Spring was attributed to gravitational sedimentation, similar to the sinking and stationary behavior of the high-density HTBs used during the preliminary field work in this study at Hazel Run. During high-flow at Sirena Spring and the Wallace Creek tests, Mähler et al. found that the clays arrived at the collection location before the solute tracers.

Sinreich et al. (2009) completed a comparative tracer test using iodide, microspheres, and Ralstonia eutropha $\mathrm{H} 16$ (R. eutropha), a non-pathogenic bacterium. R. eutropha and the microspheres are similarly sized. Testing took place in the Jura Mountains in Switzerland. The tracers were injected into a thin soil that overlaid an epikarst zone, a highly fissured and karstified part of the aquifer in located within the vadose zone. The tracers were injected at 
the surface and sampled at a depth of $10 \mathrm{~m}$. Results of the research were that the particulate tracers traveled through the system faster than the solute tracer, iodide.

The results of this research are supported by the research of others. There are many studies that found particulate tracers travel faster than solutes (Toran and Palumbo 1991, Mähler et al. 1998b, Göppert and Goldscheider 2008, Sinreich et al. 2009). These tests were conducted in a variety of settings, from granular sand columns to open karst conduits. The buoyant HTBs may trace a different flowpath than other particulates (microspheres, clays, and bacteria) and may be a better indicator of LNAPL transport processes.

With the conclusion that the HTBs are suitable proxy for understanding NAPL fate and transport processes, we can revisit the three case studies referenced in the introduction of this document and suggest some alternate theories about the transport of the NAPL at each site.

During the preliminary tests at Hazel Run, the high- and medium-density HTBs sank through the water at different rates. Before preliminary testing, the low-, medium-, and high-density HTBs were in a single container (Figure 11). After shaking the container, the high-density HTBs settled out first, with the medium-density HTBs settling on top of the high-density HTBs. This was seen in how far they traveled before settling to the channel bed. At Brown Wood, creosote was found to have migrated down sand columns (Price 1989). Creosote is a mixture of many chemicals, including dibenzofuran, fluorine, anthracene, fluoroanthene, pyrene, and naphthalene (Price 1989). These chemicals have a range of densities, and it is possible that some moved vertically down through the sand columns faster than others, similar to the HTBs. Perhaps a plume of one of these chemicals exists at a greater depth than was explored at this site.

This research shows that the low-density HTBs traveled faster than solute tracers in karst systems that had an air-water interface. Consider these findings in respect to the case studies at Park City and Richmond, KY, where LNAPLs were released into karst systems and were not recovered at known connections that were downgradient of the release (Ewers et al. 1991, Stephenson 2003). Based on this work, we conclude that LNAPLs have the ability to move 
faster than the water column, if an air-water interface is present, and perhaps the LNAPL traveled to the known connection before monitoring began.

Both the Park City and Richmond sites used estimates of travel time of LNAPL based on dye tracer. These estimates may be inaccurate because of the different behavior patterns of the dyes and LNAPLs with water. The solute tracer and NAPL are not transported in the same part of the water column. LNAPLs are restricted to flow on the surface on the channel whereas the solute tracer mixes with the water column (Field 2002). The LNAPLs are able to travel along the surface of the water but not within the depth of the column. The solute tracer will mix with more of the stream cross-section and therefore integrate over a wider range of velocities. In the case of an air-water interface, the LNAPL can mix in two-dimensions (laterally and longitudinally), but the solute tracer mixes in three-dimensions (laterally, longitudinally, and vertically). Therefore, it can take longer for the solute tracers to travel than LNAPL in an open system. Göppert and Goldscheider (2008) similarly suggest that colloidal materials travel along the faster flow paths, while solutes disperse throughout the water column and integrate all velocities present in the stream. In the Park City and Richmond case studies, the authors suggested that the LNAPL contaminants had already transported past the known connections by the time sampling began. That interpretation is supported by the results of this study. 


\subsection{Conclusions}

The most important conclusion of this study is that when buoyant HTBs and solute tracers are simultaneously released in a natural water system, the HTBs travel faster than the solutes. This is based on four separate tests and the resulting velocities and mean transit times. This was demonstrated in two stream locations: one surface creek and one vadose cave creek.

This conclusion is in agreement with studies done with particulate and microsphere tracers both in the field (Mähler et al. 1998a, 1998b, Göppert and Goldscheider 2008, Sinreich et al. 2009, Tauro et al. 2012) and in the lab (Toran and Palumbo 1991). Additional conclusions from the study include:

- Alginate-based HTBs can be created and modified to have different physical characteristics (e.g., density, size, sphericity, color).

- The HTBs are stable in natural water systems and can be used as a water tracer.

- Based on preliminary data, HTBs of different densities may mimic NAPLs of different densities. The buoyancy of the NAPL, like the HTBs, is a critical factor in transport and what trapping mechanisms may exist to prohibit transport.

These results have important implications regarding water sampling after a LNAPL enters the karst system. If the LNAPL can travel faster than dissolved tracer, travel times predicted from dye traces may not accurately reflect the appropriate time to collect water samples. 


\subsection{Future work}

While the HTBs mimic certain properties of NAPLs, we cannot quantify how similarly the HTBs behave like NAPLs. To be able to do so, we suggest a comparative tracer test using nontoxic NAPL compounds, such as olive oil, and similarly dense HTBs. The release of HTBs and nontoxic NAPLs will allow for the analysis of both materials' transport behavior and trapping mechanisms that impact their transport. With this information, we could make definitive statements on how similarly the HTBs mimic NAPL transport in a given system. An example of where this would be helpful is the Fort Campbell Army Airfield, where almost $5 \mathrm{~m}$ of free-phase product exists in monitoring wells at the airfield, but no product has been observed at Quarles Spring, the major discharge to the airfield. The HTBs could be used to evaluate trapping mechanisms in the karst. Perhaps there is only trapping of LNAPLs, and if dense HTBs were introduced to the system, they may be discharged at the Quarles Spring.

The HTBs should be of similar density to the contaminants of interest In order to accurately quantify how similarly they behave to a NAPL contaminants, therefore, we suggest future work also focus on creating HTBs of a very specific density. NAPL contaminants have a wide range of densities (Table 15). By creating a HTB that has the same density as a particular NAPL, we can complete comparative tracer tests to be able to quantify how similar the HTBs are to the NAPL. Work could focus on rates at which the HTBs travel through the system as well as where the HTBs become trapped. That information could then be analyzed to understand how a similarly dense NAPL would move through that same system.

Future work should also focus on evaluating behaviors we know the HTBs are not ideal for mimicking. Examples of instances when we expect the HTBs would not behave similarly to NAPL are when sinking into pore space between sediments and rising through joints and fractures when a system is fully submerged. Both behaviors could be evaluated in laboratory tests or in the field. Laboratory tests may be more ideal as they offer researchers the ability to 
Table 15: Density of select NAPL products

\begin{tabular}{lr} 
Compound & $\begin{array}{r}\text { Density } \\
\left(\mathrm{g} / \mathrm{cm}^{3}\right)\end{array}$ \\
\hline Butane & 0.58 \\
Ethylbenzene & 0.86 \\
$m$-xylene & 0.86 \\
$p$-xylene & 0.86 \\
Isopropylbenzene & 0.86 \\
Toluene & 0.87 \\
Benzene & 0.88 \\
o-xylene & 0.88 \\
Trimethylbenzene & 0.89 \\
Styrene & 0.91 \\
2-Methylaniline & 1.00 \\
Chlorobenzene & 1.11 \\
Naphthalene & 1.16 \\
Benzoanthracene & 1.25 \\
Pyrene & 1.27 \\
Chrysene & 1.28 \\
p, $p^{\prime}$-DDT & 1.55 \\
Tetrachloromethane & 1.59 \\
Hexachloroethane & 2.09 \\
Tribromomethane & 2.89 \\
\hline Data from Schwarzenbach et a 1.2003
\end{tabular}


control the system and observe how the HTBs are behaving, especially when testing the migration of low-density HTBs into the joints and fractures of a fully submerged system.

Lastly, NAPLs are typically a mix of specific compounds (Testa and Winegardner 2000). An example of this is at Live Oak, FL at the Brown Wood processing factory. Creosote was continuously dumped into a lagoon for 30 years (Price 1989). Creosote is a mixture of various compounds that can form DNAPL. These compounds will all behave differently; they each have an individual solubility, density, and rate of degradation. As certain compounds in the creosote degrade and solubilize, the bulk composition of the creosote will change. The HTBs cannot mimic degradation or solubilization of NAPL compounds, but different density HTBs can be injected simultaneously to understand how a combination of compounds in a NAPL would behave. Further, chemical modeling of a combined NAPL plume can determine how the chemistry of the plume would change over time. By doing this, one could adjust the ratio of the different density HTBs and thus test how the plume would travel after a certain amount of time has passed. 


\subsection{References}

Aley, T. (2002). Groundwater Tracing Handbook. Ozark Underground Laboratory, Protem, MO.

Aley, T.J. and Fletcher, M.W. (1978). The Water Tracer's Cookbook: A Guide to the Art and Science of Water Tracing Materials with Particular Emphasis on the use of Fluorescent Dyes, Lycopodium Spores, and Bacteriophage in Groundwater Investigations, Missouri Speleological Survey.

Barner, W. and Uhlman, K. (1995). Contaminant transport mechanisms in karst terraines and implications on remediation. Proceedings of the Fifth Conference on Sinkholes and the Engineering and Environmental Impacts of Karst. Gatlinburg, TN, April 25, pp 207-212.

Benischke, R., Goldscheider, N. and Smart, C.C. (2007). Tracer Techniques in: Goldscheider, N., Drew, D., Methods in Karst Hydrogeology. Taylor \& Francis, London, UK, pp. 147170.

Buchanan, T.J. and Somers, W.P. (1969). Discharge Measurements at Gaging Stations in U.S. Geological Survey Techniques of Water-Resources Investigations, Washington, DC, pp. 65.

Connell, D.W. (2005). Basic Concepts of Environmental Chemistry. 2nd ed., CRC Press, Boca Raton.

Dasher, G.R. and Balfour, W.M. (1994). The Caves and Karst of the Buckeye Creek Basin, Greenbrier County, West Virginia. West Virginia Association for Cave Studies, Maxwelton, W. Va.

Dragnet, K.I., Moe, S.T., Skjak-Brek, G., Smidsrod, O. (2006). Alginate. In: Stephen, A.M., Phillips, G. O., Williams, P.A. (Eds.). Food polysaccharides and their application. 2nd ed. CRC Press, Boca Raton. pp. 248-261. 
Ewers, R.O., Duda, A.J., Estes, E.K., Idstein, P.J. and Johnson, K.M. (1991). The transmission of light hydrocarbon contaminants in limestone (karst) aquifers. Proceedings of the Third Conference on Hydrology, Ecology, Monitoring, and Management of Ground Water in Karst Terranes. Nashville, TN, Dec. 4-10, pp. 287-306.

Field, M. (2002) The Qtracer2 program for tracer-breakthrough curve analysis for tracer tests in karstic aquifers and other hydrologic systems. U.S. Environmental Protection Agency, Office of Research and Development, National Center for Environmental Assessment, Washington Office, Washington, DC, EPA/600/R-02/001, 2002.

Field, M. (2003) Tracer-Test Planning Using the Efficient Hydrologic Tracer-Test Design (EHTD) Program 2005. U.S. Environmental Protection Agency, Washington, DC, EPA/600/R-03/034B..

Fitts, C. (2002). Groundwater Science. 1st ed. Academic Press, Waltham, MA.

Ford, D.C. and Williams, P.W. (2007). Karst Hydrogeology and Geomorphology. 2nd ed., John Wiley \& Sons, Hoboken, NJ.

Ghanem, A., Soerens, T.S., Adel, M.M. and Thomas, G.J. (2003). Investigation of fluorescent dyes as partitioning tracers for subsurface non-aqueous phase liquid (NAPL) characterization. Journal of Environmental Engineering, vol. 129, no. 8, pp. 740744.

Goldscheider, N., Meiman, J., Pronk, M. and Smart, C. (2008). Tracer tests in karst hydrogeology and speleology. International Journal of Speleology, vol. 37, no. 1, pp. 27-40.

Göppert, N. and Goldscheider, N. (2008). Solute and colloid transport in karst conduits under low- and high-flow conditions. Ground Water, vol. 46, no. 1, pp. 61-68.

Kasnavia, T., Vu, D. and Sabatini, D.A. (1999). Fluorescent dye and media properties affecting sorption and tracer selection. Ground Water, vol. 37, no. 3, pp. 376-381. 
Käss, W. (1998). Tracing Technique in Geohydrology. 1st ed., Taylor \& Francis, Oxfordshire.

Lazorchak, J.M., Klemm, D.J. and Peck, D.V. (1998). Environmental monitoring and assessment program-surface waters: field operations and methods for measuring the ecological condition of wadeable streams. U.S. Environmental Protection Agency, Washington, DC, EPA/620/R-94/004F.

Loop, C.M. and White, W.B. (2001). A conceptual model for DNAPL transport in karst ground water basins. Ground Water, vol. 39, no. 1, pp. 119-127.

Mähler, B.J., Winkler, M., Bennett, P. and Hillis, D.M. (1998a). DNA-labeled clay: A sensitive new method for tracing particle transport. Geology, vol. 26, no. 9, pp. 831-834.

Mähler, B.J., Bennett, P. and Zimmerman, M. (1998b). Lanthanide-labeled clay: A new method for tracing sediment transport in karst. Ground Water, vol. 36, no. 5, pp. 835843.

Price, D.J. (1989). Anatomy of a hazardous waste site in a paleosink basin. Proceedings of the Third Conference on Sinkholes and the Engineering and Environmental Impacts of Karst. St. Petersburg Beach, FL, Oct. 2-4, pp. 189-196.

Quinlan, J. (1989) Ground-water monitoring in karst terranes: recommended protocols and implicit assumption. U.S Environmental Protection Agency, Environmental Monitoring Systems Laboratory, Las Vegas, NV, EPA/600/X-89/050.

Ren, L. (2008). Production of alginate beads (Doctoral dissertation. Massey University, Albany, NY.

Schwarzenbach, R.P., Gschwend, P.M. and Imobden, D.M. (2002). Environmental Organic Chemistry. 2nd ed., John Wiley \& Sons, Inc., New York.

Sinreich, M., Flynn, R. and Zopfi, J. (2009). Use of particulate surrogates for assessing microbial mobility in subsurface ecosystems. Hydrogeology Journal, vol. 17, no. 1, pp. 49. 
Stephenson, J., Kaufmann, R., Archer, J., Bertz, C. and Bradley, P. (2003) Environmental investigation of a diesel spill in a karst area of Kentucky. Proceedings from the Ninth Conference on Sinkholes and the Engineering and Environmental Impacts of Karst, Huntsville, AL, Sept 6-10, pp. 415-428.

Tauro, F., Grimaldi, S., Petroselli, A. and Porfiri, M. (2012). Fluorescent particle tracers for surface flow measurements: A proof of concept in a natural stream. Water Resources Research, vol. 48, pp. w06528-WR011610.

Testa, S.M. and Winegardner, D.L. (2000). Restoration of Contaminated Aquifers Petroleum Hydrocarbons and Organic Compounds. 2nd ed., CRC Press, Boca Raton.

Toran, L. and Palumbo, A.V. (1992). Colloid transport through fractured and unfractured laboratory sand columns. Journal of Contaminant Hydrology, vol. 9, no. 3, pp. 289-303.

Vesper, D.J., Loop, C.M. and White, W.B. (2000). Contaminant transport in karst aquifers. Theoretical and Applied Karstology, vol. 13, no. 14, pp. 63-73.

Vesper D.J. (2008). Applied issues: Current research status. In Frontiers of Karst Research, Martin, J.B. and White, W.B.(Eds), Karst Waters Institute Special Publication 13, Karst Waters Institute, Leesburg VA, 65-73

Worthington, S.R.H. and Smart, C.C. (2003). Empirical determination of tracer mass for sink to spring tests in karst. In: Sinkholes and the Engineering and Environmental Impacts of Karst; Proceedings of the ninth multidisciplinary conference, Huntsville, Alabama, Sept. 6-10. Ed. B.F. Beck, American Society of Civil Engineers, Geotechnical Special, Publication No. 122, 287-298. 
Appendices 


\section{Appendix A - Data}


Table A 1: Buckeye Creek Cave tracer test A data.

\begin{tabular}{rrrr}
\hline $\begin{array}{r}\text { Time } \\
\text { (seconds) }\end{array}$ & $\begin{array}{r}\text { HTBs } \\
\text { (ug/L) }\end{array}$ & $\begin{array}{r}\text { Bromide } \\
\text { (number) }\end{array}$ \\
\hline 0 & 0.0 & 0 & 0.00 \\
20 & 0.0 & 0 & 0.00 \\
40 & 0.0 & 0 & 0.00 \\
60 & 0.0 & 0 & 0.00 \\
80 & 0.0 & 0 & 0.00 \\
100 & 0.0 & 0 & 0.00 \\
120 & 0.0 & 0 & 0.00 \\
140 & 0.0 & 0 & 0.00 \\
160 & 0.0 & 203 & 0.00 \\
180 & 48.3 & 320 & 2.31 \\
200 & 144.4 & 934 & 1.27 \\
220 & 159.1 & 152 & 2.56 \\
240 & 105.5 & 78 & 1.94 \\
260 & 61.4 & 30 & 1.32 \\
280 & 47.4 & 10 & 1.17 \\
300 & 33.1 & 11 & 1.00 \\
320 & 16.3 & 6 & 0.82 \\
340 & 11.0 & 4 & 0.75 \\
360 & 5.0 & 3 & 0.65 \\
380 & 3.0 & 1 & 0.57 \\
400 & 0.4 & 0 & 0.58 \\
420 & 0.2 & 0 & 0.54 \\
\hline & & & \\
\hline
\end{tabular}


Table A 2: Buckeye Creek Cave tracer test B data.

\begin{tabular}{rrrr}
\hline $\begin{array}{r}\text { Time } \\
\text { (seconds) }\end{array}$ & $\begin{array}{r}\text { Fluorescein } \\
\text { (ug/L) }\end{array}$ & $\begin{array}{r}\text { HTBs } \\
\text { (number) }\end{array}$ & $\begin{array}{r}\text { Bromide } \\
\text { (mg/L) }\end{array}$ \\
\hline 0 & 0.0 & 0 & 0.00 \\
20 & 0.0 & 0 & 0.00 \\
40 & 0.0 & 0 & 0.00 \\
60 & 0.0 & 0 & 0.00 \\
80 & 0.0 & 0 & 0.00 \\
100 & 0.0 & 0 & 0.00 \\
120 & 0.0 & 0 & 0.00 \\
140 & 0.0 & 0 & 0.00 \\
160 & 0.0 & 43 & 0.00 \\
180 & 47.0 & 1043 & 1.24 \\
200 & 173.1 & 775 & 2.82 \\
220 & 144.7 & 158 & 2.55 \\
240 & 114.0 & 60 & 1.90 \\
260 & 50.5 & 51 & 0.88 \\
280 & 29.7 & 24 & 1.24 \\
300 & 18.5 & 4 & 0.83 \\
320 & 14.8 & 9 & 0.77 \\
340 & 5.3 & 2 & 0.58 \\
360 & 4.1 & 7 & 0.55 \\
380 & 2.6 & 2 & 0.50 \\
400 & 0.9 & 4 & 0.52 \\
420 & 0.0 & 0 & 0.67 \\
\hline & & &
\end{tabular}


Table A 3: Rhine Creek tracer test A data.

\begin{tabular}{|c|c|c|}
\hline $\begin{array}{r}\text { Time } \\
\text { (seconds) }\end{array}$ & $\begin{array}{r}\text { Fluorescein } \\
\text { (ug/L) }\end{array}$ & $\begin{array}{r}\text { HTBs } \\
\text { (number) }\end{array}$ \\
\hline 0 & 0 & 0 \\
\hline 360 & 0 & 0 \\
\hline 380 & 0 & 3 \\
\hline 400 & 0 & 16 \\
\hline 420 & 0 & 48 \\
\hline 440 & 0 & 106 \\
\hline 460 & 0 & 126 \\
\hline 480 & 0 & 98 \\
\hline 500 & 0 & 54 \\
\hline 520 & 0 & 43 \\
\hline 540 & 0 & 48 \\
\hline 560 & 2.7 & 23 \\
\hline 580 & 6.1 & 26 \\
\hline 600 & 14.4 & 22 \\
\hline 620 & 23.5 & 19 \\
\hline 640 & 36.9 & 22 \\
\hline 660 & 49.2 & 28 \\
\hline 680 & 44.8 & 6 \\
\hline 700 & 48.8 & 12 \\
\hline 720 & 40.5 & 3 \\
\hline 740 & 35.5 & 4 \\
\hline 760 & 30.3 & 5 \\
\hline 780 & 21 & 4 \\
\hline 800 & 19.2 & 4 \\
\hline 820 & 12.2 & 6 \\
\hline 840 & 15.1 & 3 \\
\hline 860 & 19.5 & 4 \\
\hline 880 & 19.4 & 3 \\
\hline 900 & 9.6 & 2 \\
\hline 920 & 7.3 & 5 \\
\hline 940 & 7.1 & 2 \\
\hline 960 & 5.1 & 0 \\
\hline 980 & 4.7 & 1 \\
\hline 1000 & 4 & 5 \\
\hline 1020 & 3.9 & 3 \\
\hline 1040 & 3.2 & 3 \\
\hline 1060 & 2.8 & 0 \\
\hline 1080 & 2.4 & 0 \\
\hline 1100 & 1.1 & 1 \\
\hline
\end{tabular}


Table A 3: Rhine Creek tracer test A data, cont.

\begin{tabular}{rrr}
\hline $\begin{array}{r}\text { Time } \\
\text { (seconds) }\end{array}$ & $\begin{array}{r}\text { Fluorescein } \\
\text { (ug/L) }\end{array}$ & $\begin{array}{r}\text { HTBs } \\
\text { (number) }\end{array}$ \\
\hline 1120 & 0.5 & 3 \\
1140 & 0.3 & 1 \\
1160 & 0 & 4 \\
1180 & 0 & 1 \\
1200 & 0 & 0 \\
1220 & 0 & 2 \\
1240 & 0 & 5 \\
1260 & 0 & 1 \\
1280 & 0 & 0 \\
1300 & 0 & 2 \\
\hline
\end{tabular}


Table A 4: Rhine Creek tracer test B data.

\begin{tabular}{|c|c|c|}
\hline $\begin{array}{r}\text { Time } \\
\text { (seconds) } \\
\end{array}$ & $\begin{array}{r}\text { Fluorescein } \\
(\mathrm{ug} / \mathrm{L})\end{array}$ & $\begin{array}{r}\text { HTBs } \\
\text { (number) } \\
\end{array}$ \\
\hline 0 & 0 & 0 \\
\hline 380 & 0 & 0 \\
\hline 400 & 0 & 8 \\
\hline 420 & 0 & 6 \\
\hline 440 & 0 & 79 \\
\hline 460 & 0 & 92 \\
\hline 480 & 0 & 52 \\
\hline 500 & 0 & 64 \\
\hline 520 & 0 & 50 \\
\hline 540 & 0 & 30 \\
\hline 560 & 1.7 & 24 \\
\hline 580 & 4.7 & 34 \\
\hline 600 & 7.8 & 29 \\
\hline 620 & 14.9 & 29 \\
\hline 640 & 19.9 & 18 \\
\hline 660 & 22.2 & 13 \\
\hline 680 & 28.1 & 15 \\
\hline 700 & 27.8 & 21 \\
\hline 720 & 28.4 & 14 \\
\hline 740 & 32.1 & 13 \\
\hline 760 & 24.1 & 17 \\
\hline 780 & 25.9 & 14 \\
\hline 800 & 20.4 & 6 \\
\hline 820 & 20.2 & 6 \\
\hline 840 & 33 & 5 \\
\hline 860 & 15.2 & 4 \\
\hline 880 & 10.7 & 7 \\
\hline 900 & 9.5 & 5 \\
\hline 920 & 7.2 & 4 \\
\hline 940 & 6.7 & 1 \\
\hline 960 & 5.6 & 3 \\
\hline 980 & 4.7 & 6 \\
\hline 1000 & 5.2 & 7 \\
\hline 1020 & 5.5 & 3 \\
\hline 1040 & 4.6 & 3 \\
\hline 1060 & 7 & 3 \\
\hline 1080 & 5.2 & 0 \\
\hline 1100 & 3.3 & 4 \\
\hline
\end{tabular}


Table A 4: Rhine Creek tracer test B data, cont.

\begin{tabular}{rrr}
\hline $\begin{array}{r}\text { Time } \\
\text { (seconds) }\end{array}$ & $\begin{array}{r}\text { Fluorescein } \\
\text { (ug/L) }\end{array}$ & $\begin{array}{r}\text { HTBs } \\
\text { (number) }\end{array}$ \\
\hline 1120 & 3.4 & 0 \\
1140 & 3.2 & 1 \\
1160 & 3 & 4 \\
1180 & 2.5 & 5 \\
1200 & 7.1 & 5 \\
1220 & 6.1 & 0 \\
1240 & 1.4 & 0 \\
1260 & 4.4 & 5 \\
1280 & 4.9 & 2 \\
1300 & 4.9 & 0 \\
1320 & 3.6 & 0 \\
\hline
\end{tabular}




\section{Appendix B - Methods}




\section{Varian Cary Eclipse Fluorometer}

(Analysis of fluorescent dyes)

Jan 2013 Laskoskie

\section{How it works}

1. A xenon lamp flashes 80 times per seconds to produce a light source for the excitation monochromator.

2. The excitation monochromator reflects the light to excite the sample.

3. The fluorescence produced the by excitation light is filtered to the emission monochromator.

4. The emission monochromator detects the light and measures the intensity of the emission light.

Emission scans allow the user to determine what emission wavelength they would like to use and then scan over a range of excitation. Excitation scans use a single emission wavelength and scan over a range of excitations. Emission scans use a single excitation wavelength and scan over a range of emission. Synchronous scans change the excitation and emission wavelengths at a fixed delta value.

\section{Consumables \& Approximate Costs}

$\begin{array}{lll}\text { Fluorimeter cuvette, no stoppers } & \begin{array}{l}\text { Sigma Aldrich C0793 100 vials } \\ \text { Polymethacrylate }\end{array} & \$ 33.00 \\ \text { Quartz cuvettes, no stopper } & \text { Sigma Aldrich C9167 1 vial } & \$ 214.50 \\ \text { Disposable pipettes } & \begin{array}{l}\text { Greendtrees Hydroponics 5mL } \\ \text { disposable pipette 20 count }\end{array} & \$ 2.20 \\ \text { Kim Wipes } & \begin{array}{l}\text { Amazon.com } 4.4 \times 8.4 \text { inches } 280 \\ \text { count }\end{array} & \$ 4.00\end{array}$

\section{Abbreviated Procedure for single-wavelength excitation or emission scan and excitation-emission matrix data}

1. Turn on heater 5-10 min before beginning.

- Check fluid level. if low, indicator changes and tubing has bubbles once running. Antifreeze and funnel located below instrument

2. Turn on fluorometer

3. Open software, select SCAN

4. Check settings 


\section{How to check settings}

1. Click Setup on left panel.

2. Cary tab

- Select Fluorescence for the data mode.

- Scan Setup

- For excitation and emission scans, input the desired wavelengths.

- For synchronous, a wavelength separation of $\sim 20 \mathrm{~nm}$ is optimal.

- 3D Mode - Do not check.

- Scan Control - The faster the scan, the less precise the results. If you are trying to decide optimal scan parameters, fastest or survey is okay but when determining fluorescence of unknown samples, medium is best.

3. Options Tab

- Do not check any box

- The excitation and emission filters should be set to Auto-Auto or Auto-Open.

- The voltage can be adjusted to be able to read lower or higher concentrations. Generally medium is used.

4. Accessories Tab

- If using the multicell holder, check the tab and check each cell that will be holding a sample.

- The temperature is controlled by the cooling unit to the right of the fluorometer. Allowing the cooling unit to run for 5 minutes prior to scanning ensures that the cell holder will remain between 15 to $20^{\circ} \mathrm{C}$. If you do not use the cooling unit, the cell holder will overheat and melt the cuvettes.

5. Reports Tab

- Operator allows the user to input a name and comments. This is really helpful for keeping information straight - what samples you are running, when calibrated, which parameters you are using. You can save methods to reuse, in which case you will not need to make comments on parameters but rather note the methods used.

- Peaks allows you to label peaks on the graphs. This can clutter your graphs or help depending on what you are trying to do.

- X-Y Pairs table is a record of the wavelengths and measured intensities of the sample. Check the X-Y Pairs table box and choose Actual.

6. Auto-Store Tab

- Auto-store saves the data from each set of samples automatically. Under storage choose On, prompt at start. Under auto-convert choose ASCII (csv)

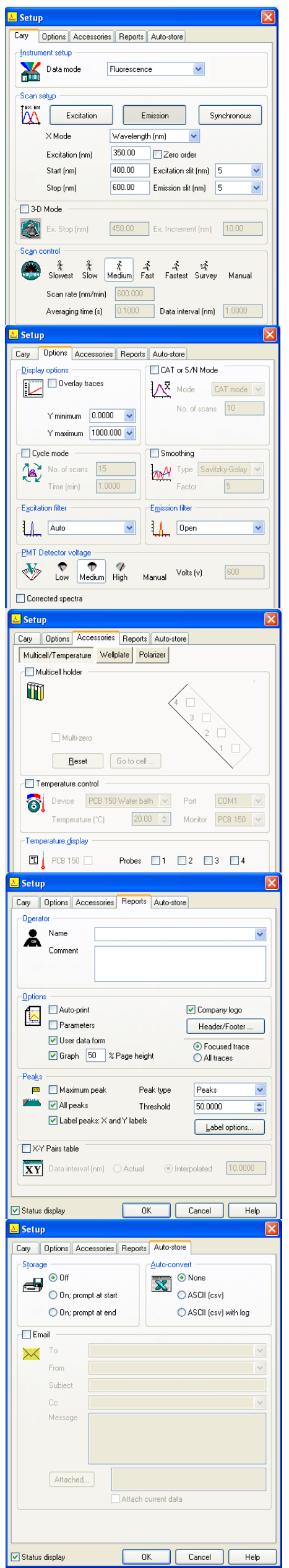




\section{Miscellaneous}

- Calibration curves must be made in the medium in which the dye is diluted. Samples diluted in deionized water and karst water resulted in very different intensity for the same dye concentrations.

- You will receive an error message if you try to scan for an emission that is less than the excitation. Ignore this message. The program will still run.

- You can adjust the voltage (under the Options tab) to scan at higher or lower concentrations.

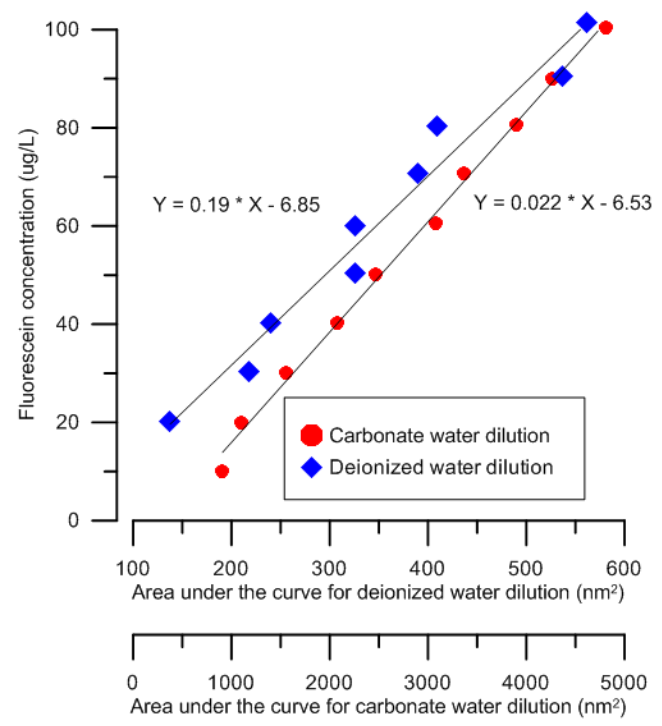

\section{Contacts}

Local Rep

Sherry Hemmingsen, Ph. D.

Molecular Spectroscopy Product Specialist

Agilent Technologies

(614) 264-4660

(614) 386-8186

Sherry.hemmingsen@agilent.com 
Dye information gathered

\begin{tabular}{|c|c|c|c|c|c|}
\hline Dye & Formula & MW & $\begin{array}{l}\text { Excitation/ } \\
\text { emission }\end{array}$ & Log Kow & Data source \\
\hline $\begin{array}{l}\text { Fluorescein } \\
\text { (Acid Yellow 73) }\end{array}$ & $\mathrm{C}_{20} \mathrm{H}_{10} \mathrm{O}_{5} \mathrm{Na}_{2}$ & 376 & $492 / 513$ & -0.39 & Ghanem et al. (2003) \\
\hline $\begin{array}{l}\text { Eosine } \\
\text { (Acid Red 87) }\end{array}$ & $\mathrm{C}_{20} \mathrm{H}_{6} \mathrm{Br}_{4} \mathrm{O}_{5} \mathrm{Na}_{2}$ & 692 & $515 / 535$ & -1.33 & Ghanem et al. (2003) \\
\hline $\begin{array}{l}\text { Rhodamine WT } \\
\text { (Acid Red 388) }\end{array}$ & $\mathrm{C}_{29} \mathrm{H}_{29} \mathrm{~N}_{2} \mathrm{O}_{5} \mathrm{Na}_{2} \mathrm{Cl}$ & 566 & $558 / 583$ & -1.33 & Ghanem et al. (2003) \\
\hline $\begin{array}{l}\text { Sulforhodamine B } \\
\text { (Acid Red 52) }\end{array}$ & $\mathrm{C}_{27} \mathrm{H}_{30} \mathrm{~N}_{2} \mathrm{O}_{7} \mathrm{~S}_{2} \mathrm{Na}_{2}$ & 604 & $560 / 584$ & -2.02 & Ghanem et al. (2003) \\
\hline $\begin{array}{l}\text { Pyranine } \\
\text { (Solvent Green 7) }\end{array}$ & $\mathrm{C}_{16} \mathrm{H}_{7} \mathrm{O}_{10} \mathrm{~S}_{3} \mathrm{Na}_{3}$ & 524 & $460 / 512$ & -0.68 & Ghanem et al.(2003) \\
\hline
\end{tabular}




\section{How to Make Hydrogel Tracer Beads}

A step-by-step instruction guide by Amanda Laskoskie

Anytime you weigh something, scoop the material into a weigh boat (drawer below the scale) and then from the weigh boat to the weighing paper. If you have extra, do not put it back into the original container.

\section{1.) Make alginate solution.}

This should be done at least $\mathbf{2 4}$ hours before you are actually going to make the beads.

For a $3 \%$ solution, dissolve 3.1 grams of sodium alginate into 100 grams of deionized water.

1. Weigh the alginate on the scale.

2. Measure the MilliQ DI water in a $100 \mathrm{~mL}$ volumetric flask.

3. Add the alginate and water to an Erlenmeyer flask.

4. Drop in a large stir bar and cover opening with parafilm.

5. Put on stir plate on a medium setting overnight or until there are no visible clumps of alginate powder.

\section{2.) Put in the additives}

Decide what you want your beads to do. I normally do floating fluorescent beads.

1. Put an empty $50 \mathrm{~mL}$ centrifuge tube into styrofoam holder and place on scale. Zero the scale. Anything you add to the centrifuge tube/styrofoam will read as the mass of only the added material. DO NOT RETARE THE SCALE UNTIL YOU USE A NEW CENTRIFUGE TUBE!

2. Add an arbitrary volume of alginate solution to the centrifuge holder.

3. Record the mass of the alginate solution.

4. Calculate how much additive you need.

I add $1 \% 3 \mathrm{M}^{\odot}$ Glass Bubbles 1\% Risk Reactor ${ }^{\odot}$ UV Pigment. If I have 40 grams of alginate in the centrifuge tube, l'll add 0.4 grams bubbles and 0.4 grams of pigment.

6. Weigh your additives out and add to alginate in centrifuge tube.

7. Cap and mix on Vortex mixer until homogenous.

\section{3.) Make some beads}

1. Prepare your $\mathrm{CaCl}_{2} \cdot 2 \mathrm{H}_{2} \mathrm{O}$ curing solution. This can range from $0.1 \mathrm{M}$ to $1 \mathrm{M}$. I use the 1 $\mathrm{M}$ because I make large batches of beads. This means I dissolve $14.78 \mathrm{grams}$ $\mathrm{CaCl}_{2} \cdot 2 \mathrm{H}_{2} \mathrm{O}$ into $1 \mathrm{~L}$ of deionized water in a volumetric flask. 
2. Put $700 \mathrm{~mL}$ of curing solution into $1 \mathrm{~L}$ beaker on a stir plate on low setting. You don't want a tornado to form.

3. Put alginate into a syringe with a needle on the end. The larger your needle, the less round your beads. The smaller your needle, the harder it is to get the alginate mix through the needle.

4. Add alginate dropwise to the curing solution. Try not to have the alginate drip directly into the center of the curing solution. Aim for close to the beaker sides

If using the syringe pump: Three syringes can be used simultaneously. The optimal setting for the syringe pump is the number set to 999 and both knobs turned all the way to the left.

5. Let cure for at least 1 minute.

6. Store in used curing solution in the fridge.

All materials used can go in the trash. DO NOT PUT ALGINATE IN THE SINK-IT WILL GEL AND CLOG THE SINK. Dry out large amounts of alginate solution in the fume hood before disposing. Make sure to leave a note describing what is there so others know what it is. Try to clean the centrifuge tubes but if you can't get them clean, throw them away too. Needles go in the sharps container.

\section{NOTES:}

- Sodium alginate is stored in the cabinets. It should be kept tightly sealed when not in use.

- Always use a face mask when using the alginate or 3M Glass Bubbles.

- Do not just walk away from the syringe pump after setting it up. Check the first few beads to make sure they are forming properly. 